\title{
Fat and Fatty Acid Terminology, Methods of Analysis and Fat Digestion and Metabolism: A Background Review Paper
}

\author{
W.M. Nimal Ratnayake ${ }^{a} \quad$ Claudio Gallib \\ ${ }^{a}$ Nutrition Research Division, Food Directorate, Health Products and Food Branch, Health Canada, Ottawa, Ont., \\ Canada; ${ }^{b}$ Department of Pharmacological Sciences, Laboratory of Lipid Pharmacology and Nutrition, \\ University of Milan, Milan, Italy
}

\section{Fat and Fatty Acid Terminology}

\section{Definition and Classification of Lipids}

Fats, oils or lipids consist of a large number of organic compounds including fatty acids, monoacylglycerols, diacylglycerols, triacylglycerols (TGs), phospholipids (PLs), eicosanoids, resolvins, docosanoids, sterols, sterol esters, carotenoids, vitamin A and E, fatty alcohols, hydrocarbons and wax esters. Classically, lipids were defined as substances that are soluble in organic solvents. This is a loose definition and could include a number of non-lipid organic compounds. A novel definition and comprehensive system of classification of lipids were proposed in 2005 [Fahy et al., 2005]. The novel definition is chemically based and defines lipids as small hydrophobic or amphipathic (or amphiphilic) molecules that may originate entirely or in part by condensations of thioesters and/or isoprene units. The proposed lipid classification system enables the cataloguing of lipids and their properties in a way that is compatible with other macromolecular data bases. Using this approach, lipids from biological tissues have been divided into 8 categories, as shown in table 1. Each category contains distinct classes and subclasses of molecules [Fahy et al., 2005].

\section{KARGER}

Fax +4161306 1234

E-Mail karger@karger.ch

www.karger.com
C 2009 S. Karger AG, Basel and FAO

0250-6807/09/0553-0008\$26.00/0

Accessible online at:

www.karger.com/anm
Table 1. Lipid categories and typical examples. Adapted from Fahy et al. [2005]

\begin{tabular}{ll}
\hline Category & Example \\
\hline Fatty acids & oleic acid \\
Glycerolipids & triacylglycerol \\
Glycerophospholipids & phosphatidylcholine \\
sphingosine \\
Sterol lipids & cholesterol \\
Prenol lipids & farnesol \\
Saccharolipids & UDP-3-0-(3-hydroxy-tetradecanoyl)- \\
Polyketides & N-acetylglucosamine \\
& aflatoxin
\end{tabular}

\section{Lipid Classes}

A summary of the 8 lipid classes is presented below. For details see Fahy et al. [2005].

\section{Fatty Acids}

These are a diverse group of molecules characterized by a repeating series of methylene groups that impart hydrophobic character. The fatty acyl structure represents the major lipid building block of complex lipids and there- 
1

Fig. 1. Chemical structure of triacylglycerol.

Fig. 2. Chemical structure of a phospholipid. $\mathrm{X}=$ Choline, ethanolamine, serine, inositol or glycerol.
2

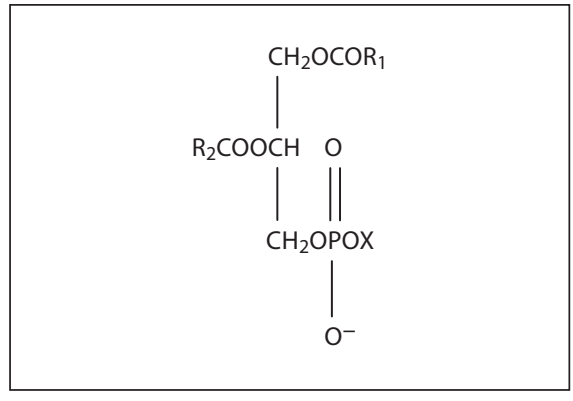

fore is one of the most fundamental categories of biological lipids. This lipid class includes the various types of fatty acids, eicosanoids, fatty alcohols, fatty aldehydes, fatty esters, fatty amides, fatty nitriles, fatty ethers and hydrocarbons. Many members of this category, especially the eicosanoids derived from $n-6$ and $n-3$ polyunsaturated fatty acids (PUFAs), have distinct biological activities.

\section{Glycerolipids}

The glycerolipids essentially encompass all glycerolcontaining lipids. The most well-known being the fatty acid esters of glycerol (acylglycerols), which includes tri-, di- and mono-acylglycerols. Additional subclasses are represented by glycosylglycerols, which are characterized by the presence of 1 or more sugar residues attached to glycerol via a glycoside linkage. Glycerophospholipids are not included in this category because of their abundance and importance as membrane constituents.

Nutritionally, the TGs are the most predominant group in this category. They comprise the bulk of lipids in seed oils and storage fat in animal tissues. The general chemical structure of a TG is shown in figure 1 . Conventionally, the 3 carbon atoms of the glycerol molecule are numbered 1, 2 and 3 from top to bottom. For designation of the stereochemistry of the acylglycerols, the glycerol molecule is drawn in a Fisher projection with the secondary hydroxyl group to the left of the central prochiral carbon atom, and then the carbons are numbered 1, 2 and 3 from top to bottom. Molecules that are stereochemically numbered in this fashion have the prefix ' $s n$ ' immediately preceding the term 'glycerol' in the name of the compound to distinguish them from compounds that are numbered in a conventional fashion.

Differences in the distribution of fatty acids in the 3 positions of the glycerol moiety in dietary TGs have some nutritional implications. In particular, the composition of $s n-2$ is of great importance, since $s n-2$ facilitates the

Fat and Fatty Acid Terminology,

Analysis, Digestion and Metabolism absorption of these fatty acids as 2-monoacyl-sn-glycerols and is utilized as such in the re-synthesis of TGs and glycerol PLs that takes place after fat absorption (see 'Absorption of Products of Digestion', below). A considerable amount of data is available in the literature on the stereospecific distribution of fatty acids of common dietary fats [Christie, 2008]. In general in seed oils, the PUFAs are greatly enriched in the $s n-2$ position while saturated fatty acids (SFAs) are concentrated in the $s n-1$ and $s n-3$ positions, and monounsaturated fatty acids (MUFAs) are relatively evenly distributed. In most dietary animal fats, the SFAs are predominantly in the $s n-1$ position, although an appreciable amount of oleic acid (OA) is usually present also. The $s n-2$ position tends to contain mainly PUFAs, especially linoleic acid (LA). In cow's milk, however, all the butyric acid (C4:0) and most of the hexaenoic acid (C6:0) is in the $s n-3$ position, whereas the long-chain SFAs (C14:0, C16:0 and C18:0) are equally distributed at the $s n-1$ and $s n-2$ positions. In human milk, palmitic acid (C16:0) is predominantly in $s n-2$, whereas stearic acid (18:0) is in $s n-1$ position. In marine lipids, SFAs and MUFAs are preferentially in the $s n-1$ and $s n-3$ positions, whereas PUFAs are greatly concentrated in the $s n-2$ position with substantial amounts also being in position $s n-3$.

\section{Glycerophospholipids}

These are also referred to as PLs. They are constituents of cell membranes which occur in foods and extracted oils. Glycerophospholipids may be subdivided into distinct classes, based on the nature of the polar head group at the $s n-3$ position of the glycerol backbone in eukaryotes and eubacteria or the $s n-1$ position in the case of archaebacteria. Examples of glycerophospholipids found in biological membranes are phosphatidylcholine, phosphatidylethanolamine and phosphatidylserine. The general structure of glycerophospholipids is shown in figure 2 . The $\mathrm{X}$ moiety attached to the phosphate includes 
choline, ethanol amine, serine or hexahydric alcohol. A SFA is usually esterified at position 1 and a PUFA at position 2. The polar group at position 3 , which contains phosphorus and the nitrogenous base or sugar molecule, provides the PL molecule with a hydrophilic region. In addition to serving as a primary component of cellular membranes and binding sites for intra- and intercellular proteins, some glycerophospholipids in eukaryotic cells, such as phosphatidic acids, are either precursors of, or are themselves, membrane-derived second messengers. Typically one or both of these hydroxyl groups are acylated with long-chain fatty acids, but there are also alkyl-linked and 1Z-alkenyl-linked (plasmalogen) glycerophospholipids, as well as dialkylether variants in prokaryotes.

Although PLs constitute a small fraction of total dietary fat, they can be important sources of essential fatty acids (EFAs).

\section{Sphingolipids}

Sphingolipids are a complex family of compounds that share a common structural feature, a sphingoid base backbone that is synthesized de novo from serine and a long-chain fatty acyl co-enzyme A (CoA), and then converted into ceramides, phosphosphingolipids, glycosphingolipids and other species. The major sphingoid base of mammals is commonly referred to as sphingosine. Ceramides ( $\mathrm{N}$-acyl-sphingoid bases) are a major subclass of sphingoid base derivatives with an amidelinked fatty acid. The fatty acids are typically SFAs or MUFAs with chain lengths from 14 to 26 carbon atoms. Ceramides are generally precursors of more complex sphingolipids. The major phosphosphingolipids of mammals are sphingomyelins (ceramide phosphocholines). The glycosphingolipids are a diverse family of molecules composed of 1 or more sugar residues linked via a glycosidic bond to the sphingoid base. Examples of these are the simple and complex glycosphingolipids such as cerebrosides, gangliosides and sulfoglycosphingolipids (sulfatides) that are abundant in myelin.

\section{Sterol Lipids}

Sterols are a class of lipids that contain the common steroid nucleus of a fused 4-ring structure with a hydrocarbon side chain and an alcohol group. Structures of some common dietary sterols are illustrated in figure 3. Dietary sterols are found in both animal fats and most vegetable oils and they occur in free form or are esterified to such compounds as fatty acids, glycosides or ferulic acid (oryzanol). Cholesterol is the primary animal fat sterol and is found in vegetable oils in trace amounts. Cholesterol is an important component of membrane lipids. Plant-derived sterols are collectively known as plant sterols or phytosterols. The type and amount of phytosterols vary with the source of oil. The major plant sterols are $\beta$-sitosterol, campesterol and stigmasterol, although several others are known to exist [Piironen and Lampi, 2004]. The total sterols (sum of esterified and non-esterified sterols) generally account for $0.2-1.0 \%$ of total lipids for most vegetable oils. Refining of vegetable oils removes up to $40 \%$ of sterols.

The steroids, which contain the same fused 4-ring core structure, are also included in this sterol lipids category. They have different biological roles from hormones and signaling agents. The C18 steroids include the estrogen family, whereas the $\mathrm{C} 19$ steroids comprise the androgens such as testosterone and androsterone. The $\mathrm{C} 21$ subclass includes the progestogens as well as the glucocorticoids and mineralocorticoids. The secosteroids, comprising various forms of vitamin $\mathrm{D}$, are characterized by cleavage of the $\mathrm{B}$ ring of the core structure. Other examples of sterols are the bile acids and their conjugates, which are synthesized from cholesterol in the liver.

\section{Prenol Lipids}

Prenol lipids are synthesized from the 5-carbon precursors isopentenyl diphosphate and dimethylallyl diphosphate that are produced mainly via the mevalonic acid pathway. The simple isoprenoids are linear alcohols, diphosphates, etc., that are formed by the successive addition of $\mathrm{C} 5$ units, and are classified according to the number of these terpene units. Structures containing 40 carbons or more are known as polyterpenes. Carotenoids are important simple isoprenoids that function as antioxidants and some carotenoids, but not all (e.g. lycopene), are precursors of vitamin A. Another biologically important class of molecules is exemplified by the quinones and hydroquinones, which contain an isoprenoid tail attached to a quinonoid core of non-isoprenoid origin. Vitamins $\mathrm{E}$ and $\mathrm{K}$ and the ubiquinones, are examples of this class.

From a nutritional point of view, vitamin $\mathrm{E}$ is the most important lipid group in the prenol lipid category. Vitamin $\mathrm{E}$ consists of a mixture of lipid-soluble phenols characterized by an aromatic chromanol head and a side chain of 16 carbon atoms. Vitamin $\mathrm{E}$ is divided into 2 subclasses: tocopherols and tocotrienols. The tocopherols have a saturated hydrocarbon tail, whereas the tocotrienols are the farnesylated analogues having an unsaturated isoprenoid tail (fig. 4). Both tocopherols and tocotrienols occur as a family of 4 isomers, namely $\alpha-, \beta-, \gamma$ - and $\delta$-tocopherol and tocotrienols. 
Fig. 3. Chemical structures of some common dietary sterols.

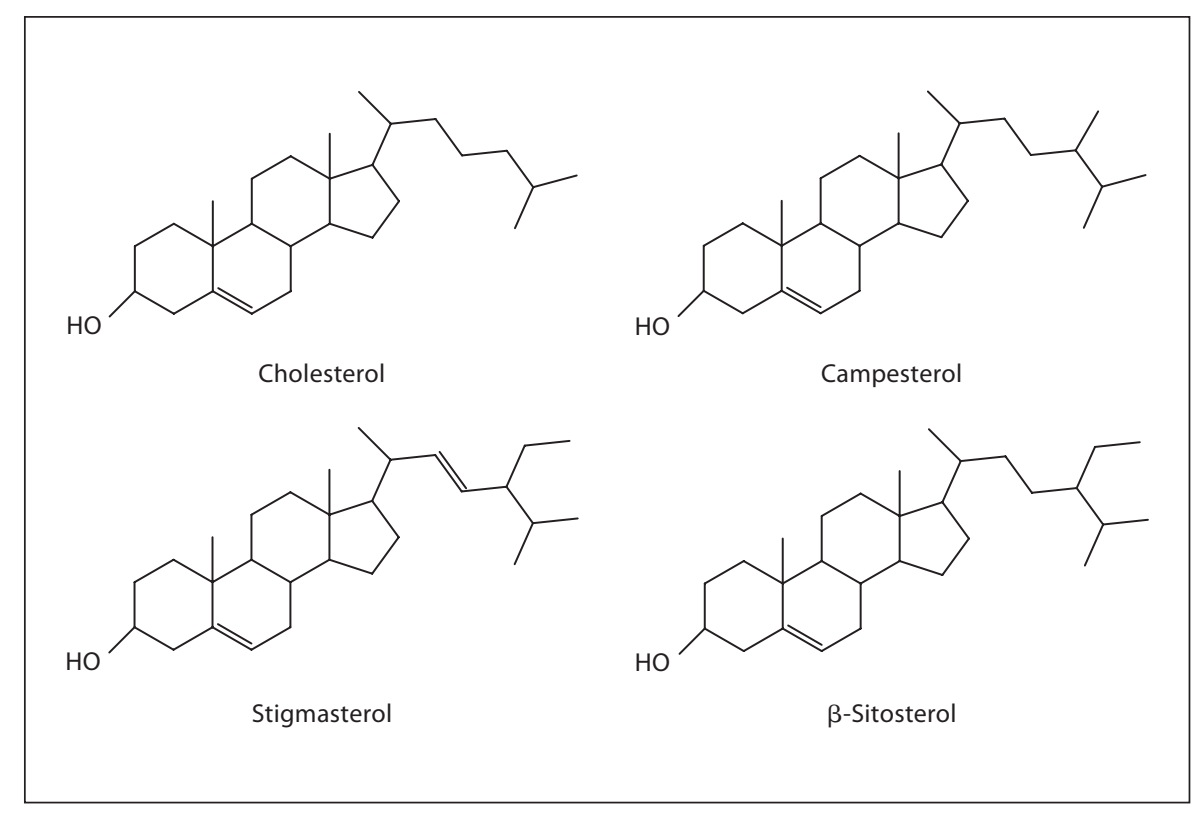

The main well-known biological function of tocopherols is for protection of PUFAs against oxidation. The different tocopherols have different antioxidant activities in vitro and in vivo. In food systems, the antioxidant activity of the tocopherol isomers decreases in the order: $\delta>\gamma>\beta>\alpha$ [Kamal-Eldin and Appelqvist, 1996]. In biological systems, however, the antioxidant activity appears to be limited to $\alpha$-tocopherol. The other forms of tocopherol do not contribute to vitamin $\mathrm{E}$ activity [Institute of Medicine, 2000]. This is because the presence in biological systems of hepatic $\alpha$-tocopherol transfer protein which selectively binds $\alpha$-tocopherol, as compared to other vitamin $\mathrm{E}$ forms and facilitates its secretion from the liver [Mustacich et al., 2006]. Tocotrienols have weak vitamin E activity but act as antioxidants in foods and provide stability against oxidation.

Evidence from in vitro and animal studies has indicated that the activity of vitamin $\mathrm{E}$ is enhanced by the presence of vitamin C [Halpner et al., 1998]. In vitro studies have suggested that synergism between vitamins $C$ and $\mathrm{E}$, in terms of hydrogen exchange between ascorbic acid and tocopheroxyl radicals, leads to recycling of vitamin E [Niki et al., 1984]. However, studies in guinea pigs and humans (healthy women) have not confirmed this interaction to a significant extent [Burton et al., 1990; Jacob et al., 1996].

In addition to its direct antioxidant function, $\alpha$-tocopherol has specific cellular functions. $\alpha$-Tocopherol

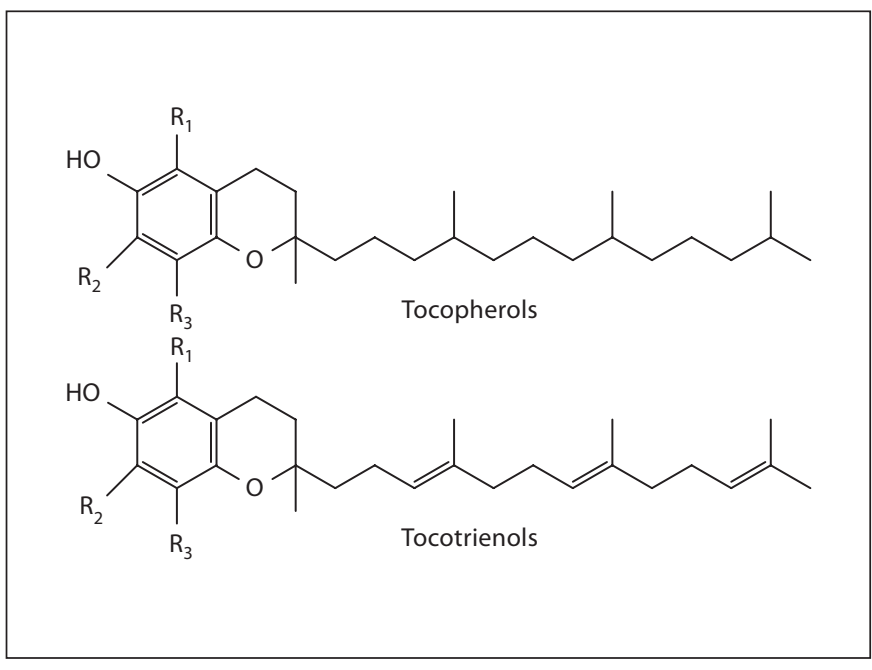

Fig. 4. Vitamin E structures. The methyl groups on the chromanol head determine whether the molecule is $\alpha\left(\mathrm{R}_{1}=\mathrm{CH}_{3}, \mathrm{R}_{2}=\right.$ $\left.\mathrm{CH}_{3}, \mathrm{R}_{3}=\mathrm{CH}_{3}\right), \beta\left(\mathrm{R}_{1}=\mathrm{CH}_{3}, \mathrm{R}_{2}=\mathrm{H}, \mathrm{R}_{3}=\mathrm{CH}_{3}\right), \gamma\left(\mathrm{R}_{1}=\mathrm{H}, \mathrm{R}_{2}=\right.$ $\left.\mathrm{CH}_{3}, \mathrm{R}_{3}=\mathrm{CH}_{3}\right)$ or $\delta\left(\mathrm{R}_{1}=\mathrm{H}, \mathrm{R}_{2}=\mathrm{H}, \mathrm{R}_{3}=\mathrm{CH}_{3}\right)$, while the tail determines whether the molecule is a tocopherol or tocotrienol.

inhibits protein kinase $\mathrm{C}$ activity, which is involved in cell proliferation and differentiation in smooth muscle cells, human platelets and monocytes. At physiologically relevant concentrations, $\alpha$-tocopherol down-regulates the expression of intercellular adhesion molecules, and 
vascular cell adhesion molecule-1, thereby decreasing the adhesion of blood cell components to the endothelium [Cominacini et al., 1997]. $\alpha$-Tocopherol also enhances the release of prostacyclin, a potent vasodilator and inhibitor of platelet aggregation [Tran and Chan, 1990].

Vegetable oils, nuts and seeds are rich sources of tocopherols, especially the $\alpha, \beta$ and $\delta$ isomers. Significant amounts are also found in green leafy vegetables and a variety of fish [Institute of Medicine, 2000]. Similar to sterols, considerable amounts of tocopherols are lost during the refining process of vegetable oils, especially during the deodorization step, where about $30-35 \%$ of the total tocopherols are distilled [Cmolik et al., 2000]. Some vegetable oils, particularly palm oil [Qureshi et al., 1991] and rice bran oil [Rogers et al., 1993] are rich sources of tocotrienols.

Recently, an ester derivative of phosphate with the hydroxyl group of tocopherol, as $\alpha$-tocopheryl phosphate ester, has been described as a novel natural form of tocopherol [Gianello et al., 2005]. Similar to $\alpha$-tocopherol, the phosphate ester is present in animal tissues as well as in the plant kingdom. Very little information is available about the biological and physiological effectiveness of $\alpha$ tocopheryl phosphate ester. A recent animal study has shown cardioprotection with $\alpha$-tocopheryl phosphate ester [Mukherjee et al., 2008].

\section{Saccharolipids}

In saccharolipids fatty acids are linked directly to a sugar backbone, forming structures that are compatible with membrane bilayers. In the saccharolipids, a sugar substitutes for the glycerol backbone that is present in glycerolipids and glycerophospholipids. The most familiar saccharolipids are the acylated glucosamine precursors of the lipid A component of the lipopolysaccharides in Gram-negative bacteria. Typical lipid A molecules are disaccharides of glucosamine, which are derivatized with as many as 7 fatty acyl chains.

\section{Polyketides}

Polyketides are synthesized by polymerization of acetyl and propionyl subunits by classic enzymes as well as iterative and multimodular enzymes that share mechanistic features with the fatty acid synthases. They comprise a very large number of secondary metabolites and natural products from animal, plant, bacterial, fungal and marine sources, and have great structural diversity. Many polyketides are cyclic molecules whose backbones are often further modified by glycosylation, methylation, hydroxylation, oxidation, and/or other processes. Many commonly used antimicrobial, antiparasitic, and anticancer agents are polyketide derivatives.

\section{Fatty Acids}

The fatty acids present in various lipid molecules are the major components of dietary fats. In the body, they are incorporated in blood lipids, in fats deposits and in structural lipids in biological membranes. Dietary fatty acids are derived from acylglycerols, free fatty acids, PLs and sterol esters. Of these, TGs are the main sources. $100 \mathrm{~g}$ of TG will yield approximately $95 \mathrm{~g}$ of fatty acids. The physical and chemical characteristics and the health and nutritional effects of dietary fatty acids are influenced greatly by the kinds and proportions of the component fatty acids.

Chemically, a fatty acid is a carboxylic acid with an aliphatic tail (chain) (fig. 5). The predominant fatty acids are straight chain, can be saturated or contain carboncarbon double bonds with an even number of carbon atoms. Fatty acids containing 1 or more double bonds in the chain are termed 'unsaturated fatty acids.' When the fatty acid contains 1 double bond, it is called 'monounsaturated' (MUFA). If it contains more than 1 double bond, it is called 'polyunsaturated' (PUFA). In almost all naturally occurring unsaturated fatty acids, the double bonds are in the cis configuration and are typically positioned at the 3rd, 6th or 9th carbon atom from the terminal methyl group. A cis configuration means that the hydrogen atoms attached to the double bonds are on the same side. If the hydrogen atoms are on opposite sides, the configuration is called trans. In almost all the naturally occurring PUFAs the double bonds are arranged in a methylene-interrupted pattern, the double bonds are separated by a single methylene group $\left(\mathrm{CH}_{2}\right)$. There is a wide spectrum of chain lengths, ranging from 4-carbon fatty acids in dairy fat to 30-carbon fatty acids in some marine lipids.

\section{Fatty Acid Nomenclature and Shorthand Notations}

There are a number of systems of nomenclature for fatty acids, however, some of the systems do not provide sufficient information as to the structure of fatty acids. A chemical name must describe the chemical structure unambiguously. For fatty acids, this is done by using the systematic nomenclature recommended by the International Union of Pure and Applied Chemistry [IUPAC-IUB Commission on Biochemical Nomenclature, 1978]. The IUPAC 
Fig.5. Structures of some common dietary fatty acids.

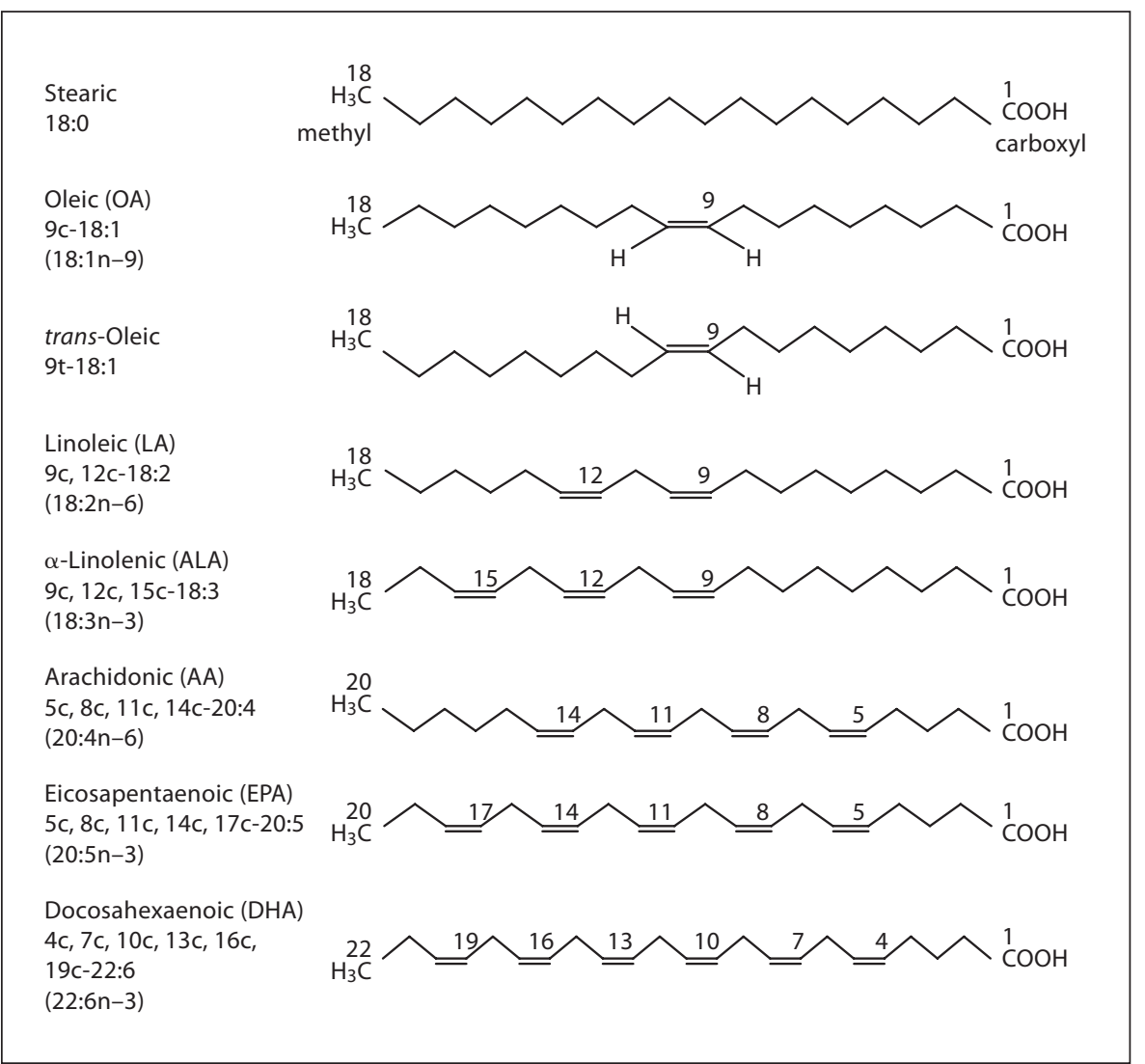

system names fatty acids solely on the basis of the number of carbon atoms, the number and position of unsaturated fatty acids relative to the carboxyl group. The configuration of double bonds, location of branched chains and hetero atoms and other structural features are also identified. The carbon of the carboxyl group is considered as number 1 and the carbons in the fatty acid chain are numbered consequently from the carboxylic carbon. By convention, a specific bond in a chain is identified by the lower number of the 2 carbons that it joins. The double bonds are labeled with $\mathrm{Z}$ or $\mathrm{E}$ where appropriate but are very often replaced by the terms cis and trans, respectively. For example the systematic name of LA is Z-9, Z-12-octadecadienoic acid or cis-9,cis-12-octadecadienoic acid.

Although the IUPAC nomenclature is precise and technically clear, the fatty acid names are too long and therefore, for convenience, 'trivial' or historical names and shorthand notations are frequently used in scientific writings. This is not surprising since those working in the scientific area of dietary fats are familiar with the chemical structure. There are several shorthand notations for dietary fatty acids, but all of them adopt the form
$\mathrm{C}: \mathrm{D}$, where $\mathrm{C}$ is the number of carbon atoms and $\mathrm{D}$ is the number of double bonds in the carbon chain. Biochemists and nutritionists very often use the ' $\mathrm{n}$ minus' system of notation for naturally occurring cis unsaturated fatty acids, which is based on categorization of unsaturated fatty acids into different families that share the same biosynthetic pathway. The term ' $n$ minus' refers to the position of the double bond of the fatty acid closest to the methyl end of the molecule. In this system the configuration of the double bond is not specified and in addition, only the position of the first double bond closest to the methyl end is denoted. The position and confirmation of the other double bonds are not specified. Thus, LA is abbreviated as 18:2T6 or 18:2n-6 because the first double bond is 6 carbon atoms from the methyl carbon. This abbreviation is applicable only to naturally occurring fatty acids. Since the double bonds of natural unsaturated fatty acids are in the cis configuration and in PUFAs, the double bonds are methylene interrupted. It is not applicable to fatty acids with trans configuration and PUFAs with non-methylene interrupted double bonds. This system easily defines the different metabolic series, such as 
Table 2. Common SFAs in food fats and oils

\begin{tabular}{|c|c|c|c|}
\hline $\begin{array}{l}\text { Common } \\
\text { name }\end{array}$ & $\begin{array}{l}\text { Systematic } \\
\text { name }\end{array}$ & $\begin{array}{l}\text { Abbre- } \\
\text { viation }\end{array}$ & Typical sources \\
\hline Butyric & butanoic & $\mathrm{C} 4: 0$ & dairy fat \\
\hline Caproic & hexaenoic & $\mathrm{C} 6: 0$ & dairy fat \\
\hline Caprylic & octanoic & C8:0 & $\begin{array}{l}\text { dairy fat, coconut and } \\
\text { palm kernel oils }\end{array}$ \\
\hline Capric & decanoic & C10:0 & $\begin{array}{l}\text { dairy fat, coconut and } \\
\text { palm kernel oils }\end{array}$ \\
\hline Lauric & dodecanoic & $\mathrm{C} 12: 0$ & coconut oil, palm kernel oil \\
\hline Myristic & tetradecanoic & C14:0 & $\begin{array}{l}\text { dairy fat, coconut oil, } \\
\text { palm kernel oil }\end{array}$ \\
\hline Palmitic & hexadecanoic & $\mathrm{C} 16: 0$ & most fats and oils \\
\hline Stearic & octadecanoic & C18:0 & most fats and oils \\
\hline Arachidic & eicosanoic & C20:0 & peanut oil \\
\hline Behenic & docosanoic & $\mathrm{C} 22: 0$ & peanut oil \\
\hline Lignoceric & tetracosanoic & C24:0 & peanut oil \\
\hline
\end{tabular}

$\mathrm{n}-9, \mathrm{n}-6$ and $\mathrm{n}-3$, etc. The $\mathrm{n}$ minus system is also referred to as the 'omega' system, but the omega system is not recommended [IUPAC-IUB Commission on Biochemical Nomenclature, 1978].

Another system that is widely used is the delta $(\Delta)$ system, in which the classification is based on the number of carbon atoms interposed between the carboxyl carbon and the nearest double bonds to the carboxylic group. This system specifies the position of all the double bonds as well as their cis/trans configuration. It is applicable to a large number of fatty acids, except those with branched chains, hetero atoms, triple bonds and other fatty acids with unusual structural features. According to the delta system, the shorthand notation for LA is cis- $\Delta 9$, cis- $\Delta 12$ 18:2. For convenience, it could be expressed as cis,cis$\Delta 9, \Delta 12-18: 2$. In some scientific papers, authors drop the ' $\Delta$ notation' and write it simply as cis-9,cis-12-18:2 or $9 c, 12 c-18: 2$. The delta system is very useful for isomeric fatty acids with double bonds in trans configuration and for PUFAs whose double bonds are not arranged in a methylene interrupted manner; for example, the shorthand notation of rumenic acid is $18: 2 \Delta 9 c, 11 \mathrm{t}$. This is a conjugated fatty acid isomer of LA present in dairy fats and meat from ruminant animals.

In this report, wherever appropriate, we will employ the IUPAC, trivial names, delta and $\mathrm{n}$ minus shorthand notations.

\section{Saturated Fatty Acids}

Those containing only single carbon-to-carbon bonds (i.e. no double bonds) are termed saturated. Most of the
SFAs occurring in nature have unbranched structures and an even number of carbon atoms. They have the general formula $\mathrm{R}-\mathrm{COOH}$, in which the $\mathrm{R}$ group is a straightchain hydrocarbon of the form $\mathrm{CH}_{3}\left(\mathrm{CH}_{2}\right)_{\mathrm{x}}$. An example of a common SFA (stearic acid) is illustrated in figure 5. Fatty acids with 2-30 carbons or more occur, but the common dietary acids contain between 4 and 24 carbons and they are listed in table 2 by their common name, IUPAC name and shorthand abbreviation. The shorthand abbreviation of SFAs includes the number of carbon atoms and a zero after the colon; for example C18:0 or 18:0. C18:0 means that the fatty acid consists of 18 carbon atoms and that there are no double bonds in it.

SFAs are the least reactive chemically and therefore they are more stable and have a longer shelf life than the unsaturated fatty acids. The melting point of SFAs increases with chain length. Decanoic and longer chain fatty acids are solid at normal room temperature.

The SFAs are further classified into 4 subclasses according to chain lengths: short, medium, long and very long. Various definitions are used in the literature for the SFA subclasses. The FAO/WHO Expert Consultation recognized that there is a need for universal definitions and recommends the following:

- Short-chain fatty acids: between 3 and 7 carbon atoms. Butyric (4:0) and caproic (6:0) are the most important members of this group and they occur in milk fats, but are not normally found in common vegetable oils.

- Medium-chain fatty acids: between 8 and 13 carbon atoms. Caproic (8:0), capric (10:0) and lauric (12:0) are members of this group; caproic and capric occur in milk fats and lauric in coconut and palm kernel oils.

- Long-chain fatty acids: between 14 and 20 carbon atoms. Palmitic (16:0) and stearic (18:0) are the most important fatty acids of this group. Palmitic acid is the most widely occurring SFA, being present in practically every fat examined, it is present in marine oils, in the milk and depot fats of land animals and in vegetable fats; main sources include palm oil, cottonseed oil, lard and beef tallow. Stearic acid is less common than palmitic acid, but present in most vegetable fats, though a significant component in only a few, such as cocoa butter and shea butter. It is also present in most animal fats and is a major component in the tallow of ruminant fats.

- Very-long-chain fatty acids: those with 21 or more carbon atoms. Behenic (22:0) and lignoceric (24:0) are the most common members and present in most dietary fats, but at very low levels, usually at less than $0.1 \%$ of total fatty acids, except in peanut, high oleic sunflow- 
Table 3. Some common cis-MUFAs in fats and oils

\begin{tabular}{|c|c|c|c|}
\hline Palmitoleic & cis-9-hexadecenoic & $9 c-16: 1$ & marine oils, macadamia oil, most animal and vegetable oils \\
\hline Oleic & cis-9-octadecenoic & $9 \mathrm{c}-18: 1(\mathrm{OA})$ & $\begin{array}{l}\text { all fats and oils, especially olive oil, canola oil and high-oleic sunflower } \\
\text { and safflower oil }\end{array}$ \\
\hline cis-Vaccenic & cis-11-octadecenoic & $11 c-18: 1$ & most vegetable oils \\
\hline Gadoleic & cis-9-eicosenoic & $9 c-20: 1$ & marine oils \\
\hline Nervonic & cis-15-tetracosenoic & $15 c-24: 1$ & marine oils \\
\hline
\end{tabular}

er and high oleic safflower oils, where the level of 22:0 and $24: 0$ could be as high as 2 and $1.5 \%$ of total fatty acids, respectively (in peanut oil).

\section{Unsaturated Fatty Acids}

Unsaturated fatty acids are categorized into 2 subcategories: MUFAs and PUFAs. Some examples of chemical structures are shown in figure 5 . Because of the presence of double bonds, unsaturated fatty acids are more reactive chemically than SFAs. This reactivity increases as the number of double bonds increases.

The unsaturated fatty acids are also further classified into 3 subgroups according to chain lengths. Various definitions have also been used in the literature for the subclasses of unsaturated fatty acids; however, there have never been universally accepted definitions. Therefore, the FAO/WHO Expert Consultation recommends the following definitions:

- Short-chain unsaturated fatty acids: fatty acids with 19 or fewer carbon atoms.

- Long-chain unsaturated fatty acids: fatty acids with 20-24 carbon atoms.

- Very-long unsaturated chain fatty acids: fatty acids with 25 or more carbon atoms.

\section{Cis-Monounsaturated Fatty Acids}

More than 100 naturally occurring MUFAs have been identified, but most of these are very rare compounds. Table 3 shows the most common dietary cis-MUFAs. In general, they have an even number of carbon atoms, between C14 to C24, and the double bond is most likely located at the $\Delta 9$ position. OA (cis-9-octadecenoic acid or 9c-18:1) is the commonest cis-MUFA and it is also the most widely distributed of all the natural fatty acids. $\mathrm{OA}$ is very often accompanied by very small amounts of cis-vaccenic acid (11c-18:1), which is the 11c isomer of OA.

Fat and Fatty Acid Terminology,

Analysis, Digestion and Metabolism
The other cis-MUFAs listed in table 3 are widely distributed in plants and animal tissues, but are very often minor components in human diets. Palmitoleic acid (9c$16: 1)$ is the most widely occurring hexadecenoic acid. It is a minor component $(<1$ or $2 \%)$ in most animal and vegetable oils, but more significant in marine oils (around $10 \%$ ), and it is a major component in a few seed oils (e.g. macadamia oil, 22\%). Among C20 (eicosenoic) MUFAs, the $9 \mathrm{c}$ and $11 \mathrm{c}$ isomers are very often present in marine oils. The 11c isomer is the major C20:1 isomer in many seed oils, but is present at very low levels $(<0.5 \%)$.

The most important C22:1 acid in human diets is erucic acid (13-cis-docosenoic acid or 22:1n-9). It occurs generally at higher levels in seed oils of plants in the family Brassicaceae, reaching a level of $40-60 \%$ in mustard seed oil and high-erucic rapeseed oil, but these oils are consumed only in some parts of Asia and eastern Europe. In most other parts of the world, erucic acid has been almost removed from rapeseed plants via selective breeding (e.g. canola) because of the possible adverse health effects of erucic acid. No negative health effects have been documented in humans, but in several animal models feeding erucic acid has resulted in the promotion of myocardial lesions. Despite this possible negative health effect, erucic acid has received some attention in medicine for the possible application in the treatment of adrenoleukodystrophy, a peroxisomal disorder leading to the accumulation of MUFAs in various tissues and in the brain. Erucic acid typically present in rapeseed oil appears to activate peroxisomal activities.

MUFAs with more than 22 carbon atoms are rare in human diets, except for $15 \mathrm{c}-24$ : 1 which is present as a minor component $(<0.2 \%)$ in many marine oils.

\section{Polyunsaturated Fatty Acids}

Natural PUFAs with methylene interrupted double bonds and with all cis configuration can be divided into 
Table 4. Nutritionally important n-6 PUFAs

\begin{tabular}{|c|c|c|c|}
\hline Common name & Systematic name & Abbreviation & Typical sources \\
\hline Linoleic acid & cis-9,cis-12-octadecadienoic & $18: 2 \mathrm{n}-6(\mathrm{LA})$ & most vegetable oils \\
\hline$\gamma$-Linolenic acid & cis-6,cis-9,cis-12-octadecatrienoic acid & $18: 3 n-6$ (GLA) & $\begin{array}{l}\text { evening primrose, borage and } \\
\text { blackcurrant seed oils }\end{array}$ \\
\hline Homo- $\gamma$-linolenic acid & cis-8,cis-11,cis-14-eicosatetrienoic acid & $20: 3 n-6$ & very minor component in animal tissues \\
\hline Arachidonic acid & cis-5,cis-8,cis-11,cis-14-eicosatetraenoic acid & $20: 4 n-6(A A)$ & animal fats, liver, egg lipids, fish \\
\hline Docosatetraenoic acid & cis-7,cis-10,cis-13,cis-16-docosapentaenoic acid & $22: 4 n-6$ & very minor component in animal tissues \\
\hline
\end{tabular}

Table 5. Nutritionally important n-3 PUFAs

\begin{tabular}{|c|c|c|c|}
\hline$\alpha$-Linolenic & cis-9,cis-12-cis-15-octadecatrienoic acid & $18: 3 n-3(A L A)$ & flaxseed oil, perilla oil, canola oil, soybean oil \\
\hline $\begin{array}{l}\text { Docosapentaenoic } \\
\text { acid }\end{array}$ & $\begin{array}{l}\text { cis-7,cis-10,cis-13,cis-16, } \\
\text { cis-19-docosapentaenoic acid }\end{array}$ & $22: 5 n-3(n-3$ DPA) & $\begin{array}{l}\text { fish, especially oily fish (salmon, herring, } \\
\text { anchovy, smelt and mackerel) }\end{array}$ \\
\hline $\begin{array}{l}\text { Docosahexaenoic } \\
\text { acid }\end{array}$ & $\begin{array}{l}\text { cis-4,cis-7,cis-10,cis-13,cis-16,cis-19- } \\
\text { docosapentaenoic acid }\end{array}$ & $22: 6 n-3$ (DHA) & $\begin{array}{l}\text { fish, especially oily fish (salmon, herring, } \\
\text { anchovy, smelt and mackerel) }\end{array}$ \\
\hline
\end{tabular}

12 different families ranging from double bonds located from the $\mathrm{n}-1$ to $\mathrm{n}-12$ positions countered from the terminal carbon of the fatty acid chain [Gunstone, 1999]. The most important families, in terms of extent of occurrence and human health and nutrition are the $n-6$ and $n-3$ families based on LA and $\alpha$-linolenic acid (ALA or $18: 3 n-3)$, respectively.

Both LA and ALA are essential for several reasons. Humans and animals cannot make them from other substrates and therefore they must be supplied in food. They are synthesized only in plant sources. Humans need dietary LA and ALA to produce C20 and C22 n-6 and n-3 highly unsaturated fatty acids (HUFAs). These PUFAs are absolutely essential for optimal development of the brain, circulating cells (red blood cells (RBCs), leukocytes, etc.) and skin. Highly specialized membranes such as synaptic terminals, retinal cells and heart myocytes, contain very high amounts of arachidonic acid (AA or 20:4n-6) and docosahexaenoic acid (DHA or 22:6n-3) in PLs mainly for structural lipids (highly fluid membranes, also in contractile cells, in the case of muscular cells) and functional (e.g. receptor functions, ion channels, neurotransmitter release) roles. The C20 PUFA are in turn converted to hormone-like substances called eicosanoids including prostaglandins (PGs), thromboxanes (TXs), prostacyclins, and lipoxins (see 'Eicosanoid and Docosanoid Formations', below). DHA is converted to docosanoids. The eicosanoids and docosanoids play important roles in the regulation of widely diverse physiological functions, including blood pressure, platelet aggregation, blood clotting, blood lipid profiles, the immune response, and the inflammation response to injury infection.

Tables 4 and 5 show the members of the $n-6$ and $n-3$ PUFA families, respectively.

\section{n-6 PUFA}

LA is the parent fatty acid of the n-6 family. It has 18 carbon atoms and 2 double bonds. The first double bond is 6 carbons from the methyl end of the fatty acid chain, hence the n-6 name. LA is comparable with OA in the extent of its occurrence. It occurs in almost every dietary fat and attains major proportions in some common veg- 
etable oils, especially sunflower, safflower, corn and soybean oils. Because of its wide distribution and abundance in many common dietary fats, many populations overconsume LA, and consequently the intake of n-3 fatty acids is very often lower than ideal.

In humans, dietary LA can be desaturated and elongated to form a series of n-6 PUFAs (see 'Eicosanoid and Docosanoid Formations', below). In this metabolic conversion, $\gamma$-linolenic acid (18:3n-6 or GLA) is the first metabolite produced through the $\Delta 6$ desaturase. GLA is a trace constituent in some animal PLs and ruminant fats. It is more readily available from seed oils of evening primrose $(8-10 \%)$, borage $(20-25 \%)$ and blackcurrant (15$18 \%)$.

Physiologically, AA and dihomo-gamma linolenic acid (DGLA or 20:3n-6) are the most important conversion products of LA. Both are substrates for eicosanoids and AA has special functions (discussed earlier). Fish, especially freshwater fish are good sources of AA [Ackman, 2008a]. AA is present in lean meat, especially in free-living animals, liver [Wood et al., 2008] and egg lipids. It is rare in the plant kingdom, but it has been reported in marine algae and other aquatic plants. The presence in marine algae is the consequence of an adaptation process to the unique environmental conditions that require the synthesis and incorporation in cells of HUFAs, such as AA, but especially eicosapentaenoic acid (EPA or $20: 5 n-3)$ and DHA. DGLA is also present in animal tissues, but at very low levels ( $<0.1 \%$ of total fat).

\section{n-3 PUFA}

ALA is the parent fatty acid of the $n-3$ family. It is primarily present in the plant kingdom. It occurs in very high concentrations in flaxseed oil (approx. 55\%) and perilla oil (approx. 60\%). Among the common vegetable oils, it is readily available in canola (6-10\%) and soybean $(5-8 \%)$ oils. Stearidonic acid (SDA or $18: 4 n-3)$ is the first metabolite in the conversion of ALA to long-chain n-3 PUFA. This is a trace constituent in animal fats and common vegetable oils and therefore most diets contain very little SDA. But there are some natural sources, notably fish oils, which contain up to $4 \%$ of SDA. Some novel seed oils contain relatively high proportions of SDA, such as blackcurrant seeds, redcurrant seeds, alpine currant seed and Echium seeds [Li et al., 2002a]. Recently, soybean plants have been genetically modified to produce oil containing a substantial amount of SDA (15-30\% w/w of total fatty acids) [Ursin, 2003]. The other important $n-3$ PUFAs are EPA (20:5n-3), docosapentaenoic acid (n-3 DPA or $20: 5 n-3)$ and DHA (22:6n-3) which are major

Fat and Fatty Acid Terminology,

Analysis, Digestion and Metabolism components of marine lipids. Marine fish such as mackerel, salmon, sardine, herring and smelt are excellent sources of EPA, n-3 DPA and DHA [Ackman, 2008a]. Fish oils containing $60 \%$ of EPA and DHA are sold as sources of these important n-3 HUFAs. Algal oils and single-cell oil sources of the long-chain PUFAs are now becoming available to provide EPA + DHA + AA. Furthermore, genetically modified oil sources are now being developed and will be widely available in the near future by the genetic manipulation of soy and other plants.

EPA is a precursor for the $n-3$ derived PGs and TXs and DHA is the precursor of docosanoids. DHA is present in very high proportions in some tissues in humans, such as cardiomyocytes, sperms, retinal cells and those of the brain (synaptic membranes).

\section{Trans Fatty Acids}

Although the double bonds of most naturally occurring unsaturated fatty acids in food fats are in the cis configuration, double bonds in the trans configuration do occur in nature. Small amounts $(2-6 \%)$ of trans fats are naturally present in ruminant deposits and milk fats [Huth, 2007]. Trans fatty acids arise in the stomach of ruminants as a result of the hydrogenation of dietary unsaturated fatty acids during bacterial fermentation [Kepler et al., 1966].

Human diets contain not only natural trans fatty acids, but also those arising from technological treatments, such as partial hydrogenation of oils to produce fat blends for margarine, shortening and deep fat frying [CraigSchmidt and Teodorescu, 2008]. Partially hydrogenated vegetable and marine oils constitute the main source of trans fats in human diets in some parts of the world. Trans fatty acids derived from partial hydrogenation are often referred to as industrial trans. Trans fatty acids are also formed inadvertently during the refining process of vegetable oils [Ackman et al., 1974]. As a result, refined vegetable oils can contain small amounts $(<2 \%)$ of trans fatty acids [Ratnayake and Zehaluk, 2005].

Both, biohydrogenation and industrial partial hydrogenation result in isomerization of naturally occurring cis unsaturated fatty acids to trans isomers as well as to positional isomers. Thus, partial hydrogenation results in the formation of an assortment of new cis and trans isomers of MUFA and PUFA. In ruminant fats and partially hydrogenated vegetable oils, the trans-octadecenoic acid (trans-oleic or trans-18:1) isomers are the most important group of trans fatty acids. The position of the double bond of these dietary trans 18:1 isomers, counted from the carboxylic carbon, usually varies from $\Delta 4$ to 
Table 6. Distribution of positional trans 18:1 isomers of some partially hydrogenated canola oil (PHCO) and soybean (PHSO) basestocks hydrogenated to different extents

\begin{tabular}{|c|c|c|c|c|c|c|}
\hline \multirow{2}{*}{$\begin{array}{l}\text { Trans 18:1 } \\
\text { isomer }\end{array}$} & \multicolumn{3}{|c|}{ PHCO } & \multicolumn{3}{|l|}{ PHSO } \\
\hline & IV 92 & IV 80 & IV 64 & IV 109 & IV 86 & IV 64 \\
\hline $4 \mathrm{t}$ & - & - & 0.1 & - & 0.1 & 0.1 \\
\hline $5 t$ & - & - & 0.1 & - & 0.1 & 0.1 \\
\hline $6 \mathrm{t}$ & - & 0.2 & 0.5 & 0.1 & 1 & 0.6 \\
\hline $7 \mathrm{t}$ & - & 1 & 3.8 & 1.2 & 1.2 & 1.4 \\
\hline $8 \mathrm{t}$ & 6 & 9.9 & 13.4 & 8.5 & 7.6 & 8.8 \\
\hline $9 t$ & 38.6 & 28.7 & 23 & 21.1 & 18.6 & 22.5 \\
\hline $10 t$ & 20.8 & 25.5 & 23.3 & 23.7 & 26.9 & 21.8 \\
\hline $11 t$ & 14.9 & 16.1 & 15.7 & 23.4 & 23.8 & 18.2 \\
\hline $12 t$ & 8.6 & 9.4 & 9.7 & 9.7 & 9.9 & 12.5 \\
\hline $13 t$ & 5.3 & 5.1 & 5.7 & 7.5 & 6.3 & 8.1 \\
\hline $14 \mathrm{t}$ & 2.6 & 2.2 & 3.1 & 3.4 & 2.8 & 3.5 \\
\hline $15 t$ & 2.2 & 0.9 & 1.3 & 1.4 & 1.1 & 1.4 \\
\hline $16 \mathrm{t}$ & 1 & 1 & 0.3 & - & 0.6 & 1 \\
\hline
\end{tabular}

\begin{tabular}{ccccccc}
\hline $\begin{array}{c}\text { Total t-18:1 (\% of } \\
\text { total fatty acids) }\end{array}$ & 18.9 & 38.3 & 39.8 & 13.8 & 27 & 36.7 \\
\hline Total trans fatty acids & 25.3 & 40.1 & 4.4 & 17.7 & 30.6 & 37.4 \\
\hline
\end{tabular}

IV = Iodine value.

Table 7. Distribution of positional trans 18:1 isomers (\% of total trans 18:1 isomers) in some dairy products purchased from retail stores in Canada in 2006; from Mendis et al. [2008]

\begin{tabular}{lrrrr}
\hline $\begin{array}{l}\text { Trans 18:1 } \\
\text { isomer }\end{array}$ & \multicolumn{1}{l}{$\begin{array}{l}\text { Milk } \\
(\mathrm{n}=6)\end{array}$} & $\begin{array}{l}\text { Butter } \\
(\mathrm{n}=7)\end{array}$ & \multicolumn{1}{c}{$\begin{array}{c}\text { Cheese } \\
(\mathrm{n}=9)\end{array}$} & \multicolumn{1}{c}{$\begin{array}{l}\text { Cream } \\
(\mathrm{n}=2)\end{array}$} \\
\hline $4 \mathrm{t}$ & $0.7 \pm 0.1$ & $0.7 \pm 0.04$ & $0.9 \pm 0.1$ & $0.6 \pm 0.2$ \\
$5 \mathrm{t}$ & $0.5 \pm 0.1$ & $0.5 \pm 0.05$ & $0.6 \pm 0.1$ & $0.6 \pm 0.2$ \\
$6 \mathrm{t}-8 \mathrm{t}$ & $2.0 \pm 0.7$ & $2.6 \pm 0.4$ & $1.9 \pm 0.4$ & $3.7 \pm 0.7$ \\
$9 \mathrm{t}$ & $4.7 \pm 0.8$ & $5.5 \pm 0.4$ & $4.7 \pm 0.7$ & $6.7 \pm 0.5$ \\
$10 \mathrm{t}$ & $11.4 \pm 1.3$ & $11.8 \pm 0.7$ & $10.5 \pm 1.1$ & $13.4 \pm 0.2$ \\
$11 \mathrm{t}$ & $33.4 \pm 1.8$ & $35.8 \pm 2.0$ & $32.8 \pm 2.3$ & $30.2 \pm 0.3$ \\
$12 \mathrm{t}$ & $10.4 \pm 0.4$ & $9.5 \pm 0.3$ & $11.0 \pm 0.6$ & $10.4 \pm 0.2$ \\
$13 \mathrm{t}$ & $10.4 \pm 0.4$ & $9.6 \pm 0.3$ & $9.9 \pm 0.5$ & $10.7 \pm 0.2$ \\
$14 \mathrm{t}$ & $11.6 \pm 0.5$ & $10.6 \pm 0.6$ & $12.0 \pm 0.9$ & $11.5 \pm 0.6$ \\
$15 \mathrm{t}$ & $7.7 \pm 0.3$ & $7.6 \pm 0.2$ & $8.4 \pm 0.5$ & $7.8 \pm 0.0$ \\
$16 \mathrm{t}$ & $7.3 \pm 1.2$ & $5.8 \pm 0.7$ & $7.4 \pm 1.8$ & $4.3 \pm 0.2$ \\
\hline
\end{tabular}

Total t-18:1

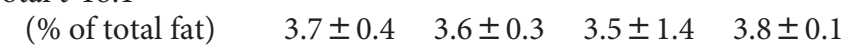

Total trans fatty acids

( \% of total fat) $\quad 5.6 \pm 0.6 \quad 5.2 \pm 0.3 \quad 5.3 \pm 1.3 \quad 5.4 \pm 0.1$
$\Delta 16$. The trans $18: 1$ isomer distribution in partially hydrogenated vegetable oils depends on the fatty acid composition of the starting oil, the extent of hydrogenation and very often the trans 18:1 isomers form a Gaussian distribution that centers around the $\Delta 9$ or $\Delta 10$ double bond (table 6) [Ratnayake, 2004].

The trans 18:1 isomer distribution of dairy fats is distinctly different from that of partially hydrogenated vegetable oils. Vaccenic acid (11t-18:1) is always the major isomer in ruminant fats $(30-60 \%$ of total $t-18: 1)$, whereas 9t-18:1 and 10t-18:1 isomers occur in relatively low amounts (table 7) [Parodi, 1976; Mendis et al., 2008].

In addition to the trans 18:1 isomers, partially hydrogenated oils contain several cis-octadecenoic isomers (cis-18:1), whose double bond position generally ranges from $\Delta 6$ to $\Delta 16$. The naturally occurring cis isomer, OA is always the predominant isomer followed by 10c-18:1 and 11c-18:1. Ruminant fat also contains several cis-18:1 isomers. The isomer distribution, however, is less complex than that for partially hydrogenated vegetable oils [Ratnayake, 2004]. Here also, OA is the predominant isomer and it accounts for approximately $95 \%$ of the total isomers.

Dietary fats also contain a number of positional and geometrical isomers of LA and ALA which are frequently present in low concentrations in both partially hydrogenated and non-hydrogenated dietary fats [Ratnayake, 2004]. Partially hydrogenated vegetable oils contain 15 or more isomers of LAs; the major ones generally are 9c,13t18:2, 9c,12t-18:2 and 9t,12c-18:2. These isomers are often detected in large quantities in mildly hydrogenated vegetable oils (up to $6 \%$ of total fatty acids), whereas they are hardly detectable in heavily hydrogenated oils.

The LA and ALA isomers present in non-hydrogenated fats or in many common food fats are the result of exposure of these PUFAs to some form of heat treatment, such as steam deodorization or stripping during refining of oils [Ackman et al., 1974] or simple heating in deep fat frying [Grandgirard, 1984]. In these processes, the double bonds do not shift in position, but are isomerized from cis to trans, resulting in the formation of small amounts of geometric trans isomers of LA and ALA.

\section{Conjugated Linoleic Acid Isomers}

Small amounts of positional and geometrical isomers of LA having 2 conjugated double bonds (CLA isomers) are also present in the human diet, primarily derived from ruminant fats. CLA is produced in the rumen as a result of biohydrogenation of dietary LA. A total of 24 CLA isomers have been identified and rumenic acid (i.e. 
$9 \mathrm{c}, 11 \mathrm{t}-18: 2$ or $9 \mathrm{c}, 11 \mathrm{t}-\mathrm{CLA})$ is the major isomer. The CLA levels in dairy fats usually range from $0.3-0.6 \%$ of total fat [Parodi, 2003]. Since the discovery in 1987 that an extract from grilled ground beef later identified as CLA had biological effects [Ha et al., 1987], numerous studies have revealed various beneficial biological functions of CLA isomers [Tricon et al., 2005]. The beneficial functions include its antimutagenic, anticarcinogenic, and antiobesity properties as well as its effects on regulating lipid metabolism and immune response. However, most of the CLA research in humans to date has focused mainly on readily available commercial mixtures of CLA, rather than on pure $9 \mathrm{c}, 11 \mathrm{t}-\mathrm{CLA}$, which is the naturally occurring CLA in dairy fats and ruminant depot fats. Commercial CLA preparations consist of an equal mixture of $10 \mathrm{t}, 12 \mathrm{c}-18: 2$ and $9 \mathrm{c}, 11 \mathrm{t}-18: 2$. The $10 \mathrm{t}, 12 \mathrm{c}-18: 2$ isomer is generally present only in trace amounts in dairy fats and ruminant depot fats. The biological effects of pure $9 \mathrm{c}, 11 \mathrm{t}-$ $18: 2$ is yet to be determined.

Recent advances in dairy technology have enabled the production of milk naturally enriched with 9c,11t-CLA by altering animal feed [Bauman et al., 2000]. However, this manipulation has also resulted in increasing the trans fatty acid content, in particular vaccenic acid. A recent study reported that there is no significant difference in the effect of butter enriched with CLA + vaccenic acid on the plasma lipid profile in pigs compared to regular butter containing normal levels of CLA and vaccenic acid [Haug et al., 2008]. More studies are needed to evaluate the nutritional and biological effects of milk products enriched with CLA and vaccenic acid.

\section{Conjugated Linolenic Acid Isomers}

Conjugated fatty acids other than CLA exist in nature. Seed oils of certain plants, such as tung, pomegranate, catalpa, bitter gourds and karela contain a mixture of conjugated linolenic acid isomers (CLN) at levels of 40$80 \%$ [Takagi and Itabashi, 1981]. All 3 double bonds of the CLN isomers of these seed oils are in conjugation and several isomers exist, which include: 9c,11t,13t-18:3 ( $\alpha$-eleostearic acid); $9 c, 11 \mathrm{t}, 13 \mathrm{c}-18: 3$ (punicic acid); $9 \mathrm{t}, 11 \mathrm{t}, 13 \mathrm{c}-$ $18: 3 ; 9 t, 11 t, 13 t-18: 3$ and $8 t, 10 t, 12 c-18: 3$. Very often, $\alpha$-eleostearic acid and punicic acid are the predominant isomers.

Interest in the biological activity of CLN is growing. CLN is a potent suppressor of growth of various tumor cells [Igarashi and Miyazawa, 2000; Suzuki et al., 2001]. Its antitumor effect is stronger than CLA [Tsuzuki et al., 2004]. In addition, CLN is effective in reducing body fat mass in rats [Kolbe et al., 2002]. In rats, $\alpha$-eleostearic acid

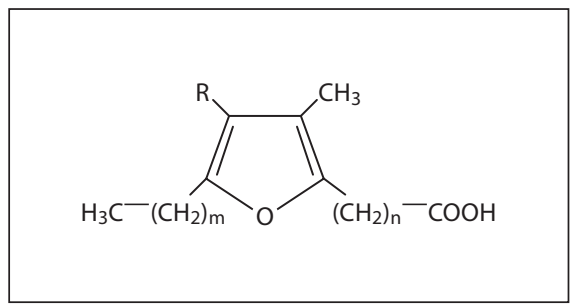

Fig. 6. Structures of the most abundant furan fatty acids. $\mathrm{m}=2-4$; $\mathrm{n}=8-12 ; \mathrm{R}=\mathrm{H}$ or $\mathrm{CH}_{3}$.

and punicic acid are metabolized to 9t,11c-CLA [Tsuzuki et al., 2006]. Since these 2 CLN isomers are present in some plant seeds in large amounts, they can act as sources of 9t,11c-CLA after metabolism.

\section{Furan Fatty Acids}

Furan fatty acids are a large group of naturally occurring unusual fatty acids characterized by a furan ring with the general structure shown in figure 6 . These fatty acids occur widely but at low levels in freshwater and marine fish. They have also been detected in marine bacteria, algae, yeast, fungi, plants, fruits, food fats such as butter, virgin olive oil and blood, including that of humans [reviewed by Spiteller, 2005]. Thus, it appears that these fatty acids are widely distributed in all living matter.

Fish, other marine organisms and mammals consume furan fatty acids in their foods and incorporate them into PLs and cholesterol esters. Some short-chain dibasic furan fatty acids, which might be metabolites of the longchain acids, have been detected in the urine and blood of humans. Furan fatty acids have been shown to be scavengers of hydroxyl and peroxyl radicals [Okada et al., 1990, 1996]. Spiteller [2005] has suggested that the radical scavenging ability of furan fatty acids may contribute to the cardioprotective properties of fish and fish oils. This is an interesting suggestion that needs to be clinically tested.

\section{Analytical Methods}

Analysis of fatty acids of biological or food samples generally involves 3 steps: extraction of lipids, conversion of the extracted lipids to a volatile derivative, often to fatty acid methyl esters (FAMEs) and analysis of the FAMEs by gas-liquid chromatography (GC) for the fatty acid profile.

At every stage of the fat analysis, precautions have to be taken to minimize the risk of hydrolysis of lipids 
and autoxidation of unsaturated fatty acids. This can be achieved by performing all procedures under subdued light in an inert atmosphere of nitrogen. All animal tissues should ideally be analyzed immediately after removal from the living organism to avoid enzymatic lipolysis. When this is not feasible, the tissue should be frozen as soon as possible, with dry ice or liquid nitrogen and stored at very low temperature (ideally $-60^{\circ} \mathrm{C}$ or below) in a sealed glass container in a nitrogen atmosphere.

\section{Fat Extraction}

\section{Total Fat Recovery}

Several excellent methods are available, but the choice of the extraction procedure depends on the nature of the sample matrix [Christie, 2003, 2008]. Simple extraction procedures, such as Soxhlet extraction or heating in a sealed glass test tube using hexane, heptane, petroleum ether or other non-polar solvents can be used for TG-rich samples such as oil seeds, certain foods (e.g. margarine, butter) and adipose tissue. Animal and plant tissues contain an assortment of non-polar and polar lipids in close association with proteins and polysaccharides, with which they link by hydrophobic or van der Wal forces and by ionic bonds. Quantitative recovery of the complex lipid mixture from animal tissues is most conveniently achieved using procedures that employ a mixture of polar solvents such as the chloroform-methanol system of Folch et al. [1957] or Bligh and Dyer [1959]. If the procedures are followed exactly as instructed in the original papers, both methods can give reliable results.

The lipids of plant material and photosynthetic tissues are liable to undergo extensive enzyme-catalyzed degradation when extracted with chloroform-methanol. The problem is best overcome by means of conducting a preliminary extraction with propan-2-ol, followed by reextraction of the residue with chloroform-methanol [Nicholos, 1963].

In recent years, supercritical fluids have been evaluated as extractants for lipids [King, 2002], while these appear to hold promise for extraction of some simple lipids, there appears to be little prospect for more general use.

\section{Total Fatty Acid Recovery without Lipid Extraction}

Since fatty acids are the dietary components that are of most nutritional interest, very often the objective of fat analysis is to obtain information only on fatty acids. Prime examples are the current nutrition labeling regulations in Canada [Health Canada, 2003] and the USA
[Food and Drug Administration, 2006], where the total fat in a food is defined as the sum of all fatty acids expressed as TG equivalents. Information on the lipid profile is not required for food labeling and therefore, there is no reason to recover lipids in their intact form. The AOAC official method 996.06 [AOAC, 2005] complies with the current definition of fat and is applicable to a variety of food samples, ranging from low-fat foods (cereals, breads, etc.) to high-fat foods (margarine, butter, cheese, etc.) as well as to meat and meat products, and fish and fish products. The procedure involves extraction of the fat from the food samples by acid- or base-hydrolysis, which provides a complete breakdown of the food matrix and release of fat, followed by ether extraction of the released fat, transesterification of fatty acids to FAMEs and analysis of the fatty acid profile by capillary GC. Individual fatty acids are measured quantitatively with respect to a suitable fatty acid internal standard (C11:0 TG, C17:0 TG or C21:0 TG), and each fatty acid is converted to its TG equivalent and is summed to give total fat.

Recently an elegant procedure has been established for analysis of fatty acid composition of whole blood lipids by GC without lipid extraction. Drops of blood (50 $\mu \mathrm{l}) \mathrm{col}-$ lected from fingertips have been placed on a chromatography paper; the paper is then placed in a test tube and directly subjected to transmethylation for GC analysis [Marangoni et al., 2004a]. This is a rapid and inexpensive method for the analysis of circulating fatty acids applicable to large population groups [Marangoni et al., 2007]. It also helps in storing samples for long periods and transportation of small amounts of blood samples.

\section{Preparation of Fatty Acid Methyl Esters}

Analyses of fatty acid compositions of foods, animal and plant tissues are best performed by GC as their FAME derivatives. Various procedures are available for preparation of FAMEs [Christie, 2003, 2008]. In general, FAMEs are prepared by transesterification using hydrogen chloride $(\mathrm{HCl})$, sulphuric acid $\left(\mathrm{H}_{2} \mathrm{SO}_{4}\right)$, or borontrifluoride $\left(\mathrm{BF}_{3}\right)$ in methanol $(\mathrm{MeOH})$. In a typical procedure, about $10-20 \mathrm{mg}$ of the fat sample is dissolved in toluene in a 10$\mathrm{ml}$ screw capped (Teflon-lined) centrifuge tube, $14 \% \mathrm{BF}_{3}$ $\mathrm{MeOH}$ (alternatively $5 \% \mathrm{HCl}-\mathrm{MeOH}$ or $2 \% \mathrm{H}_{2} \mathrm{SO}_{4^{-}}$ $\mathrm{MeOH})$ is added and the mixture heated to $100^{\circ} \mathrm{C}$ for $60 \mathrm{~min}$. The reaction mixture is diluted with water $(3 \mathrm{ml})$ and the FAME extracted with toluene, hexane or diethyl ether. After concentrating under nitrogen, the FAME sample is ready to be analyzed by GC. 
Methylation of amidic-bound fatty acids, as in sphingolipids, requires stronger conditions. Overnight heating at $95^{\circ} \mathrm{C}$ with $10 \% \mathrm{BF}_{3}-\mathrm{MeOH}$ has been used for preparation methyl esters from sphingolipids [Lopez et al., 2008].

Although $\mathrm{BF}_{3}-\mathrm{MeOH}$ is a convenient and a very popular reagent, caution needs to be exercised when using it. The $\mathrm{BF}_{3}-\mathrm{MeOH}$ reagent has a limited shelf life, even when refrigerated and the use of old and overly concentrated $(>7 \%)$ solutions might result in the production of artefacts and the loss of appreciable amounts of HUFAs [Christie, 2003].

Acidic methylation procedures should not be used for samples containing CLA isomers. Methylation using sodium methoxide is recommended [Kramer et al., 1997]. In contrast to acidic methylation, sodium methoxide does not isomerize CLA.

For pure oil samples which contain primarily TGs, base-catalyzed transesterification is recommended for simplicity and speed [Christopherson and Glass, 1969]. Sodium or potassium hydroxide or methoxide in methanol are the most common base-catalyzed transesterification reagents. Treatment of 19 parts of $10 \%$ solution of the pure fat sample in petroleum ether or hexane with 1 part of either $2 \mathrm{~N}$ methanolic potassium hydroxide or sodium hydroxide at room temperature results in the almost instantaneous formation of FAMEs. The solution may be analysed by GC at once.

\section{Analysis of Fatty Acids by Gas Chromatography}

Analyses of fatty acid profiles are executed by GC using a flame ionization detector, which is a universal detector and its response is linear for a wide range of sample sizes, gas flows and detector temperatures. Either hydrogen or helium is necessary as carrier gas. Optimum separation of fatty acids (as their FAME derivatives) are obtained on polar fused silica capillary (FFSC) columns.

\section{Non-Hydrogenated Oils}

For analyses of FAME mixtures containing no or very little trans fatty acids, such as non-hydrogenated fish oils, vegetable oils, animal fats, plant lipids and tissue lipids, bonded polar columns prepared from Carbowax-20m as Supelco-wax, or Omegawax-259 or Omegawax-320 are recommended [AOCS, 2003a, 2003b; Ackman, 2008b]. The separation of FAME takes place according to the fatty acid chain length, the number of double bonds and the position of the double bonds. There are almost no overlaps

Fat and Fatty Acid Terminology,

Analysis, Digestion and Metabolism of FAMEs with different chain lengths. The retention characteristics of FAME are also less sensitive than those of more polar capillary columns. Capillary columns of various lengths and internal diameters (i.d.) are commercially available, but for most analytical work $30 \mathrm{~m} \times 0.32$ (or 0.25 ) mm i.d. capillary columns are sufficient. These columns give superior separation of all the fatty acids. Typical GC run time of FAME from fish oils and other lipids which contain long-chain HUFAs such as DHA, is about $65 \mathrm{~min}$, when the column temperature is operated isothermally at $190^{\circ} \mathrm{C}$ with helium carrier gas at 12 psig. With column temperature programming (hold at $190^{\circ} \mathrm{C}$ for $8 \mathrm{~min}$, program at $3^{\circ} \mathrm{C} / \mathrm{min}$ to $240^{\circ} \mathrm{C}$ ) the same analysis can be executed in a run time of about 25 min [Ackman, 2008b]. The use of temperature programming is very useful for routine analysis of large numbers of samples. Fast GC technique, based on FAME separation under high elution pressure allows analysis of complex fatty acid mixtures in shorter times than conventional GC. However, the separation between a few of the closely eluting FAMEs may be compromised.

In recent years, $10 \mathrm{~m}$ FFSC columns have been made available. These are more suited for routine quality control analysis of simple fatty acid mixtures, such as those from common vegetable oils. GC run times of $5 \mathrm{~min}$ or less are feasible.

\section{Partially Hydrogenated Oils and Dairy Fats:}

Cis and Trans Isomers

Complete analysis of FAME from partially hydrogenated oils which contain a complex mixture of cis and trans isomers requires a column of special polarity, usually 100 m FFSC columns coated with highly polar cyanopolysiloxane stationary phases [Ratnayake, 2004; Sebedio and Ratnayake, 2008]. A variety of cyanopolysiloxane 100 m FFSC columns are available from chromatographic suppliers and are marketed under trade designations such as SP-2560, CP-Sil 88, BPX-70 and HP-88. These columns separate the cis and trans isomers that cannot be separated by columns of less polarity such as those coated with Carbowax- $20 \mathrm{~m}$. The best separation of all the fatty acids of partially hydrogenated vegetable oils with minimum overlaps of cis-trans isomers of $18: 1$ as well as other fatty acids is achieved when the column temperature is operated isothermally at $180^{\circ} \mathrm{C}$, using hydrogen as the carrier gas with a flow rate of $1.0 \mathrm{ml} / \mathrm{min}$ [Ratnayake et al., 2006]. These GC parameters have been adopted by the American Oil Chemists' Society (AOCS) in their official method Ce $1 \mathrm{~h}-05$ for the determination of the fatty acid composition of vegetable or non-ruminant 
animal oils and fats by GC [AOCS, 2005]. These GC operating parameters in conjunction with the fat extraction procedure of AOAC Official Method 996.06 [AOAC, 2005] are widely used for the determination of total fat and saturated, trans, mono-fatty acids and PUFAs for food labeling in Canada and the USA.

Although much useful information on the sample can be extracted using the $100 \mathrm{~m}$ cyanolpolysiloxane columns, minor GC peak overlaps of some cis and trans18:1 isomers may occur. The GC peak for 15t-18:1 overlaps with $9 c-18: 1$ peak and the peak for $13 t, 15 t-18: 1$ overlaps with 3 cis-18:1 isomers (6c-, 7c-, 8c-18:1). Very often, 15t-18:1 and 6c-, 7c-18:1 and 8c-18:1 are minor components in partially hydrogenated oils and therefore, these overlaps impart only a minor error in the determination of the levels of trans and cis-18:1 isomers of dietary fats. These minor overlaps cannot be corrected by isothermal operation of the GC column temperature. In fact, isothermal operations lead to further worsening of cis-trans isomer overlap [Ratnayake, 2004; Sebedio and Ratnayake, 2008]. In particular, the late eluting trans 18:1 isomers, from $12 \mathrm{t}$ to $15 \mathrm{t}-18: 1$, are hidden under $9 \mathrm{c}-18: 1$ and $16 \mathrm{t}-18: 1$ is hidden under $14 \mathrm{c}-18: 1$. The overlapping isomers could be easily quantified using auxiliary fractionation techniques, such as silver nitrate thin-layer chromatography (TLC) or silver ion high pressure liquid chromatography ( $\mathrm{Ag}^{+}$-HPLC) [Wolff, 1995; Ratnayake, 2004].

Other techniques that are useful in trans fat analysis are four transform infrared (FT-IR) coupled to GC and attenuated total reflection (ATR) infrared cell in FT-IR [Mossoba et al., 2004]. The FT-IR/GC technique can differentiate $c$ is and trans isomers, including those present in PUFAs. The ATR/FT-IR is helpful in determining the total trans content in a very short time ( $5 \mathrm{~min}$ ) in pure fats and oil samples without converting them to FAME or other derivatives. To resolve the problems of cis-trans isomer identification, many laboratories now use gas chromatography mass spectrometry (GC-MS). The bond position is easily identified by analyzing the fatty acid samples as nitrogen compounds such as picolinyl, pyrrolidide or 4,4-dimethyloxazoline derivatives [Ratnayake, 2004; Ackman, 2008b; Christie, 2008].

\section{Dairy Fats: Short-Chain Fatty Acids, CLA and Trans Isomers}

Complete analysis of dairy fatty acids is difficult and tedious, because they are a complex mixture of a wide variety of fatty acids, which includes short-, medium- and long-chain fatty acids and an assortment of trans and cis isomers of OA, LA and CLA. The short-chain fatty acids are volatile and water soluble. Therefore, precautions should be taken not to lose them during fat extraction, methylation and GC analysis. In addition, the CLA isomers are heat sensitive and can undergo isomerization if great care is not taken during extraction, methylation and GC analysis.

As for the partially hydrogenated oils, 100-meter capillary columns coated with cyanopolysiloxane liquid phases effectively resolve most of the total FAMEs from milk fat. However, it is not possible to get complete information by a single GC analysis [Kramer et al., 2004; CruzHernandez et al., 2006]. Two separate GC analyses and a complimentary pre-fractionation technique are required. $\mathrm{GC}$ isothermal analysis at $180^{\circ} \mathrm{C}$ provides good resolution of all the fatty acids including the trans-18:1 isomers. However, a shortcoming of this analysis is that the shortchain fatty acids from 4:0 to 8:0 elute with the solvent front. Therefore, a second GC run is required to get information on the short-chain fatty acids. This is achieved by temperature programming from 45 to $215^{\circ} \mathrm{C}$ [Kramer et al., 2004; Cruz-Hernandez et al., 2006]. It gives good separation of all the fatty acids. However, there are some drawbacks: in addition to the incomplete separation of the trans-18:1 isomers, CLA isomers are also not adequately separated [Cruz-Hernandez et al., 2004; Kramer et al., 2004]. As mentioned previously, dairy fats contain at least 24 CLA isomers. If information on all the individual CLA isomers is required, then it can be obtained by combining $\mathrm{GC}$ analysis with $\mathrm{Ag}^{+}$-HPLC fractionation [Cruz-Hernandez et al., 2004].

\section{Separation of Lipid Classes}

In lipid analysis of biological specimens, very often there is a need to examine the fatty acid composition of lipid classes, for example PL, TG and cholesterol esters (CEs) in plasma, liver and other tissues. This requires isolation of the lipid classes and then analysis of their fatty acid composition. TLC is the most convenient technique for isolation of small amounts of lipid components. It permits excellent separations with comparatively short elution times. Separation of most of the important lipid classes such as PL, TG, CE, cholesterol, free fatty acids, etc., in biological tissue samples can be achieved by 1-dimensional TLC in a single run using mobile phases consisting of a mixture of hexane and diethyl ether, with a little formic or acetic acid to ensure that free fatty acids migrate successfully. More polar lipids such as phospha- 
tidylcholine or phosphatidylserine will remain at the origin of sample application, and they can be isolated as a single class of very polar lipids [Christie, 2003].

The separation of the various PL classes can be achieved either by double development TLC or 2-dimensional TLC procedures. In the double development procedure, initially the plate is developed as a part of the way in a very polar solvent system (e.g. chloroform:methanol:water at 60:30:5 by volume) to separate the PL, and then for the full length of the plate with a less polar mobile phase (e.g. hexane:diethyl ether:acetic acid at 70:30:1.5 by volume) in order to resolve each of the simple lipids. Twodimensional TLC procedures are used with more complex lipids, especially those samples containing both PLs and glycolipids. In this method, the plates are developed in 1 direction and after allowing sufficient time for drying, the plate is developed at right angles to the first direction. Plate development in both directions is performed using very polar solvent systems containing chloroform, methanol, water and a small amount of acetic acid.

For non-destructive detection of individual lipids separated by TLC, $2^{\prime}, 7^{\prime}$-dichlorofluorescein $(0.1 \%)$ solution in ethanol is preferable to the commonly used Rhodamine $6 \mathrm{G}$ or iodine vapor. The less polar bands are extracted with mixtures of hexane-diethyl ether and highly polar bands with chloroform-methanol. The extracted bands are directly transmethylated using $0.5 \mathrm{M}$ methanolic $\mathrm{HCl}$ prior to GC analysis for the fatty acid composition.

\section{Lipidomics}

The sciences of genomics, proteomics and metabolomics led to the new science of lipidomics. The term lipidomics started to appear in the literature from 2003 onwards [Lagarde et al., 2003]. Lipidomics is the full characterization of the molecular species of lipids in biological samples. Its aim is to relate the lipid compositions of biological systems to their biological roles with respect to expression of proteins involved in lipid metabolism and function, including gene regulation [Spener et al., 2003]. The molecular species of lipids of biological samples are extremely diverse and are arranged in various combinations and permutations. Identification of these complex molecules is a considerable challenge. The other challenge is to relate the analytical data to their biological functions. Nevertheless, the underlying strategy in lipidomics involves firstly isolation of the biological sample and their sub-fractions, and secondly, extraction of the complex lipids free from the proteins and other compo-

Fat and Fatty Acid Terminology,

Analysis, Digestion and Metabolism nents [Wolf and Quinn, 2008]. The extracted lipids are then fractionated, usually using a multi-step chromatography process. In the final step, the individual molecular species are identified and quantified. A flow diagram of the overall lipidomics procedure is illustrated in figure 7. Identification of the lipid molecular species is performed using sophisticated technology. Modern mass spectrometry methods involving ionization by electrospray, fast atom bombardment, atmospheric pressure chemical ionization, atmospheric pressure photoionization, and matrix-assisted laser desorption techniques are highly sensitive and can produce excellent quantitative data. There may be no need for extensive sample preparation or for a chromatographic interface with the instrument, since samples can be injected directly. In addition, tandem mass spectrometry methods greatly enhance the obtainable information. The practical procedures of lipidomics were recently reviewed by Wolf and Quinn [2008].

An important outcome of lipidomics has been the development of the comprehensive classification system for lipids that was discussed previously (see 'Lipid Classes', above). This new classification system will facilitate international communication about lipids and helps to deal with the massive amounts of data that will be generated by lipidomilogists.

\section{Fat Digestion, Metabolism and Physiology}

\section{Digestion}

Digestion is the process by which large food molecules are broken to smaller components which are small enough to be absorbed by the gastrointestinal tract lining. Digestion is accomplished by enzymes secreted by both intrinsic and accessory glands into the lumen of the alimentary canal.

Dietary fats are composed mainly of TGs containing various long-chain saturated and unsaturated fatty acids as well as a small proportion of short- and medium-chain fatty acids. Since they are water-insoluble compounds, they cannot be transferred to the enterocyte in their intact form. Therefore, the ingested TGs are emulsified and hydrolyzed to monoacylglycerols and free fatty acids prior to absorption. The digestive process is very complex and requires coordinated lingual, gastric, intestinal, biliary and pancreatic functions. Usually, the entire fat digestive and absorption process lasts for $16-24 \mathrm{~h}$ if no food is consumed after the initial meal [Bisagaier and Glickman, 1983]. Initially, the dietary fat is masticated and 
Fig.7. A flow diagram of the overall lipidomics procedure. $\mathrm{LC}=$ Long-chain; $\mathrm{MS}=$ mass-spectrometry. Adapted from Wolf and Quinn [2008].

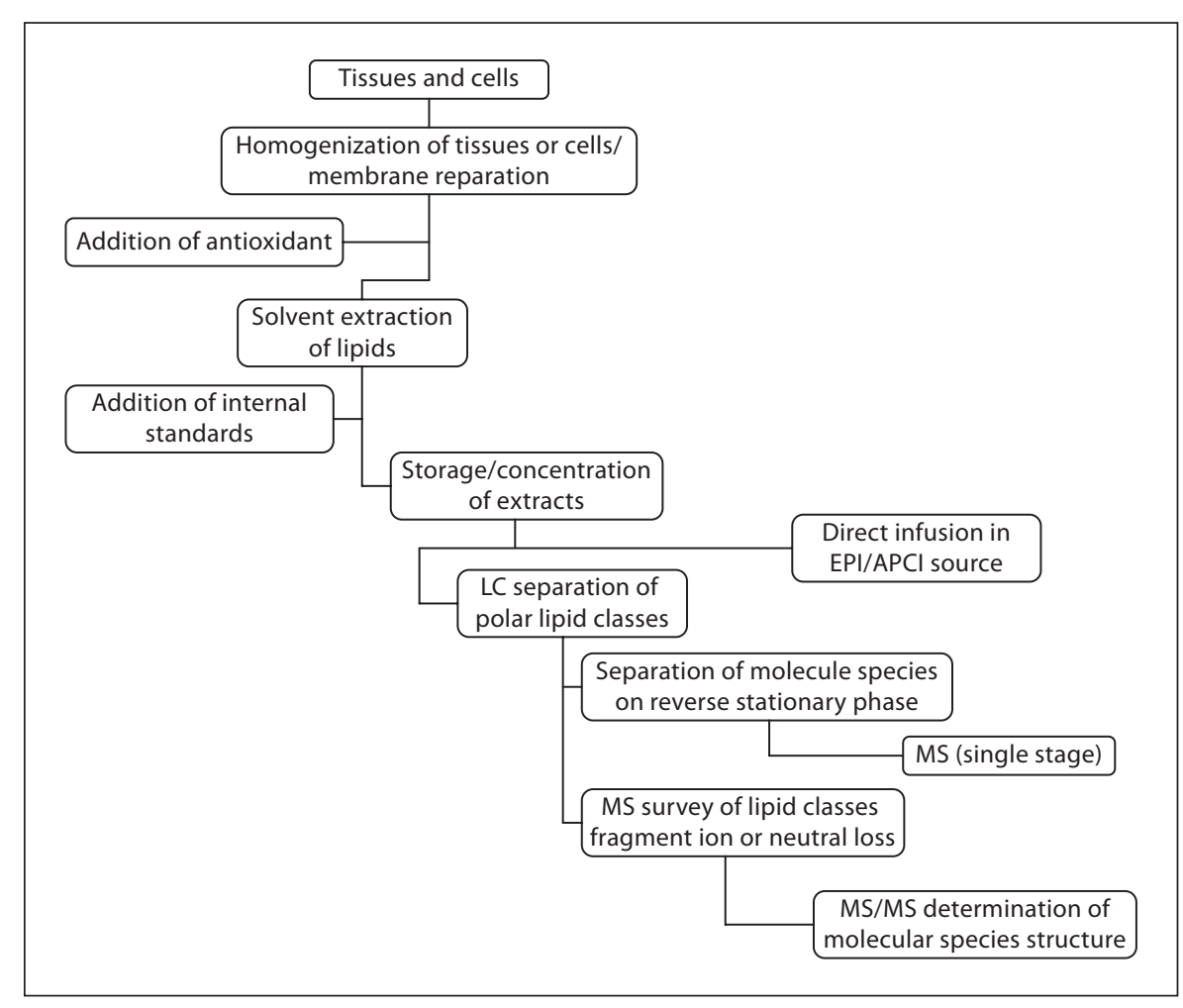

mixed with lingual lipase, followed by hydrolysis by gastric lipase in the stomach and then by pancreatic lipase in the small intestine. Although a small amount of fat-digesting enzyme (or lipase) is secreted from glands of the tongue (lingual lipase), in children and adults, the small intestine is essentially the sole site of fat digestion because the pancreas is the only significant source of fat-digesting lipases. In the newborn, however, the pancreatic secretion of lipases is low. In newborns, partial breakdown of fat is performed by a lipase present in human milk and a lingual lipase before the main digestive site of the small intestine is reached. As the baby is weaned onto solid food, the major site of fat digestion shifts to the upper part of the intestine, the duodenum, and this remains the primary site of fat digestion into adulthood [Gurr, 1999].

In children and adults, TGs are first hydrolyzed by a gastric acid lipase which predominantly attacks the shortand medium-chain fatty acids in the $s n-3$ position of the TG molecule. The gastric lipase is responsible for up to $20 \%$ of total TG hydrolysis [Lehner and Kuksis, 1996]. The released short- and medium-chain fatty acids are absorbed directly into the bloodstream from the stomach.

The stomach plays a further role in fat digestion, since its churning action facilitates formation of oil-in-water emulsion. This emulsion is stabilized by PLs. The emul- sification reduces the attraction between the fat molecules so that they can be widely spread. This process vastly increases the number of TG molecules exposed to the pancreatic lipases. The emulsified acylglycerols enter the duodenum where they stimulate contraction of the gallbladder and release of bile and pancreatic juice. The bile acids attach themselves to the emulsion particles imparting a negative charge and co-attracting colipase, a protein present in pancreatic juice that binds to TG molecules. The composition of the fat entering the upper duodenum is $80 \%$ TG with the remainder consisting of partially digested hydrolysis products formed primarily by gastric lipase. The pancreatic secretion contains a $s n-1(3)$-specific pancreatic lipase. This enzyme acts on TGs yielding small amounts of 1,2- and 2,3-diacylglycerols as intermediates and 2-monoacylglycerols and free fatty acids as final products [ $\mathrm{Mu}$ and Porsgaard, 2005]. Although, the pancreatic lipase attacks both 1 and 3 positions of TG, the relative rates of hydrolysis depend on the molecular structure of fatty acids in the TG molecules [Jensen et al., 1995]. In general, over short periods of time, the enzyme discriminates against long-chain fatty acids [Yang et al., 1990; Ikeda et al., 1995]. As a result, the longer-chain fatty acids (chains longer than C20) are released more slowly than the more common $\mathrm{C} 16$ and $\mathrm{C} 18$ fatty acids. The 
degree of unsaturation seems to have a minimum influence. However, these differences in the relative rates of hydrolysis fatty acids are a very minor issue, because prolonged digestion leads to hydrolysis of all fatty acids in 1 and 3 positions and to formation of 2-monoacylglycerols. As previously discussed (see 'Glycerolipids', above), most dietary fats tend to have the PUFAs in the $s n-2$ position and therefore the formation of 2-monoacylglycerols facilitates the absorption of PUFA at the $s n-2$ position and the retention of these fatty acids in the glycerol lipids that are subsequently generated and transferred to tissues.

The pancreatic secretion also contains phospholipase $\mathrm{A}_{2}$ which hydrolyses the fatty acids in the $s n-2$ position of glycerophospholipids and gives rise to the $s n-1$-lysophospholipd and free fatty acids [Tidwell et al., 1963; Borgstrom, 1974]. Any ingested CEs are hydrolyzed completely to free cholesterol and free fatty acids in the duodenum by pancreatic CE hydrosylate [Nilsson, 1969]. Fat soluble vitamins (vitamins $\mathrm{A}, \mathrm{D}, \mathrm{E}$ and $\mathrm{K}$ ) require no hydrolysis.

\section{Absorption of Products of Digestion}

Generally, fatty acids of chain length shorter than C12 are directly absorbed across the gut wall as individual fatty acids, bound to albumin and travel through the portal vein and are transported to the liver, where they are rapidly oxidized [Gurr and Harwood, 1991].

Long-chain fatty acids, 2-monoacylglycerol, lysophospholipids and cholesterol are mixed with bile salts and lecithin (a PL found in bile) to form micelles, which are polymolecular aggregates of fatty elements clustered together with bile salts in a way that the polar (hydrophilic) ends of the molecules face the water and the non-polar portions (hydrophobic) form the core. Also trapped in the hydrophobic core are cholesterol molecules and fat soluble vitamins. The micelles are very small particles (which are about 1/100 as large in diameter as the emulsion particles) [Johnston, 1970] and easily diffuse between microvilli of the enterocyte of the intestinal wall and come in close contact with luminal cell surface. The various lipid substances then leave the micelles and enter epithelial cells by diffusion. The fat-soluble vitamins are absorbed at the enterocytes by interacting with transporters, and this gives rise to competition between lipidsoluble micronutrients and saturation of the process.

In humans, the absorption [(intake - excreted)/intake] of most common dietary fatty acids is $>95 \%$. However, the absorption of stearic from high stearic acid sources appears to be low (65\%) according to some studies, al-

Fat and Fatty Acid Terminology,

Analysis, Digestion and Metabolism though investigators in other studies have observed absorption rates similar to those of other SFAs. In mixed diets fed to humans, absorption of stearic acid was found to be as high as 94\% [Baer et al., 2003].

\section{Effect of Food Structure on the Bioavailability of Lipids}

There are some studies which indicate that food structure can influence the apparent bioavailability of lipids from foods. The physical nature in which triglycerides are found in foods can affect the rate of digestion of the food TGs. This concept is already well established for carbohydrates in the glycemic index. Nestel et al. [2005] showed that a diet containing $40 \mathrm{~g}$ dairy fat eaten daily for 4 weeks as cheese did not raise total and low-density lipoprotein (LDL) cholesterol compared with butter. Clemente et al. [2003] found that the physical structure of fat-rich foods (milk, mozzarella cheese, butter) had no major effect on postprandial plasma triglyceride concentrations; however, there was a significant influence on the timing of the triglyceride peak in plasma. Another study reported that pre-emulsification of an oil mixture prior to ingestion increased the absorption of longer chain PUFAs (especially EPA and DHA) but did not affect absorption of shorter chain less SFAs [Garaiova et al., 2007].

The $n-3$ fatty acids from fish appear to be more efficacious, in terms of cardio protection, than equivalent amounts provided as capsules [Visioli et al., 2003]. Volunteers were given, for 6 weeks, either $100 \mathrm{~g} /$ day of salmon, providing $383 \mathrm{mg}$ of EPA and $544 \mathrm{mg}$ of DHA or 1 or 3 capsules of fish oil/day, providing $150 \mathrm{mg}$ of EPA and $106 \mathrm{mg}$ of DHA or $450 \mathrm{mg}$ of EPA and $318 \mathrm{mg}$ of DHA, as ethyl esters. Further, they evaluated data from a previous study carried out with the same design, i.e. with 3 and 6 capsules/day of fish oil, providing 1,290 and 2,580 mg/ day EPA and 960 and 1,920 mg/day DHA. Marked increments in plasma EPA and DHA concentrations $(\mu \mathrm{g} / \mathrm{mg}$ total lipid) and percentages of total fatty acids were recorded at the end of treatment with either n-3 capsules or salmon. Net increments of EPA and DHA in plasma lipids were linearly and significantly correlated with the dose after capsule administration. Further, increments in plasma EPA and DHA concentration after salmon intake were significantly higher than after administration of capsules. The same increments would be obtained with at least 2- and 9-fold higher doses of EPA and DHA, respectively, if administered with capsules rather than salmon. These data provide experimental evidence that n-3 fatty acids from fish are more effectively incorpo- 
rated into plasma lipids than when administered as capsules and that increment in plasma concentrations of EPA and DHA given as capsules are linearly correlated with their intakes.

\section{Transport of Lipids}

The lipid digestion products absorbed into the enterocyte are transported to the endoplasmic reticulum in association with a fatty acid binding protein [Lehner and Kuksis, 1996]. The fatty acids are activated to their CoA derivatives by acylcoenzyme A and converted into TG by either the monoacylglycerol pathway or the sn-glycero-3phosphate pathway. In the monoacylglycerol pathway, the free fatty acids are esterified with the 2-monoacylglycerols sequentially to form first a diacylglycerol and then a TG. This conversion is catalyzed by acylcoenzyme CoA synthetase, monoacylglycerol transacylase, and diacylglyceroltransacylase which are present in the smooth endoplasmic reticulum [Tso, 1985]. The other pathway takes place in the rough endoplasmic reticulum. It involves activation of the free fatty acids to acylcoenzyme A derivative and stepwise acylation of $s n$-glycero-3-phosphate and/or dihydroxyacetone, produced during glycolysis, to phosphatidic acid, hydrolysis of phosphatidic acid to $s n$-1,2-diacylglycerol, which is acylated further to TG [Lehner and Kuksis, 1996].

About $75-85 \%$ of TG is synthesized via the monoacylglycerol pathway. The sn-glycero-3-phosphate pathway becomes active when only long-chain 2-monoacylglycerols (hydrolytic product of dietary TGs) are absorbed by the enterocyte.

The absorbed lysophospholipids can be esterified to phosphatidylcholine by the action of lysolecithin acyltransferase which is found in both smooth and rough endoplasmic reticulum [Tso, 1985]. A high proportion of the absorbed cholesterol is esterified in the intestine at the cellular level, including enterocytes, by the acyl CoA acyl transferase, and in plasma through the lecithin cholesterol acyl transferase, the enzyme that transfers the fatty acids in position 2 of phosphatidyl choline (lecithin), mainly PUFA, to cholesterol.

The newly synthesized TGs, PLs and CEs are transported out of the enterocyte and into the bloodstream via the lymph vessels. Since lipids are insoluble in the aqueous environment of the blood, they are bound to protein to form a lipoprotein that is soluble in aqueous media. This particles are called chylomicrons, which are processed in the Golgi apparatus and consists of a non-polar core containing the re-synthesized TGs and CEs that is covered by a coat of protein, PLs and cholesterol. The protein moieties are known as apolipoproteins (or apo). In addition to stabilizing the lipoproteins, the apolipoproteins confer specificity to particles, allowing them to be recognized by specific receptors on the surface of the cells in different body tissues and organs, thereby enabling them to be taken up from the blood and regulating their metabolism. The apolipoprotein of chylomicrons include mainly apoB-48, with some apoA-I, apoA-II, apoA-IV, and apoE [Simmonds, 1972].

While in the blood stream, the TGs of the chylomicrons are hydrolyzed to free fatty acids and glycerol by lipoprotein lipase, an enzyme associated with the capillary endothelium. The fatty acids and glycerol can then pass through the capillary walls to be used by cells as energy or stored as fats in adipose tissue. Some of the free fatty acids released bind to albumin and are cleared by the liver [Bergman et al., 1971]. The remnants of chylomicron material are combined with proteins of the liver cells and these new lipoproteins are used to transport cholesterol in the blood.

The chylomicron remnants have some apoB-48, apo E, PLs, cholesterol, CEs, and some TGs [Havel, 1985]. These remnants are cleared from the circulation by the liver LDL receptor [Redgrave, 2004]. ApoE is the major apoprotein constituent of chylomicrons, their remnants and also that of very-low density lipoprotein (VLDL). It is a determinant for the receptor-mediated catabolism of these TG-rich lipoproteins. Thus, high ApoE levels are generally expected to increase lipid clearance [Chalas et al., 2002]. ApoB-48 does not bind to the LDL receptor and thus does not aid in the clearance of chylomicron remnants [Hui et al., 1981].

VLDLs are large TG-rich lipoproteins produced in the liver from endogenous fat, as opposed to chylomicrons which transport exogenous fat. VLDLs consist primarily of TGs, small amounts of cholesterol and PLs, and release them into the circulation [Havel, 1985]. VLDLs are the main carriers of TGs and also substrates for endothelial lipoprotein lipase and supply free fatty acids to adipose and muscle tissues. Through the lipase hydrolysis, they lose some of the TGs and are transformed to intermediate-density lipoproteins and finally to LDL. The core mainly consists of CEs and PLs [Polonovski and Beucler, 1983] and 1 type of apolipoprotein B [Smith et al., 1978]. LDL is taken by LDL receptor of peripheral tissue and liver. LDL primarily transfers CEs in plasma to the peripheral tissues where they are hydrolyzed to free cholesterol and then re-esterified [Sodhi et al., 1978]. 
Another lipoprotein that plays an important role in lipid transport is high-density lipoprotein (HDL). In humans, HDL carries $15-40 \%$ of plasma total cholesterol and is involved in the transport of cholesterol from peripheral tissues to liver. HDL particles consist of apoE, apoA-I, apoA-II, apoA-IV, apoA-V, apoC-I, apoC-III with PLs and unesterified cholesterol. ApoA-I and apoA-II are the major apolipoproteins [Watts et al., 2008]. There is recent evidence that nascent HDL particles originate in liver and intestine as lipid-free or lipid-poor apolipoproteins [Basso et al., 2003; Brunham et al., 2006] and these newly formed HDL particles gradually acquire cholesterol and PLs from the liver and from cells in extrahepatic tissues. ApoA-I and to a lesser extent apoA-II play a key role in cholesterol efflux [Watts et al., 2008]. The enzyme lecithin cholesterol acyltransferase, carried on HDL particles, then esterifies the free cholesterol to CEs, which migrate to the core of the HDL particles to form the mature spherical HDL particles [Lewis and Rader, 2005; Krimbou et al., 2006]. The mature HDL particles transfer CEs to VLDL and chylomicrons and this transfer is mediated by cholesterol ester transfer protein (CETP).

\section{Metabolism of Fatty Acids}

\section{Fat Oxidation}

Fat, stored as TGs, is the body's most concentrated source of energy. The energy yield from the catabolism of $1 \mathrm{~g}$ of fat is approximately $9 \mathrm{kcal}(37.7 \mathrm{kj})$, compared to $4 \mathrm{kcal}(16.8 \mathrm{kj})$ from protein or carbohydrates.

Catabolism of fat involves the oxidation of their 2 building blocks, glycerol and fatty acid chains. Most body cells easily convert glycerol to glyceraldehyde phosphate. Glyceraldehyde is half a glucose molecule, and the energy released from it is half that of carbohydrate and accounts approximately for $5 \%$ of fat energy [FAO/WHO, 1994].

Fatty acids yield energy by $\beta$-oxidation in the mitochondria. During this process, fatty acid chains are broken apart into acetic acid fragments and yields acetyl CoA molecules which enter the tricarboxylic cycle to be oxidized to carbon dioxide and water and release energy. Overall the $\beta$-oxidation process is not very efficient since it requires transport into the mitochondria by carnitine in steps: dehydrogenation at the $\alpha-\beta$ carbon atoms with the formation of a trans bond at $\Delta 2$ yielding a trans- $\Delta 2$ enoyl-CoA, hydroxylation of the trans bond, oxidation of the hydroxyl groups to form ketogroups and cleavage of acetyl-CoA. This may be one of the reasons why fatty acids are less efficiently used for energy production than carbohydrates, and are preferentially stored in the adipose tissue. In addition, oxidation of long-chain fatty acids takes place initially in peroxisomes and is not very efficient. This is probably one of the reasons why erucic acid is somewhat cardiotoxic because it is not oxidized in the heart and therefore tends to accumulate resulting in cardiac lipidosis.

The fatty acid structure affects the rate of fatty acid oxidation. In general, various animal and human studies have suggested that long-chain fatty acids are oxidized more slowly and unsaturated fatty acids oxidized more rapidly than SFAs. In rats, oxidation of SFAs decreases with increasing carbon chain length (laurate $>$ myristate $>$ palmitate $>$ stearate) [Leyton et al., 1987]. For unsaturated fatty acids, 24-hour oxidation is in the order ALA $>$ OA $>$ LA $>$ AA. However, data from human studies using isotopic tracer methodologies have revealed inconsistent observations. Jones et al. [1985] have shown a greater oxidation rate of OA compared with LA or ALA. DeLany et al. [2000] gave human subjects labelled fatty acids in a blended meal and found that the oxidation of ALA was higher than that of LA and OA, which had similar rates of oxidation. A recent study by McCloy et al. [2004] also found greater oxidation of ALA compared to LA, but the oxidation rate of ALA was similar to that of OA.

The inconsistencies in the various tracer studies may be related to the method used to measure fatty acid oxidation and possibly also to the differences in the background diets. The importance of the composition of pretrial diet was outlined by Jones [1994] who found that rats fed a pre-trial diet containing equal amounts of OA, LA and ALA for 10 weeks exhibited no differences in the capacity to oxidize 18 carbon unsaturated fatty acids. These inconsistencies in the literature may suggest that our understanding of the relative oxidation rates of the more common unsaturated fatty acids is far from complete.

\section{De novo Synthesis of Fatty Acids}

The synthetic process involves the breakdown of excess dietary carbohydrates to acetate units and condensation of acetate, as acetyl CoA with bicarbonate to form malonyl CoA. Acetyl CoA then combines with a series of malonyl CoA to form SFAs of different carbon lengths, of which the end product is palmitic acid (16:0). The fatty acid synthetic reactions up to this stage take place within the fatty acid syntheses complex. Once palmitic acid is released from the synthetic complex, it can be elongated to stearic acid and even higher SFAs by further additions of acetyl groups, through the action of fatty acid elongation systems. 
In animal tissues the desaturation of de novo synthesized SFAs stops with the formation of MUFA of the $n-9$ series. This conversion is performed by $\Delta 9$ desaturase, which is a very active desaturase enzyme in mammalian tissues, and introduces double bonds at the 9-10 position of the fatty acid chain. OA (18:1 $\Delta 9$ or 18:1n-9) is the main product of $\Delta 9$ desaturation. Small amounts of $16: 1 n-9$ are also formed. These MUFAs may be substrates for fatty acid elongase, which produces cis-vaccenic acid $(18: 1 \Delta 11$ or $18: 1 \mathrm{n}-7)$ from palmitoleic acid and eicosenoic (20:1n-9), erucic (22:1n-9) and nervonic acids (24:1n-9) from OA.

In the absence of dietary LA and other PUFAs, OA, which is the most abundant unsaturated fatty acid in tissues, is further desaturated and this step is followed immediately by elongation as shown in figure 7 to form the n-9 family of PUFAs. The $\Delta 6$ desaturase introduces a double bond at the 6-7 position and the $\Delta 5$ desaturase at the 5-6 position of the fatty acid chain. In a similar fashion, palmitoleic acid is converted to form the $n-7$ family of PUFAs. The accumulation of eicosatrienoic acid, 20:3n-9 (Mead acid) of the n-9 family in tissues, which is normally found in trace amounts only, is characteristic of EFA deficiency [Holman, 1970]. However, EFA deficiency seldom occurs in the general population consuming ordinary diets. The accumulation of $20: 3 n-9$ in tissues can be prevented by intake of LA at $1 \%$ of total energy [FAO/WHO, 1994]. It should be cautioned, however, that the amount of EFAs required to prevent deficiency symptoms may not represent the amount needed for maintaining optimum functioning of the body.

Dietary fatty acids have a significant influence on the de novo synthesis of fatty acids. For some time it was thought that only PUFA suppressed fatty acid synthesis, but SFA also suppresses fatty acids synthesis [Kelly et al., 1986]. It is likely that all dietary fatty acids, except shortchain fatty acids absorbed through the portal vein suppress de novo fatty acid synthesis [Vemuri and Kelley, 2007]. The excess CoA derived from dietary fatty acids in the liver is probably responsible for suppressing the de novo synthesis by inhibiting both acetyl CoA carboxylase and fatty acid synthase [Gurr and James, 1980].

De novo synthesis is well documented in simple biological systems such as in cultured cells and in many animal species. However, generally it is accepted that little or no de novo synthesis takes place in humans when adequate or excess calories are consumed in a high-fat diet. But when carbohydrates are fed in excess of energy requirement, the conversion of carbohydrates to fatty acids occurs, and this takes place in the liver. Studies by Straw- ford et al. [2004] have shown that free-living healthy humans have the capacity for de novo synthesis. They estimated based on the incorporation of deuterium from deuterated water on the glycerol moiety of TGs that de novo synthesis contributes on average approximately $20 \%$ of newly formed adipose TG-palmitate. However, there was a considerable individual variation (12 to 36\%). The biological sources of individual variability remain unresolved, but Strawford et al. [2004] have indicated that factors such as background diet, physical activity, genetics, hormones, etc., may explain most of the variability among individuals.

\section{Metabolism of LA and ALA to Long-Chain PUFAs}

Although mammals can readily introduce double bonds at the $\Delta 9$ position, they cannot introduce additional double bonds between $\Delta 10$ and the methyl terminal end. Thus, LA and ALA cannot be synthesized by mammals, but plants can synthesize both, by introducing double bonds at $\Delta 12$ and $\Delta 15$. Because they are necessary precursors for the synthesis of long-chain PUFAs and eicosanoids, LA and ALA are EFAs and they must be obtained from plant materials in the diet.

Once LA and ALA are obtained from the diet, they are converted to $n-6$ and n-3 PUFA families by a series of alternating desaturation and elongation reactions. Figure 8 presents a schematic representation of the biosynthetic pathway as it is currently understood. The 2 pathways (i.e. n-6 and n-3) are independent of each other and there are no cross reactions. Nevertheless, both pathways use the same desaturation and elongation enzymes. Therefore, there is competition between LA and ALA for these enzymes. $\mathrm{OA}$ is also a substrate for the $\Delta 6$ desaturase and therefore it also competes with LA and ALA for the $\Delta 6$ desaturase. The pathway needs only the $\Delta 6$ and $\Delta 5$ desaturases of the microsomal system and a chainshortening step involving the $\beta$-oxidation mechanism in the peroxisomes [Moore et al., 1995; Sprecher, 2002]. The first step involves insertion of a double bond at the $\Delta 6$ position of LA and ALA by the action of $\Delta 6$ desaturase, which is followed by chain elongation by 2 carbon units by elongase and an insertion of another double bond at the $\Delta 5$ position by $\Delta 5$ desaturase to form AA (20:4n-6) and EPA (20:5n-3), respectively. The first step of desaturation by $\Delta 6$ desaturase activity is the rate-limiting step of this pathway. The affinity for $\Delta 6$ desaturase for ALA is greater than for LA. However, the typically high intake of LA and also higher concentration of LA and low concentration of ALA in tissue lipids results in greater conversion of n-6 PUFA. In the next step, AA and EPA are elon- 
Fig. 8. Schematic pathways of $n-9, n-7$, n-6 and n-3 fatty acid metabolism.

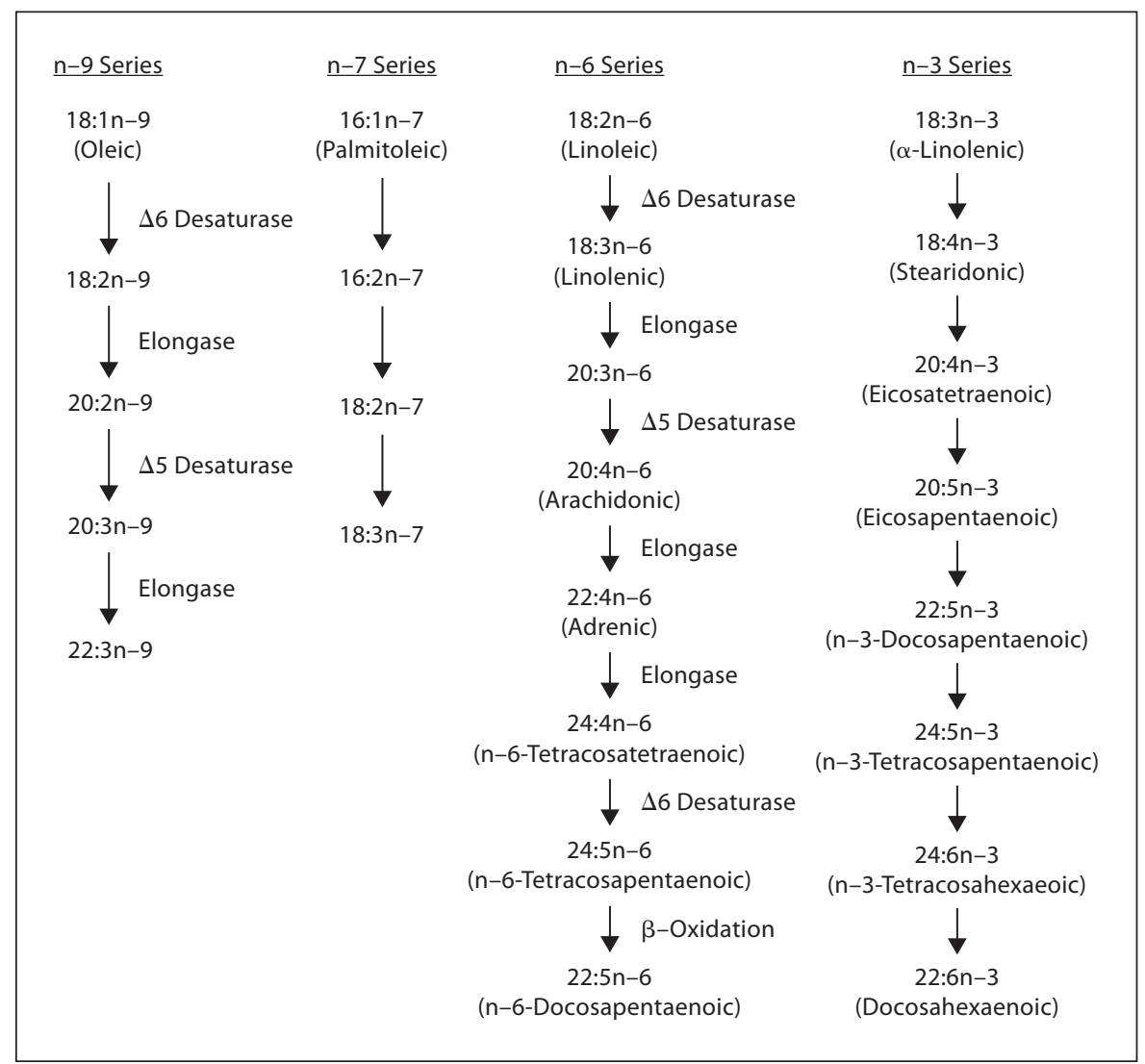

gated by 2 carbon units to $22: 4 n-6$ and $22: 5 n-3$, respectively.

For a long time it was assumed that a $\Delta 4$ desaturase is involved in the final steps of the $\mathrm{n}-6$ and $\mathrm{n}-3$ biosynthetic pathway. But, now it is known that the pathway involves further elongation of 2 carbon units in $22: 4 n-6$ and $22: 5 n-3$ (n-3 DPA) to produce $24: 4 n-6$ and $24: 5 n-3$, respectively (fig. 8). These C24 PUFAs are then desaturated by $\Delta 6$ desaturase to yield $24: 5 n-6$ and $24: 6 n-3$. This is the same desaturase enzyme that desaturates LA and ALA [D'Andrea et al., 2002]. DHA is formed from $24: 6 n-3$ by chain shortening by 2 carbon units by 1 cycle of the $\beta$-oxidation pathway. By the same chain shortening mechanism, $22: 5 n-6$ is produced from $24: 5 n-6$. The $\Delta 5$ desaturase and the subsequent steps in the pathway are found only in animals but not in plants.

AA is the predominant product of the $n-6$ pathway and it is present only in the animal kingdom and aquatic plants. AA is present in animal foods, but to a limited extent [Ackman, 2008a] and estimates of daily intakes are in the order of a few hundred milligrams. AA is a major constituent of structural lipids in most tissues, and total

Fat and Fatty Acid Terminology,

Analysis, Digestion and Metabolism amounts in the body can be estimated in the order of several tens of grams, especially considering the very high levels in certain organs (brain, liver, heart). Due to the limited direct supply by the diet, the high levels in the body and also the high turnover rates and requirements, it is therefore feasible that most of the endogenous AA is produced through metabolic LA conversion. This is supported by various types of evidence. Various agents and conditions appear to affect the LA conversion in vitro and in vivo. For examples, lipid lowering drugs [Hroboticky et al., 1994; Risé et al., 1997, 2001], cigarette smoke [Marangoni et al., 2004b; Agostoni et al., 2008]. Furthermore, the immediate precursor of AA, DGLA (20:3n-6) is detectable in appreciable concentrations in plasma and cells, while it is not apparently supplied by the diet, indicating that it is produced through LA conversion. Measurement of the AA/DGLA ratios in the appropriate lipid pools in the body (plasma, cells), may therefore be an indirect indicator of the efficiency of the $\Delta 5$ desaturation step.

The global conversion rates of LA to AA in relation to the uptakes, however, have not been fully assessed. It ap- 
pears in essence that, above certain levels in the diet, LA intakes do not result in elevation of AA levels [Marangoni et al., 1992]. In human studies in different population groups, higher dietary levels of LA also do not appear to be correlated with higher AA levels in platelets and RBC [Dougherty et al., 1987]. Controlled studies with the administration of liquid formulas devoid of AA and containing either 0 or $20 \%$ of LA showed that enhancement of dietary LA intakes does not consistently contribute to PG biosynthesis [Adam et al., 2003a]. Possible mechanisms underlying these types of effects are:

- inhibition of key desaturation steps in the conversion of LA to AA (the $\Delta 6$ and 5 desaturases) by high concentrations of the substrates, a process observed during in vivo studies;

- competition for esterification into the 2 position of glycerol of glycerolipids between the 2 PUFAs, a process that would lead to reduction of AA in the presence of high availability of LA;

- enhanced oxidation of LA, following high intakes, may also contribute to reduce the overall conversion of LA to AA;

- very high LA intakes would probably result in enhanced storage of the excess LA in the adipose tissue, and hence this fatty acid would be 'sequestered' from metabolic conversion.

However, the intake of preformed AA may partly contribute to endogenous AA levels. As shown by the higher AA levels in subjects on a normal Western diet compared with those on a lacto-vegetarian diet providing less than $90 \mathrm{mg} \mathrm{AA} /$ day [Adam et al., 2003b] and in subjects eating meat at least 3 times/week versus $<2$ times/week [Marangoni et al., 2007].

\section{EFA Deficiency and Long-Chain PUFA Levels in}

Tissues

In the case of EFA deficiency (inadequate intakes of LA), reduction of AA levels occurs and is partially counterbalanced by enhanced conversion of OA to its longer chain, more unsaturated derivative, 20:3n-9, whose concentration in plasma and tissues is usually low. The $20: 3 n-9 / 20: 4 n-6$ ratio is therefore increased, which is a biomarker of EFA deficiency.

In brain lipids, the longer chain products $22: 4 n-6$ and $24: 4 n-6$ are detectable. However, of the other $n-6$ longer products, $24: 5 n-6$ is not measurable in plasma, cells and tissues, being detectable only in metabolic studies, e.g. in cultured cells, with the use of isotopes. $22: 5 n-6$ is present only in trace amounts in plasma and tissues, but its concentrations are raised in the case of $n-3$ deficiency [Galli et al., 1971; Innis, 1991; Greiner et al., 2003], most likely to compensate for the reduction of DHA. The 22:5n-6/ $22: 6 n-3$ ratio proposed as a marker of $n-3$ deficiency in animal studies, however, does not appear to be predictive of the DHA status in humans [Innis et al., 2004].

The attention concerning the biological properties of long-chain PUFA has been mainly devoted to EPA and DHA, but $n-3$ DPA (22:5n-3) also deserves attention for various reasons. It is an intermediate in the conversion of EPA to DHA. Its level in tissues depends on the balance from EPA and its conversion to DHA. The relative levels of n-3 DPA can hence be considered indicators of the overall metabolic pathway in the body. Evidence is also emerging that n-3 DPA levels may be positively correlated with expression of certain enzymes involved in inflammatory processes in the cardiovascular system (e.g. metalloproteinase 9) [Solakivi et al., 2005]. It is postulated that inflammatory processes may activate the overall n-3 metabolic pathway, but the reduced efficiency of the metabolic process under these conditions will lead to elevation of n-3 DPA.

\section{Efficiency of Conversion of ALA to EPA and DHA}

The efficiency of conversion of ALA to its C20 and C22 n-3 PUFA is an important nutritional issue since there is evidence that enhanced EPA and DHA status in blood and tissues is important for optimal health; for example, there are beneficial effects on key risk factors of coronary heart disease and, in infants, for the development of the central nervous system. It has been proposed that an omega-3 index (erythrocyte EPA + DHA levels with respect to total fatty acids) $<8 \%$ can be considered as a potential risk factor for coronary heart disease, especially sudden cardiac death [Harris, 2008]. Since the consumption of EPA and DHA (mainly from marine fish) is very low and ALA is the primary $n-3$ fatty acid consumed (from plant sources) in many parts of the world, it is imperative to have a good understanding of the extent to which ALA is converted to EPA and DHA. Unlike, AA, very little EPA, n-3 DPA and DHA are present in tissue lipids of animals eating a diet derived largely from terrestrial plants and animals.

Although humans and animals have the capacity to convert ALA to EPA and DHA, the efficiency of conversion appears to be low, in particular to DHA. This is attributable to the observation that increased dietary intakes of ALA result in an increase in the level of ALA, EPA and n-3 DPA, but little or no change in the level of DHA in plasma or tissues [Li et al., 1999; Burdge and Calder, 2005; Brenna et al., pers. commun., 2008]. Tissue
Ratnayake/Galli 
compositional studies in animals have demonstrated that diets rich in ALA do not lead to high tissue levels of DHA. However, increases in ALA in most tissues and smaller increases in EPA and n-3 DPA have been noted [Christie, 1981; Woods et al., 1996; Abedin et al., 1999; Bowen et al., 1999; Bowen and Clandinin 2000, 2005; Fu and Sinclair, 2000]. The predominant fate of ALA is catabolism [Cunnane and Anderson, 1997; Plourde and Cunnane, 2007] and carbon recycling to acetate [Cunnane et al., 2003]. In rodents only about $16 \%$ of dietary ALA is found in tissues, and 6\% was converted to long-chain PUFA [Lin and Salem Jr., 2007].

The outcomes of most of the human feeding studies with ALA were similar to those of the above animal studies [Mantzioris et al., 1994; Gerster, 1998; Li et al., 1999, 2002a, 2002b; Francois et al., 2003; Burdge and Calder, 2005; Brenna et al., pers. commun., 2008]. Generally, ALA intakes led to increases in ALA, EPA and n-3 DPA but very little increase in DHA in plasma fractions (platelets, white cells and RBCs) or breast milk. Many studies also reported a tendency for DHA to decline when ALA consumption is markedly increased [Burdge and Calder, 2005]. Stable isotope tracer studies have also shown that healthy adult men have only a limited potential to convert ALA to EPA and that further transformation to DHA is very low. According to Pawlosky et al. [2001], the efficiency of conversion of ALA to EPA is $0.2 \%$, of EPA to $n-3$ DPA is $65 \%$ and of $n-3$ DPA to DHA is $37 \%$. The overall efficiency of conversion of ALA to EPA is $0.2 \%$, to $n-3$ DPA is 0.13 and $0.05 \%$ to DHA. There are several possible explanations for the poor conversion of ALA to DHA. A large proportion of ingested ALA is $\beta$-oxidized to acetyl CoA, which is recycled into de novo synthesis of cholesterol, SFAs and MUFAs, or further metabolized to carbon dioxide [DeLany et al., 2000]. It is the most rapidly oxidized unsaturated fatty acid [Nettleton, 1991]. Unlike LA, acylation ALA to tissue lipids is low. The concentration of ALA in PLs of plasma and tissues is usually $<0.5 \%$ of total fatty acids [Burdge and Calder, 2005]. It is not known whether this low content of ALA is sufficient to compete with LA for the $\Delta 6$ desaturase.

There are reports, however, that have shown significant increases in plasma DHA levels with ALA intakes for a long period or with very high doses. Mest et al. [1983] reported that $30 \mathrm{ml}$ of flaxseed oil consumed daily (providing approximately $15 \mathrm{~g}$ ALA per day) with the usual diet for 4 weeks resulted in significant increase in EPA and DHA, and decrease in AA in plasma PL in healthy volunteers. A study in Japan tested effects of long-term intakes of ALA on elderly subjects [Ezaki et al., 1999]. In this study, daily intake of ALA was increased to $3 \mathrm{~g}$ by substituting perilla ( $55-60 \%$ ALA) for soy oil (7\% ALA). At 3 months, there were increases in plasma ALA and EPA, but not DHA. At 10 months, DHA increased by $21 \%$, and then returned to baseline 3 months after being switched back to soy oil. A study in India showed considerable increases of EPA, n-3 DPA and DHA in plasma, but not in platelets, by partially substituting canola oil $(10 \%$ ALA) for sunflower oil ( $<1 \%$ ALA) or peanut oil $(<1 \%$ ALA) to obtain cooking oils with $25-40 \%$ LA and 4\% ALA [Ghafoorunissa et al., 2002]. On the basis of increased long-chain n-3 PUFA, the authors estimated that $0.75 \%$ energy ( $2.2 \mathrm{~g}$ ) as ALA may be required to increase plasma PL levels of long-chain n-3 PUFA to the same extent as $0.1 \%$ energy $(0.3 \mathrm{~g})$ from pre-formed $n-3$ longchain PUFA of fish oil. The above studies suggest that blood levels of DHA can be improved by long term intakes of vegetable oils containing ALA and less LA. The results of the Indian study suggests that it is not essential to have a large increase in ALA intake, but a modest increase leads to significant improvement in the long-chain $\mathrm{n}-3$ PUFA status. This observation is very important for vegetarians and for those who for various reasons do not include fish in their regular diets. Further research needs to be performed to confirm these findings. However, the increase in DHA may not be immediate and also may not be as effective as direct consumption of DHA from fish or fish oil supplements [Innis and Hansen, 1996; Grimsgaard et al., 1997; Mori et al., 2000; Park and Harris, 2002; Woodman et al., 2002; Arteburn et al., 2006].

A major rate-limiting step in ALA conversion to longchain n-3 PUFA is considered to be the first $\Delta 6$ desaturation, the product of which is SDA. SDA is the precursor of 20:4n-3 and is regarded as a good metabolic source of C20 and C22 n-3 PUFA. In both human and animal studies, the tissue EPA levels were significantly more increased in groups with dietary SDA than in the ALA group [Li et al., 2002a]. Dietary SDA from the novel oils as mentioned previously might be viable sources of longchain n-3 PUFA, particularly for vegetarian groups. However, even with SDA, the tissue accumulation of DHA is poor.

The competition between substrates for $\Delta 6$ desaturase also extends to the 24 carbon fatty acids ( $24: 5 n-3$ and $24: 4 n-6)$ at the second use of the enzyme in the synthesis of DHA and 22:5n-6, respectively (fig. 8). Most likely, both $24: 5 n-3$ and $24: 4 n-6$ are in direct competition with LA and ALA for access to the $\Delta 6$ desaturase. These competitions further limit the formation of DHA in tissues [Portolesi et al., 2007]. 
Limited data suggest that the conversion of ALA to EPA and DHA is substantially greater in young women [Burdge and Wootton, 2002] than in men of similar age [Burdge et al., 2002]. This may be due to regulatory effects of estrogen and partly to lower partitioning of ALA in women towards $\beta$-oxidation [Burdge and Calder, 2005; Pawlosky et al., 2007]. Capacity to up-regulate ALA conversion in women may be important for meeting the demands of the fetus and neonate for DHA.

In summary, the biosynthetic pathway in humans does not appear to provide sufficient levels of ALA for it to be a substitute for dietary EPA and DHA. High levels of EPA and DHA in blood or other cells are attained only when they are provided as such in the diet and this would occur mostly from the consumption of fish and fish oil which are rich sources of these long-chain PUFAs.

\section{Influence of Environmental Factors on the Conversion} of LA and ALA to n-6 and n-3 Long-Chain PUFA

A balance between LA and ALA in the diet is important because of their competitive nature and their different biological roles. The 1994 joint expert consultation report recommended that the relative amounts of LA and ALA in the diet should be between 5:2 and 10:1 [FAO/ WHO, 1994]. In a piglet study, it was shown that when the level of LA is held constant at $13 \%$ of total fat, the maximum incorporation of DHA into erythrocytes, plasma, liver and brain tissues appeared to be between LA:ALA ratios of 4:1 and 2:1 [Blank et al., 2002]. This study and other animal studies have predicted that ratios $<4: 1$ would have little beneficial effect on tissue DHA status [Woods et al., 1996; Bowen et al., 1999]. However, a recent hamster study observed that when the level of LA is held constant at $2 \%$ of total energy, the maximum incorporation of DHA occurred in liver and plasma at an LA:ALA ratio of 1:2 [Aziz et al., 2008].

In contrast to animal studies, a human feeding study showed that the absolute amount of ALA, more than the LA:ALA ratio, influences the conversion of ALA to its derivatives [Goyens et al., 2006]. An increase in EPA synthesis was obtained by lowering the LA in the diet from $7 \%$ energy to $3 \%$ energy, whereas an increase in $\mathrm{DHA}$ synthesis was achieved by increasing the amount of dietary ALA from $0.3 \%$ energy to $1.1 \%$ energy. These results suggest that a reduction in dietary LA together with an increase in ALA intake would be the most appropriate way to enhance EPA and DHA synthesis [Sinclair et al., 2002; Goyens et al., 2006]. Both absolute amount and the ratio are important factors influencing the conversions. However, this approach would not lead to substantial in- crease in plasma DHA contents as can be obtained with a moderate consumption of fish or marine oils [Brenna, 2002].

Another current concern is the extremely high level of LA in the diets of many Western populations [Lands, 2008]. Typical consumption of LA in Europe, Australia and North America ranges between 8.3 and 19.0 g per day in men and 6.8 and $13.2 \mathrm{~g}$ per day in women [Burdge and Calder, 2005]. This is typically about 10 -fold higher than the consumption of ALA. These levels of LA may be far above that needed to prevent EFA deficiency. Drastic reduction in the consumption of LA is warranted in Western countries [Lands, 2008] which would result in greater conversion of ALA to EPA and DHA. However, one needs to be cautious with this approach since the Nurses' Health Study over many years showed that those nurses with higher intakes of LA exhibited lower risks of cardiovascular disease and related mortality [Hu et al., 1997]. It is possible that the deficit in physiological levels of EPA and DHA may be particularly important in contrast to higher intakes of ALA. However, for those who are not consuming long-chain n-3 PUFA as EPA/DHA, the competition for conversion to long-chain n-3 PUFA from ALA may be compromised. It should be noted here that plant based n-3 PUFAs may particularly reduce CHD risk when seafood-based n-3 PUFA intake is low, which has implications for populations with low consumption or availability of fatty fish [Mozaffarian et al., 2005].

Nutritional factors other than dietary levels of PUFA are known to affect the activity of $\Delta 6$ desaturase and may therefore affect the efficiency of conversion of LA and ALA to long-chain n-6 and n-3 PUFAs. Low insulin levels, deficiency of protein and minerals such as iron, zinc, copper and magnesium, which are often associated with malnutrition, decrease $\Delta 6$ desaturase activity. Human studies report a positive correlation between zinc levels and AA and 20:3n-6 levels in plasma of cystic fibrosis patients. In healthy subjects zinc showed an inverse relationship with long-chain n-3 PUFA. High carbohydrate intakes increased circulating epinephrine and glucose depressed $\Delta 6$ desaturase activity. These observations may have significance while considering the efficiency of conversion of LA and ALA in populations from developing countries whose diets are deficient in energy and several nutrients.

Alcohol consumption has generally been found to decrease tissue long-chain PUFA concentrations, purportedly by suppressing conversion of LA to AA, as well as ALA to EPA and DHA, by inhibiting $\Delta 6$ and $\Delta 5$ desaturases [Horrobin, 1987]. In animal studies, chronic alcohol 
exposure has resulted in decreased levels of AA, EPA and DHA in liver, brain, retina and kidney [Harris et al., 1984; Salem et al., 1996; Pawlosky and Salem Jr., 1995; Araya et al., 2003]. Decreases in these long-chain PUFAs have also been observed in the blood of alcoholics [Pawlosky and Salem Jr., 2004]. In contrast, a study reported that low alcohol consumption during pregnancy is associated with increased cord plasma DHA concentrations [Denkins et al., 2000]. This finding might suggest that DHA, which is required for central nervous system development and function, is selectively conserved during pregnancy.

Cigarette smoking also affects the serum levels of long-chain PUFAs. In epidemiological studies, smoking is associated with lower serum levels of AA [Santos et al., 1984; Leng et al., 1994; Simon et al., 1996] and DHA [Simon et al., 1996]. Smoking is known to increase platelet aggregation, an effect consistent with smoking-associated differences in DHA levels [US Public Health Service, 1990]. Consistent with these findings, a cell culture study has shown that cigarette smoke negatively and dose-dependently affects the biosynthetic pathway of the n-3 PUFA series in human mammary epithelial cells [Marangoni et al., 2004b]. Furthermore, a case-control study has shown that maternal smoking during pregnancy is associated with a reduction in long-chain PUFA levels in infants [Agostoni et al., 2008]. In particular, higher levels of LA and ALA and lower levels of the metabolic products $20: 3 n-6, A A$, and DHA were found in infants born to late smokers compared to nonsmokers. The 20:3n-6/LA, AA/20:3n- 6 and DHA/ALA ratios, which are indices of the metabolic processes in long-chain PUFA synthesis, were also lower in infants born to smokers compared with those born to nonsmokers.

In contrast to the above-mentioned studies, a recent study of the effects of cigarette smoking on long-chain PUFA biosynthesis using stable isotopes has shown that smoking increases the metabolism, fractional synthesis rate and plasma incorporation of n-3 PUFA in both men and women [Pawlosky et al., 2007]. As a consequence, the bioavailability of n-3 PUFA to tissues may be enhanced in smokers compared with nonsmokers. Also, among male and female smokers, the percent conversion of EPA to n-3 DPA was enhanced and the fractional synthesis rate for formation of DHA among women smokers was triple that of nonsmokers. Agostoni et al. [2008] interpret these contradictory results as a compensation for losses resulting from lipid oxidation secondary to smoking.

An additional issue concerning PUFA metabolism, that would need to be studied in detail, considering that the conversion of LA and ALA to their long-chain prod-

Fat and Fatty Acid Terminology,

Analysis, Digestion and Metabolism ucts takes place mainly in the liver, is the efficiency of the conversion steps in relation to liver function and disease conditions. This topic has not been adequately studied but it appears from the limited data available that levels of AA and EPA are reduced in diabetic [Bassi et al., 1996] and cirrhotic patients.

Fatty Acid Distribution in Different Lipid Classes and in Different Types of Cells

DHA and AA are important structural components of membrane lipids of the central nervous system [Sastry, 1985]. DHA can constitute up to $50 \%$ of the fatty acids in phosphatidylethanolamine and phosphatidylserine of the outer segments of the retina rods and cones. These membranes are specialized for rapid transmission of light. The PL of brain grey matter contains high proportion of DHA in phosphatidylethanolamine and phosphatidylserine and high amounts of AA in phosphatidylinositol. AA is also present in membrane PL, particularly in phosphatidylinositol throughout the body. LA usually represents $<1 \%$ of brain and retina fatty acids and ALA is almost completely absent.

Although there is a large body of data on the fatty acid profiles of lipid classes of other tissues, it is difficult to provide a generalized picture on fatty acid distribution in lipids. This is primarily due to the fact that the fatty distribution in different lipid classes is the net result of various processes, dietary fat intake, absorption and metabolism. For example, King et al. [2006] found that many fatty acids in RBC, PL and CE responded differently to low-fat and high-fat diets. Nevertheless, results of a recent study by Risé et al. [2007] are summarized below to illustrate the distribution pattern in blood specimens and in lipid classes.

In this study, the fatty acid profiles of whole blood, plasma, lipoproteins and RBC of 10 healthy subjects on their usual lifestyle and diet were determined [Risé et al., 2007]. The results show that LA is higher in plasma, lipoproteins (LDL and HDL) than in blood cells (platelets and RBC). Whereas AA, 22:4n-6 and 22:5n-6 were more concentrated in blood cells than in plasma and lipoproteins. The percentages of ALA were similar in plasma, lipoproteins, while in platelets they were $50 \%$ lower. RBC contained no ALA. DHA is higher than EPA in all blood specimens, the highest levels were in RBC. On average, EPA levels were $0.9 \%$ of total fatty acids, with the maximum value (1.1\%) found in platelets. SFAs were higher than total PUFA in RBCs, whereas platelets contained similar proportions of SFAs and PUFAs. In all blood specimens MUFAs were in the lowest proportion. 
Fig. 9. The biosynthesis of eicosanoids from arachidonic acid. COX = Cyclooxygenase; HETE = hydroxyeicosatetraenoic acid. HPETE = hydroxyperoxyeicosatetraenoic acid; $\mathrm{LOX}=$ lipooxygenase; $\mathrm{LT}=$ leukotriene; $\mathrm{PG}=$ prostaglandin; $\mathrm{TX}=$ thromboxane. Adapted from Lee and Hwang [2008].

Fig. 10. Biosynthetic pathways of EPA-derived eicosanoids. The binding of a stimulant (e.g. a glucocorticosteroid) to a membrane receptor results in the activation of phospholipase A2, which cleaves EPA from membrane phosphatidylcholine. After its release from membrane PLs, free EPA can be metabolized by various enzyme systems to form a range of biologically active compounds. They are generally less potent than the AA-derived metabolites that compete with EPA for the enzymes. Adapted from Li et al. [2002a].
Dietary $n-6$ polyunsaturated fatty acids

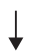

Cell membrane phospholipids

$$
\downarrow \text { Phospholipase }
$$
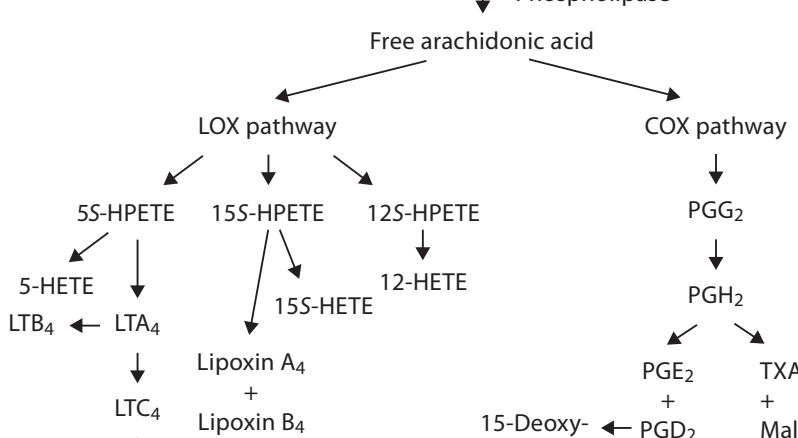

$\downarrow$

$\mathrm{LTD}_{4}$

$\downarrow$

$\mathrm{LTE}_{4}$

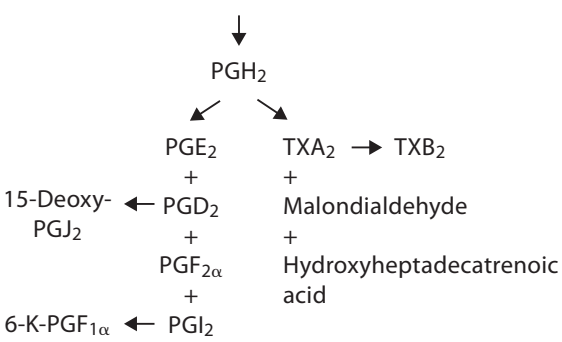

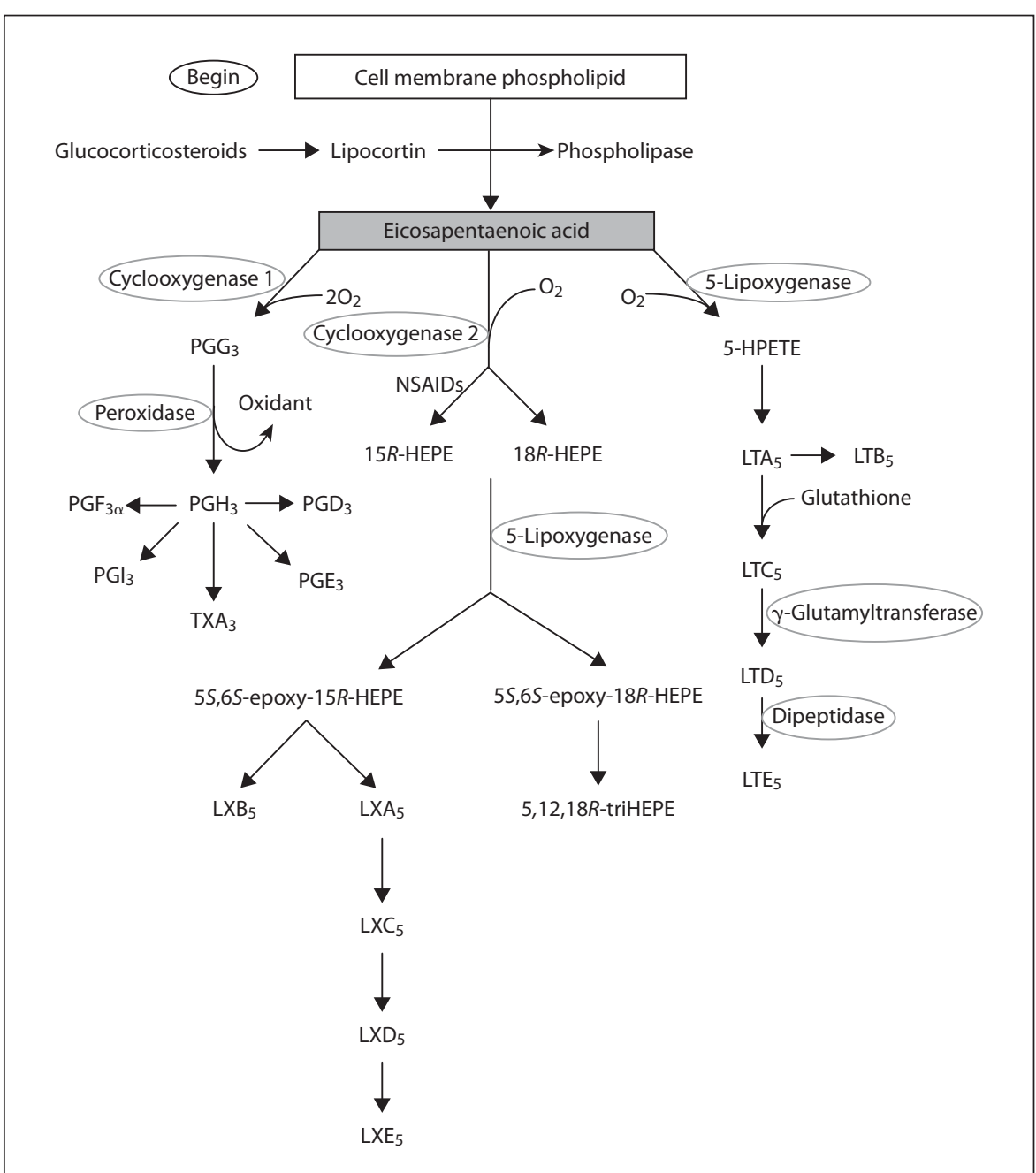




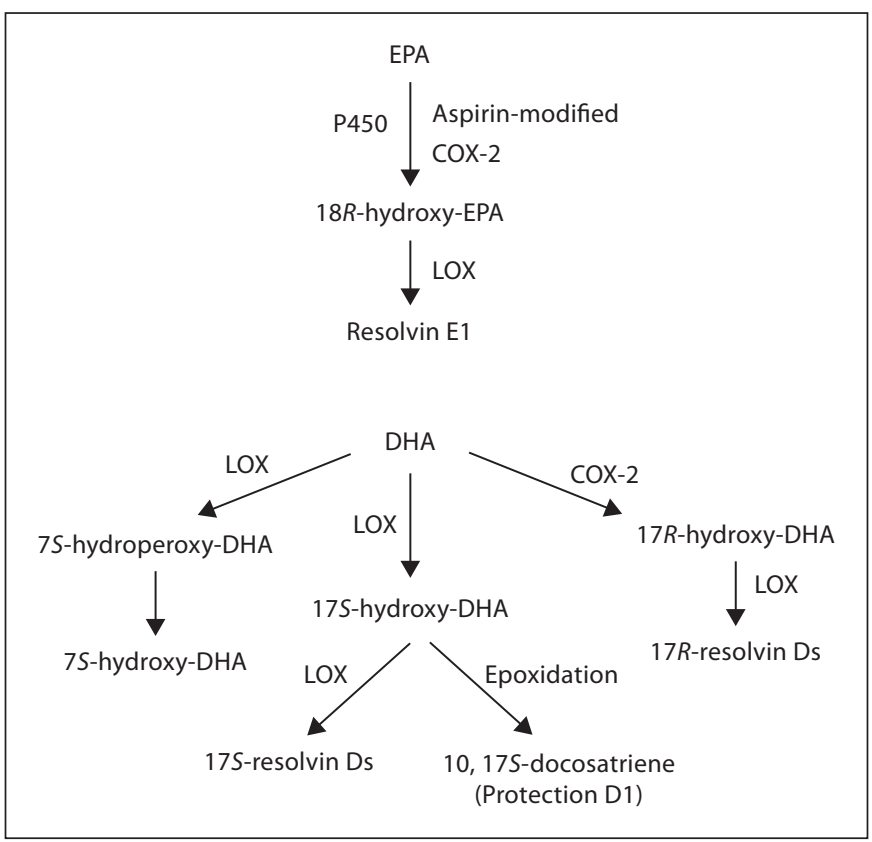

Fig. 11. The metabolic pathways for the conversion of EPA and DHA to resolvins and protectins. LOX = Lipooxygenase; COX = cyclooxygenase. Adapted from Lee and Hwang [2008].

Concerning the fatty acid distribution in lipid classes, the following observations can be made. In all blood specimens, the long-chain n- 6 and n-3 PUFAs are minimally incorporated in TGs. Palmitic and LA are the most abundant fatty acids in PL, whereas OA and LA prevail in TGs and CE. DHA is contained almost exclusively in $\mathrm{PL}$, whereas EPA is present primarily in PL and CE. AA is predominantly incorporated in PL.

Another observation of Risé et al. [2007] was that PL in plasma and RBCs are quantitatively the major contributors in determining the fatty acid profile in blood but EPA is not appreciably incorporated in PL. Therefore, plasma and whole blood are the most representative pools for the assessment of the fatty acid status in relation to physiopathological conditions.

Skeaff et al. [2006] found that dietary-induced changes in the fatty acid composition of plasma PL and CE and platelet and erythrocyte phosphatidylcholine as a function of time are qualitatively similar and largely complete within 2 weeks. King et al. [2006] also found that in switching from a high-fat diet to a low-fat diet, the fatty acid changes were generally in the same direction for $\mathrm{RBC}, \mathrm{PL}$ and $\mathrm{CE}$. These findings also suggest that fatty acid analysis of whole blood is an adequate approach for

Fat and Fatty Acid Terminology,

Analysis, Digestion and Metabolism the fatty acid status assessment. A simple, rapid method for whole blood fatty acid analysis was previously described (see 'Fat Extraction', above).

\section{Eicosanoid and Docosanoid Formations}

The C20 and C22 PUFAs in the membrane PLs, in addition to their role in maintaining the structure of cell membranes, have a functional role in serving as precursors of eicosanoids and docosanoids. Eicosanoids include PGs, TXs, leukotrienes (LTs), hydroxyeicosatetraenoic acids (HETEs) and hydroxyperoxyeicosatetraenoic acids (HPETEs).

The first step in the biosynthesis of eicosanoids is the release of a C20 PUFA from cell membrane PLs by phospholipase $\mathrm{A}_{2}$. The free acid is the substrate for the enzymes that synthesizes various eicosanoids. As discussed previously, tissues typically contain a high proportion of AA and low proportions of $n-3$ PUFAs, especially EPA. Thus, AA is the dominant substrate for eicosanoid synthesis. The metabolic map for the AA cascade is shown in figure 9 [Lee and Hwang, 2008]. Metabolism by COX (cyclooxygenase) enzymes gives rise to the 2-series PG and TX. There are 2 isoforms of COX (COX-1 and COX-2). Both are present in many normal human tissues and are up-regulated in various pathologic conditions [Zidar et al., 2008]. COX-1 is a constitutive enzyme and is mainly involved in the basal production of eicosanoids in physiological conditions, whereas COX-2 is inducible and overexpressed, for example, in inflammation. COX-2 is responsible for the markedly increased production of PG. Metabolism of AA by the 5-lipooxygenase (5-LOX) pathway gives rise to 5-HETE and 5-HPETE and the 4-series LTs.

EPA can be metabolized by both COX and 5-LOX leading to the formation of 3-series PGs, thromboxane $\mathrm{A}_{3}$ $\left(\mathrm{TXA}_{3}\right)$ and 5-series LTs (fig. 10) [Li et al., 2002a]. Thus, EPA acts as a competitive inhibitor for production of eicosanoids derived from AA. However, EPA is a poorer substrate for COX than AA and, therefore, the production of 3-series of PG and TX is low. Increased consumption of preformed EPA and DHA from fish oils or from other sources results in increased accumulation of these fatty acids in cell PLs, partly at the expense of AA. Since less substrate is available for the synthesis of eicosanoids from AA, dietary EPA and DHA can suppress the production of PGs, TXs, LTs and 5-HETE derived from AA in inflammatory cells.

In addition to the eicosanoids, in recent years a novel group of mediators formed from EPA by aspirin modified COX-2, termed E-series resolvins has been identified (fig. 11) [Serhan et al., 2000]. DHA is a poor substrate for 
Table 8. Biological actions of eicosanoids derived from AA

\begin{tabular}{|c|c|}
\hline Eicosanoid & Physiological action \\
\hline $\mathrm{PGE}_{2}$ & $\begin{array}{l}\text { pro-inflammatory, pro-aggregatory, suppresses im- } \\
\text { mune response, promotes cell growth, proliferation, } \\
\text { vasodilation, broncoconstriction, mild anti-inflam- } \\
\text { matory (inhibits 5-LOX and so decreases inflamma- } \\
\text { tory } 4 \text {-series LTs, induces 15-LOX which promotes } \\
\text { formation of anti-inflammatory lipoxins) }\end{array}$ \\
\hline $\mathrm{PGI}_{2}$ & $\begin{array}{l}\text { anti-inflammatory, inhibits platelet aggregation, } \\
\text { potent vasodilator }\end{array}$ \\
\hline $\mathrm{TXA}_{2}$ & potent platelet aggregation, potent vasoconstrictor \\
\hline $\mathrm{PGD}_{2}$ & $\begin{array}{l}\text { inhibits platelet aggregation, vasodilation, } \\
\text { promotion of sleep }\end{array}$ \\
\hline $\mathrm{PGF}_{2 \alpha}$ & $\begin{array}{l}\text { induces smooth muscle contraction, uterine } \\
\text { contraction }\end{array}$ \\
\hline $\mathrm{LTB}_{4}$ & $\begin{array}{l}\text { pro-inflammatory, causes neutrophil aggregation, } \\
\text { neutrophil and eosinophil chemotaxis }\end{array}$ \\
\hline $\mathrm{LTC}_{4}$ & $\begin{array}{l}\text { pro-inflammatory, promote endothelial cell } \\
\text { permeability, contracts smooth muscle cells, } \\
\text { constricts peripheral airways }\end{array}$ \\
\hline $\mathrm{LTD}_{4}$ & $\begin{array}{l}\text { contracts smooth muscle cells, constricts peripheral } \\
\text { airways }\end{array}$ \\
\hline 12-HETE & $\begin{array}{l}\text { neutrophil chemotaxis, stimulates glucose-induced } \\
\text { insulin secretion }\end{array}$ \\
\hline 15-HETE & inhibits 5 - and 12 -LOX \\
\hline Lipoxin A & superoxide anion generation, chemotaxis \\
\hline Lipoxin B & inhibits NK cell activity \\
\hline
\end{tabular}

Table 9. Physiological actions of eicosanoids derived from EPA and docosanoids derived from DHA

\begin{tabular}{ll}
\hline Eicosanoid/docasanoid & Physiological action \\
\hline $\mathrm{PGE}_{3}$ & mild anti-aggregatory, vasodilation \\
$\mathrm{PGI}_{3}$ & mild anti-aggregatory \\
$\mathrm{TXA}_{3}$ & mild pro-aggregatory \\
EPA resolvin E1 & potent anti-inflammatory \\
DHA resolvin D & potent anti-inflammatory \\
DHA protectin D1 & potent anti-inflammatory \\
\hline
\end{tabular}

COX and therefore, DHA is not known to produce bioactive mediators. However, DHA-derived bioactive docosanoids, termed D-series resolvins and protectins (neuroprotectins D1) by COX-2 and LOX have been identified [Serhan et al., 2002; Bazan, 2007; Lee and Hwang, 2008].

\section{Physiological Actions}

Dietary fats have a wide range of physiological actions which are important in health and disease. Some are discussed below.

\section{Physiological Actions of Eicosanoids}

The eicosanoids derived from AA and EPA and the docosanoids derived from DHA are involved in a variety of physiological actions including modulating inflammation, platelet aggregation, immune response, cell growth and proliferation, and contraction and dilation of smooth muscle cells [Lee and Hwang, 2008] (tables 8, 9). Eicosanoids are produced when cells are stimulated and they are rapidly metabolized and hence they are not accumulated in cells. Imbalance in the synthesis of eicosanoids in tissues can lead to development of certain pathological conditions. The eicosanoids derived from EPA are generally less potent compared with those derived from AA (tables 8,9$)$. Prostaglandin $\mathrm{E}_{2}\left(\mathrm{PGE}_{2}\right)$ and $\mathrm{TXA}_{2}$ derived from AA are produced in platelets and promote inflammation with potent chemoactivity, serve as vasoconstrictors and stimulate platelet aggregation. PGs and TXs from EPA act as vasodilators and anti-aggregators. Prostaglan$\operatorname{din} \mathrm{I}_{2}\left(\mathrm{PGI}_{2}\right)$ derived from AA is also an inhibitor of platelet aggregation.

In addition to anti-aggregatory actions, increase of $\mathrm{PGI}_{2}$ formation suppresses the proliferation and migration of smooth muscle cells in response to injury. Other products of the COX pathway of AA also exert various physiological effects. $\mathrm{PGE}_{2}$ is involved in cell growth and proliferation, contraction and dilation of smooth muscle cells and inflammation. Pro-inflammatory effects include inducing fever, increasing vascular permeability and enhancing pain and edema caused by other agents such as bradykinin and histamine. Although $\mathrm{PGE}_{2}$ is pro-inflammatory it has also some anti-inflammatory effects. It inhibits the activity of 5-LOX and so suppresses the production of inflammatory 4-series LTs and induces 15-LOX activity, which promotes formation of lipoxins that have been found to be anti-inflammatory [Calder, 2006]. $\mathrm{PGD}_{2}$ is the major eicosanoid produced in mast cells during allergic response and asthma. $\mathrm{PGF}_{2 \alpha}$ induces smooth muscle contraction.

LTs are generated in leukocytes by the action of 5-LOX and they act on vascular parameters and have chemotactic properties. Leukotriene $\mathrm{A}_{4}\left(\mathrm{LTA}_{4}\right)$ derived from $\mathrm{AA}$ is metabolized immediately after its formation to a series of mediators (fig. 8). $\mathrm{LTB}_{4}$ increases the adhesion of leukocytes. $\mathrm{LTC}_{4}, \mathrm{LTD}_{4}$ and $\mathrm{LTE}_{4}$ promote endothelial cell 
permeability and airway smooth muscle constriction during anaphylactic reactions. The LTs produced from EPA are less potent than those derived from AA in chemotactic and aggregating activities for human neutrophiles.

The resolvins derived from EPA and DHA appear to have potent anti-inflammatory activities through the inhibitory effects on the leukocytes activation and the inflammatory mediator synthesis [Serhan and Savill, 2005]. The DHA-derived neuroprotectin D1 is formed in retinal pigment epithelial cells when they are confronted with oxidative stress, in the brain during experimental stroke and in the human brain from Alzheimer's disease patients as well as in human brain cells in culture. Neuroprotectin D1 displays potent anti-inflammatory and neuroprotective bioactivity [Bazan, 2007].

The eicosanoids (PGs, TXs and LTs) derived from AA have high biological activity and are mostly pro-inflammatory, whereas those from EPA and DHA have less biological activity and are weakly anti-inflammatory. The eicosanoid biosynthesis can be modulated by dietary fatty acids. The immediate precursor of eicosanoids is the fatty acid in the $s n-2$ position of cell PLs, which in turn derives from fatty acid in the $s n-2$ position of dietary fat. Therefore the amount and type of PUFA in the $s n-2$ position influence eicosanoid synthesis. Since LA and ALA compete for desaturases and elongases for conversions to their long-chain PUFA, the dietary levels of LA and ALA also have an influence on eicosanoid synthesis. Higher dietary levels of ALA can suppress AA production. The dietary levels of preformed EPA and DHA also have an influence on eicosanoid production and their influence is more effective than ALA. Consumption of EPA and DHA from fish or fish oil results in incorporation of these n-3 PUFAs in inflammatory cells such as monocytes, macrophages, neutrophils and lymphocytes at the expense of AA [Calder et al., 2002]. Thus, there is less substrate available for synthesis of eicosanoids from AA. Since EPA competitively inhibits the metabolism of AA, fish oil feeding results in a decreased capacity of cells to synthesize eicosanoids from AA. In fact, fish oil supplementation studies have reported decreased production of AA derived PGs, TXs, LTs and 5-HETE by inflammatory cells and increased in EPA derived eicosanoids $\mathrm{LTB}_{4}$, LTE $_{5}$ and 5-HEPE [Calder, 2006]. n-3 PUFAs alter eicosanoid biosynthesis not only at the substrate level but also at the level of gene expression. n-3 PUFAs have been shown to reduce expression of COX-2, 5-LOX and 5-LOX activating protein in chondrocytes [Curtis et al., 2000, 2002]. Thus, increased intakes of EPA from fish oil most likely reduce the inflammatory activity associated with eicosanoids derived from AA and are therefore helpful in suppression of inflammation.

However, a major issue concerning the AA cascade, as well as the production of all the long-chain PUFA derived mediators, is that limited information is available on overall quantitative balance in the generation of the various compounds, considering also that different cells are sequentially involved in these processes.

\section{Other Physiological Effects}

Although the key anti-inflammatory effects of EPA and DHA are mediated via antagonizing AA metabolism, these $n-3$ fatty acids have a number of other anti-inflammatory effects. The $\mathrm{n}-3$ fatty acids affect cytokines and other factors. Cytokines are a family of proteins produced and released by cells involved in inflammatory process and in the regulation of the immune system. Cell culture studies have shown that $n-3$ fatty acids can decrease the endothelial expression of a variety of cytokine-induced leukocyte adhesion molecules and of secretable protein products implicated in leukocyte recruitment and local amplification of inflammation. DHA, but not EPA, is effective in reducing endothelial expression of E-selectin, intercellular cell adhesion molecule 1 and vascular cell adhesion molecule 1, and impairs the ability of ligand bearing monocytes to adhere [De Caterina and Libby, 1996]. The magnitude of this effect parallels incorporation of DHA into cellular PLs.

Mean platelet volume is a marker of platelet activation. Mean platelet volume is increased in patients at risk of acute myocardial infarction [Endler et al., 2002]. Large platelets show a higher degree of adhesion than small ones [Schoene, 1997]. n-3 DPA and EPA [Li et al., 2002b], but not DHA [Park and Harris, 2002], have been suggested to decrease mean platelet volume in healthy subjects.

Another important biological role of $n-3$ and $n-6$ PUFA is the regulation of enzymes involved in lipid metabolism. PUFAs activate the expression of genes of fatty acid transport and oxidation (acyl CoA synthetase, acyl CoA oxidase, liver fatty acid binding protein, carnitine palmityoyltransferase-1 and cytochrome P450A1) and suppress the expression of genes of de novo synthesis of lipids (stearoyl CoA desaturase, acetyl CoA carboxylase, and fatty acid synthase) [Jump, 2002, 2008; Sampath and Ntambi, 2005]. PUFA exert these effects on gene expression by regulating 3 major transcription factors controlling multiple pathways involved in lipid metabolism. PUFAs activate peroxisome proliferators activated receptor (PPAR) $\alpha$ and suppress the nuclear abundance of car- 
bohydrate regulatory element binding protein (ChREBP)/ Max-like factor X (MLX) and sterol regulatory element binding protein (SREBP-1). PUFA activation of PPAR $\alpha$ enhances fatty acid oxidation, while PUFA suppression of SREBP-1 and ChREBP/MLX results in inhibition of de novo synthesis of fatty acids. As such PUFAs promote a shift in metabolism toward fatty acid oxidation and away from fatty acid synthesis and storage. The result of this 2 -fold action of PUFAs is a negative fat balance, thereby making PUFAs a good candidate for the dietary management of hyperlipidemia. The transcription factors display a differential response to PUFAs. EPA, but not DHA is potent activator of PPAR $\alpha$, DHA but not EPA controls SREBP-1 nuclear abundance. Nuclear abundance of the ChREBP/MLX, appears equally responsive to a wide range of C18-C22 carbon n-3 and n-6 PUFAs [Jump, 2008]. More studies are required to evaluate the significance of these differences. Evaluation of these differences may provide new insights into disorders of lipid metabolism associated with chronic metabolic diseases such as diabetes and obesity.

In adipose tissue, $n-3$ and n-6 PUFA inhibit fatty acid synthase. PUFAs also repress transcription of the leptin gene. Leptin is an adipose derived hormone that regulates appetite, body weight and adiposity. Increased plasma leptin levels have been correlated with increased adiposity, while weight loss results in decreased plasma leptin levels. Substitution of PUFA for SFAs in the diet causes a decrease in plasma leptin levels [Reseland et al., 2001; Duplus et al., 2000].

\section{Conclusions and Recommendations}

More research is recommended to test the application of direct methylation methods, which eliminate the tedious steps of fat extraction and solvent removal, for analysis of fatty acid profiles of biological samples as well as for food samples.

GC analytical parameters for the analysis of various types of fatty acids are now well established. But GC requires very long capillary columns $(30,60$ or $100 \mathrm{~m})$ and very detailed analysis, which can run to $2 \mathrm{~h}$. It is this length that deters the analysts. More research is needed to determine whether shorter columns $(5-15 \mathrm{~m})$ and fast GC programs would provide sufficient fatty acid data in a reasonable time frame.

Dietary fatty acids have a profound effect on de novo synthesis of fatty acids. Inhibition of de novo synthesis by high fat diets, by dietary PUFAs, particularly by LA, is well established. However, there is some uncertainty as to whether dietary saturated fats are effective in suppressing de novo fatty acid synthesis. It is also not known whether SFAs of different chain lengths have different effects on de novo synthesis. Further research is required to establish the influence of SFAs on de novo synthesis of fatty acids.

Animal studies have suggested that the maximum incorporation of DHA into erythrocytes, plasma, liver and brain tissues appears to be between LA:ALA ratios of 4:1 and 2:1. However, a human feeding study showed that the absolute amount of ALA, more than the LA:ALA ratio, influences the conversion of ALA to its derivatives. A reduction in dietary LA together with an increase in ALA intake would be the most appropriate way to enhance EPA and DHA synthesis. Further human studies are needed to determine the dose-dependent effects of LA and ALA on the formation of their long-chain PUFA.

Conversion rates of LA to AA in relation to the intakes also need to be assessed.

Despite the knowledge of the many health benefits of n-3 PUFAs, their consumption remains at a very low level in many parts of the world. On the other hand consumption of n-6 PUFA (primarily as LA) has markedly increased, especially in the USA. Thus, an increase in the consumption of n-3 PUFAs and a decrease in the consumption of n-6 PUFA are needed to balance the dietary ratio between these 2 families of fatty acids.

An additional issue concerning PUFA metabolism, that would need to be studied in detail considering that the conversion of LA and ALA to their long-chain products takes place mainly in the liver, is the efficiency of the conversion steps in relation to liver function and disease conditions. This topic has not been adequately studied but it appears from the limited data available that levels of AA and EPA are reduced in cirrhotic patients.

\section{Acknowledgments}

Special thanks are due to Drs. Andrew Sinclair, Duo Li, A. Ghafoorunisa, Tom Brenna, Bruce Holub and Phillipe Legrand who all read and commented on the draft version of the manuscript, and to Valerie Casey for drawing the figures.

\section{Disclosure Statement}

Prof. Galli serves as a consultant for Company A.I.D.I. (Association of Italian Dairy Industries). Prof. Galli declares that no financial or other conflict of interest exists in relation to the content of the article. Dr. Ratnayake has nothing to disclose. 


\section{References}

Abedin L, Lien EL, Vingrys AJ, Sinclair AJ: The effects of dietary alpha-linolenic acid compared with docosahexaenoic acid on brain retina, liver and heart in the guinea pig. Lipids 1999;34:475-482.

Ackman RG: Fatty acids in fish and shellfish; in Chow CK (ed): Fatty Acids in Foods and Their Health Implications. London, CRC Press, 2008a, pp 155-185.

Ackman RG: Application of gas-liquid chromatography to lipid separation and analysis: Qualitative and quantitative analysis; in Chow CK (ed): Fatty Acids in Foods and Their Health Implications. London, CRC Press, 2008b, pp 47-65.

-Ackman RG, Hooper SN, Hooper DL: Linoleic acid artifacts from the deodorization of oils. J Am Oil Chem Soc 1974;51:42-49.

-Adam O, Wolfram G, Zollner N: Influence of dietary linoleic acid intake with different fat intakes on arachidonic concentrations in plasma and platelet lipids and eicosanoid biosynthesis in female volunteers. Ann Nutr Metab 2003a;47:31-36.

Adam O, Beringer C, Kless T, et al: Anti-inflammatory effects of low arachidonic acid diet and fish oil in patients in patients with rhematoid arthritis. Rhematol Int 2003b;23:2736.

-Agostoni C, Riva E, Giovannini M, Pinto F, Colombo C, Risé Galli C, Marangoni F: Maternal smoking habits are associated with differences in infants' long-chain polyunsaturated fatty acids in whole blood: a casecontrol study. Arch Dis Child 2008;93:414418.

AOCS: AOCS official method Ce 1b-89. Fatty acid composition by GLC marine oils; in Official Methods and Recommended Practices of the AOCS, ed 5. Urbana, American Oil Chemists' Society, 2003a.

AOCS: AOCS official method Ce 1e-91. Determination of fatty acids in edible oils and fats by capillary GLC; in Official Methods and Recommended Practices of the AOCS, ed 5. Urbana, American Oil Chemists' Society, 2003b.

AOAC: AOAC official method 996.06. Fat (total, saturated, and unsaturated) in foods, hydrolytic extraction gas chromatographic method, revised 2001; in Horwitz W (ed): Official Methods of Analysis of AOAC International, ed 18. Gaithersburg, AOAC, 2005.

AOCS: AOCS official method Ce 1h-05. Determination of cis-, trans-, saturated, monounsaturated and polyunsaturated fatty acids in vegetable or non-ruminant animal oils and fats by capillary GLC method; in Official Methods and Recommended Practices of the AOCS, ed 5. Urbana, American Oil Chemists' Society, 2005.

-Araya J, Rodrigo R, Orellana M, Garcia V: Effects of red wine consumption on kidney FA composition. Lipids 2003;38:275-279.
Arterburn IM, Hall EB, Oken H: Distribution, interconversion, and dose response of $\mathrm{n}-3$ fatty acids in humans. Am J Clin Nutr 2006; 83(6 suppl):1467S-1476S.

Aziz AA, Cruz-Hernandez C, Xiao CW, Cockell KA, Ratnayake WMN: The effect of altering the linoleic/ $\alpha$-linolenic (LA:ALA) ratio at a low LA content in the diet on lipid metabolism of hamsters. Paper at 98th AOCS Ann Meet Expo, Quebec City, 2008.

- Baer DJ, Judd JT, Kris-Etherton PM, Zhao G, Emken EA: Stearic acid absorption and its metabolizable energy value are minimally lower than those of other fatty acids in healthy men fed mixed diets. Am J Clin Nutr 2003;133:4129-4134.

Bassi A, Avogaro A, Crepaldi C, Pavan P, Zambon S, Marin R, Macdonald I, Manzato E: Short-term diabetic ketosis alters $n-6$ polyunsaturated fatty acid content in plasma phospholipids. J Clin Endocrinol Metab 1996;81:1650-1653.

- Basso F, Freeman I, Knapper CL, Remaley A, Stonki J, Neufeld EB Jr: Role of the hepatic ABCA 1 transporter in modulating intrahepatic cholesterol and plasma HDL cholesterol concentrations. J Lipid Res 2003;44:296-302.

- Bauman DE, Barbano DM, Dwyer DA, Griinari JM: Technical note: production of butter with enhanced conjugated linoleic acid for use in biomedical studies with animal models. J Dairy Sci 2000;83:2422-2425.

Bazan NG: Omega-3 fatty acids, pro-inflammatory signaling and neuroprotection. Curr Opin Clin Nutr Metab Care 2007;10:136141.

Bergman EN, Havel RJ, Wolfe BM, Bohmer T: Quantitative studies of the metabolism of chylomicron triglycerides and cholesterol by liver and extrahepatic tissues of sheep and dogs. J Clin Invest 1971;50:1831-1839.

Bisagaier C, Glickman RM: Intestinal synthesis, secretion and transport of lipoproteins. Ann Rev Biochem 1983;45:625-636.

Blank C, Neumann MA, Makrides M, Gibson RA: Optimizing DHA levels in piglets by lowering the linoleic acid to $\alpha$-linolenic acid ratio. J Lipid Res 2002;43:1537-1543.

Bligh EG, Dyer WJ: A rapid method of total lipid extraction and purification. Can J Biochem Physiol 1959;37:911-917.

Borgstrom B: Fat digestion and adsorption; in Smyth DH (ed): Biomembranes. New York, Plenum, 1974, vol 4b, pp 555-620.

Bowen RA, Clandinin MT: High dietary 18:3n-3 increases the 18:3n-3 but not the 22:6n-3 content in the whole body, brain, skin, epididymal fat pads, and muscles of suckling rat pups. Lipids 2000;35:389-394.

Bowen RA, Clandinin MT: Maternal dietary $22: 6 n-3$ is more effective than $18: 3 n-3$ in increasing the $22: 6 \mathrm{n}-3$ content in phospholipids of glial cells from neonatal rat brain. $\mathrm{Br} \mathrm{J}$ Nutr 2005;93:605-611.
Bowen RA, Wierzbicki AA, Clandinin MT: Does increasing dietary linolenic acid content increase the docosahexaenoic acid content of phospholipids in neuronal cells of neonatal rats. Pediatr Res 1999;45:505-516.

Brenna JT: Efficiency of conversion alpha-linolenic acid to long chain n-3 fatty acids in man. Curr Opin Clin Nutr Metab Care 2002; 5:127-132.

Brunham LR, Kruit JK, Iqbal J, Fievet C, Timmins JM, Pape TD, Coburn BA, Bissada N, Staels B, Groen AK, Hussain MM, Parks JS, Kuipers F, Hayden MR: Intestinal ABCA 1 directly contributes to HDL biogenesis in vivo. J Clin Invest 2006;116:1052-1062.

Burdge GC, Wootton SA: Conversion of $\alpha$-linolenic acid to eicosapentaenoic, docosapentaenoic and docosahexaenoic acids in young women. Br J Nutr 2002;88:411-420.

Burdge GC, Calder PC: Conversion of $\alpha$-linolenic acid to longer-chain polyunsaturated fatty acids in human adults. Reprod Nutr Dev 2005;45:581-597.

Burdge GC, Jones AE, Wootton SA: Eicosapentaenoic and docosapentaenoic acids are the principal products of $\alpha$-linolenic acid metabolism in young women. Br J Nutr 2002;88: 355-363.

Burton GW, Wronska U, Stone L, Foster DG, Ingold KU: Biokenetics of dietary $R R R$ - $\alpha$-tocopherol in the male guinea pig at three dietary levels of vitamin $\mathrm{C}$ and two levels of vitamin $\mathrm{E}$ : evidence that vitamin $\mathrm{C}$ does not 'spare' vitamin E in vivo. Lipids 1990;25: 199-210.

-Calder PC, Yaqoob P, Thies F, Wallace FA, Miles EA: Fatty acids and lymphocyte functions. Br J Nutr 2002;87(suppl 1):S31-S48.

Calder PC: Polyunsaturated fatty acids and inflammation. Pros Leuk EFA 2006;75:197202.

Chalas J, Audibert F, Francoual J, Le Bihan B, Frydman R, Lindenbaum A: Concentrations of apolipoproteins E, C2, and C3 and lipid profile in preclampsia. Hypertens Pregnancy 2002;21:199-204.

Clemente G, Mancini M, Nazzaro F, Lasorella G, Rivieccio A, Palumbo AM, Rivellese AA, Ferrara L, Giacco R: Effects of different dairy products on postprandial lipemia. Nutr Metab Cardiovasc Dis 2003;13:377-383.

Christie WW: The Composition, Structure and Function of Lipids in the Tissues of Ruminant Animals. Oxford, Pergamon Press, 1981, pp 99-152.

Christie WW: Lipid Analysis. Isolation, Separation, Identification and Structural Analysis of Lipids, ed 3. Bridgwater, The Oily Press, 2003.

Christie WW: Preparation of lipid extracts from tissues. The Lipid Library. www.lipidlibrary. co.uk/topics/extract2/index.htm (accessed August 7, 2008). 
Christopherson SW, Glass RL: Preparation of milk fat methyl esters by alcoholysis in an essentially non-alcoholic solution. J Dairy Sci 1969;52:1289-1290.

-Cmolik J, Schwarz W, Svoboda Z, Pokorny J, Reblova Z, Dolezal M, Valentova H: Effects of plant-scale alkali refining and physical refining on the quality of rapeseed oil. Euro J Lipid Sci Technol 2000;102:15-22.

Cominacini I, Garbin U, Pasini AF, Davoli A, Campagnola M, Contessi GB, Pastorino AM, Cascio V: Antioxidants inhibit the expression of intercellular cell adhesion molecule-1 induced by oxidized LDL on human umbilical vein endothelial cells. Free Radic Biol Med 1997;22:117-127.

Craig-Schmidt MC, Teodorescu CA: Trans-fatty acids in foods; in Chow CK (ed): Fatty Acids in Foods and Their Health Implications. London, CRC Press, 2008, pp 377-437.

-Cruz-Hernandez C, Deng Z, Zhou J, Hill AR, Yurawecz MP, Delmonte P, Mossaba M, Dugan MER, Kramer JKG: Methods for analysis of conjugated linoleic acids and trans-18:1 isomers in dairy fats by using a combination of gas chromatography, silver-ion thin-layer chromatography/gas chromatography, and silver-ion liquid chromatography. J AOAC Int 2004;87:545-562.

Cruz-Hernandez C, KramerJKG, Kraft J, Santercole V, Or-Rashid M, Deng Z, Dugan MER, Delmonte P, Yurawecz MP: Systematic analysis of trans and conjugated linoleic acids in the milk and meat of ruminants; in Yurawecz MP, Kramer JKG, Gudmundsen O, Pariza MW, Banni S (eds): Advances in Conjugated Linoleic Acid Research. Urbana, AOCS Press, vol 3, 2006, pp 45-93.

Cunnane SC, Anderson MJ: The majority of dietary linoleate in growing rats is beta-oxidized or stored in visceral fat. J Nutr 1997; 127:146-152.

-Cunnane SC, Ryan MA, Nadeau CR, Bazinet RP, Musa-Veloso K, McCloy U: Why is carbon from some polyunsaturates extensively recycled into lipid synthesis? Lipids 2003;38: 477-484.

-Curtis CL, Hughes CE, Flannery CR, Little CB, Harwood JL, Caterson B: n-3 Fatty acids specifically modulate catabolic factors involved in articular cartilage degradation. J Biol Chem 2000;275:721-724.

-Curtis CL, Rees SG, Little CB, Flannery CR, Hughes CE, Wilson C, Dent CM, Otterness IG, Harwood JL, Caterson B: Pathologic indicators of degradation and inflammation in human osteoarthritic cartilage are abrogated by exposure to n-3 fatty acids. Arthritis Rheum 2002;46:1544-1553.

D'Andrea S, Guillou H, Jan S, Catheline D, Thibault JN, Bouriel M, Rioux V, Legrand P: The same $\Delta 6$-desaturase not only acts on 18 but also on 24-carbon fatty acids in verylong-chain polyunsaturated fatty acid biosynthesis. Biochem J 2002;364:49-55.
De Caterina R, Libby P: Control of endothelial leukocyte adhession molecules by fatty acids. Lipids 1996;31:S57-S63.

DeLany JP, Windhauser MM, Champagne CM, Bray GA: Differential oxidation of individual dietary fatty acids in humans. Am J Clin Nutr 2000;72:905-911.

Denkins YM, Woods J, Whitty JE, Hannigan JH, Martier SS, Sokol RJ, Salem N Jr: Effects of gestational alcohol exposure on the fatty acid composition of umbilical cord serum in humans. Am J Clin Nutr 2000;71(suppl):300S306S.

Dougherty RM, Gali C, Ferro-Luzzi A, Iacono JM: Lipid and phospholipids fatty acids composition of plasma, red blood cells and platelets and how they are affected by dietary lipids: a study of normal subjects from Italy, Finland and the USA. Am J Cin Nutr 1987; 45:443-455.

Duplus E, Glorian M, Forest C: Fatty acid regulation of gene transcription. J Biol Chem 2000; 275:30749-30752.

Endler G, Klimesh A, Sunder-Plassman H, Schillinger M, Exner M, Mannhalter C, Jordanova N, Christ G, Thalhammer R, Huber K, Sunder-Plasman R: Mean platelet volume is an independent risk factor for myocardial infarction but not for coronary artery disease. Br J Haematol 2002;117:399-404.

Ezaki O, Takahashi M, Shigematsu T, Shimamura K, Kimura J, Ezaki H, Gotoh T: Long term effects of dietary alpha-linolenic acid from perilla oil on serum fatty acid composition and on the risk factors of coronary heart disease in Japanese elderly subjects. J Nutr Sci Vitaminol (Tokyo) 1999;45:759-762.

Fahy E, Subramanium S, Brown AH, Glass CK, Merril AH Jr, Murphy RC, Raetz CRH, Russell DW, Seyama Y, Shaw W, Shimizu T, Spener F, van Meer G, VanNieuwenhze MS, White SH, Witztum JL, Dennis EA: A comprehensive classification system for lipids. J Lipid Res 2005;46:839-861.

FAO/WHO: Fats and oils in human nutrition: report of a joint expert consultation. FAO Food and Nutrition Paper 57. Rome, FAO, 1994.

Folch J, Lees M, Sloane-Stanley GH: A simple method for isolation and purification of total lipids from animal tissues. J Biol Chem 1957; 226:497-509.

Food and Drug Administration: FDA acts to provide better information to consumers on trans fats. 2005 www.health.gov/dietaryguidelines/dga2005/document (accessed March 17, 2006).

Francois CA, Connor SL, Bolewicz LC, Connor WE: Supplementing lactating women with flaxseed oil does not increase docosahexaenoic acid in their milk. Am J Clin Nutr 2003; 77:226-233.

Fu Z, Sinclair AJ: Increased alpha-linolenic acid intake increases alpha-linolenic acid content and apparent oxidation with little effect on tissue docosahexaenoic acid in the guinea pig. Lipids 2000;35:395-400.
Galli C, Trzeciak HI, Paoletti R: Effects of dietary fatty acids on the fatty acid composition of brain ethanolamine phosphoglyceride: reciprocal replacement of n-6 and n-3 fatty acids. Biochim Biophysica Acta 1971; 248:449-454.

-Garaiova I, Guschina IA, Plummer SF, Tang J, Wang D, Plummer NT: A randomised crossover trial in healthy adults indicating improved absorption of omega- 3 fatty acids by pre-emulsification. Nutr J 2007;6:4.

Gerster H: Can adults adequately convert $\alpha$-linolenic acid to eicosapentaenoic acid and docosahexaenoic acid? Internat J Vit Nutr Res 1998;68:159-173.

Ghafoorunissa A, Vanni R, Laxmi R, Sesikeran B: Effects of dietary alpha-linolenic acid from blended oils on biochemical indices of coronary heart diseases in Indians. Lipids 2002;37:1007-1086.

Gianello R, Libinaki R, Azzi A, Gavin PD, Negis Y, Zingg JM, Holt P, Keah HH, Griffey A, Smallridge West SM, Ogru E: $\alpha$-Tocopheryl phosphate: a novel natural form of vitamin E. Free Radi Biol Med 2005;39:970-976.

Goyens PLL, Spiker ME, Zock PL, Katan MB, Mensink RP: Conversion of $\alpha$-linolenic acid in humans is influenced by the absolute amounts of $\alpha$-linolenic acid and linoleic acid in the diet and not by the ratio. Am J Clin Nutr 2006;84:44-35.

-Grandgirard A, Sébédio JL, Fleury J: Geometrical isomerization of linoleic acid during heat treatment of vegetable oils. J Am Oil Chem Soc 1984;61:1563-1568.

-Greiner RS, Catalan JN, Moriguchi T, Salem N Jr: Docosapentaenoic acid does not completely replace DHA in $\mathrm{n}-3 \mathrm{FA}$-deficient rats during early development. Lipids 2003;38: 431-435.

Grimsgaard S, Bonaa KH, Hanse JB, Nordoy A: Highly purified eicosapentaenoic acid and docosahexaenoic acid in humans have similar triacylglycerol lowering effects but divergent effects on serum fatty acids. Am J Clin Nutr 1997;66:649-659.

Gunstone FD: Fatty acid structure; in Gunstone FD, Harwood JL, Padley FB (eds): The Lipid Handbook, ed 2. London, Chapman and Hall, 1999, pp 1-19.

Gurr ML: Lipids in Nutrition and Health: a Reappraisal. Bridgwater, The Oily Press, England, 1999.

Gurr ML, James AT: Lipid Biochem, ed 3. London, Chapman \& Hall, 1980, pp 96-104.

Gurr ML, Harwood JL: Lipid Biochemistry: an Introduction, ed 4. London, Chapman and Hall, 1991.

Ha YL, Grimm NK, Pariza MW: Anticarcinogens from fried ground beef: heat altered derivatives of linoleic acid. Carcinogenesis 1987;8:1881-1887.

Halpner AD, Handelman GJ, Belmont CA, Harris JM, Blumberg JB: Protection by vitamin $\mathrm{C}$ of oxidant-induced loss of vitamin $\mathrm{E}$ in rat hepatocytes. J Nutr Biochem 1998;9:355359. 
-Harris RA, Baxter DM, Mitchell M, Hitzemann RJ: Physical properties and lipid composition of brain membranes from ethanol tolerant-dependent mice. Mol Pharmacol 1984; 25:401-409.

-Harris WS: n-3 Fatty acids and health: da Vinci's Code. Am J Clin Nutr 2008;88:595-596.

- Haug A, Sjøgren P, Hølland N, Müller H, Kjos NP, Taugbøl O, Fjerdingby N, Biong AS, Selmer-Olsen E, Harstad OM: Effects of butter naturally enriched with conjugated linoleic acid and vaccenic acid on blood lipids and LDL particle size in growing pigs. Lipids Health Dis 2008;7:31. www.lipidworld.com/ content

- Havel RJ: Role of the liver in the atherosclerosis. Arteriosclerosis 1985;5:569-590.

Health Canada: Regulations Amending the Food and Drug Regulations (Nutrition Labelling, Nutrient Content Claims and Health Claims). Department of Health, Canada Gazette, part 11, 2003.

Holman RT: Biochemical activities of and requirements for polyunsaturated fatty acids. Prog Chem Fats Other Lipids 1970;9:607687.

Horrobin DF: Essential fatty acids, prostaglandins, and alcoholism: an overview. Alcohol Clin Exp Res 1987;11:2-9.

-Hroboticky N, Tang L, Zimmer B, Lux I, Weber PC: Lovastatin increases arachidonic acid levels and stimulates synthesis in human liver and monocyte cell lines. J Clin Invest 1994;93:195-203.

- Hu FB, Stampfer MJ, Manson JE, Rimm EB, Wolk A, Colfitz GA, Hennekens CH, Willett WC: Dietary fat intake and risk of coronary heart disease in women. N Engl J Med 1997; 337:1491-1499.

-Hui DY, Innerrarity TL, Mahley RW: Lipoprotein binding to canine hepatic membranes: metabolically distinct apo $\mathrm{E}$ and apo $\mathrm{B}$ receptors. J Biol Chem 1981;256:5646-5655.

Huth PJ: Ruminant trans fatty acids: composition and nutritional characteristics; in List GR, Kristchevsky D, Ratnayake WMN (eds): Trans Fats in Foods. Urbana, AOCS Press, 2007, pp 97-126.

-Igarashi M, Miyazawa T: New recognized effect of conjugated trienoic fatty acids on cultured human tumor cells. Cancer Lett 2000;148: 173-179.

Ikeda I, Sasaki E, Yasunami H, Nomiyama S, Nakayama M, Sugano M, Imaizumi K, Yazawa K: Digestion and lymphatic transport of eicosapentaenoic and docosahexaenoic acids given in the form of triacylglycerol, free acid and ethyl esters in rats. Biochim Biophys Acta 1995; 1259:297-304.

Innis SM: Essential fatty acids in growth and development. Prog Lipid Res 1991;30:39-103.

Innis SM, Hansen JW: Plasma fatty acid responses, metabolic effects, and safety of microalgal and fungal oils rich in arachidonic and docosahexaenoic acids in healthy adults. Am J Clin Nutr 1996;64:159-167.
Innis SM, Vaghry Z, King DJ: n-6 Docosapentaenoic acid is not a predictor of low docosahexaenoic status in Canadian preschool children. Am J Clin Nutr 2004;80:768-773.

Institute of Medicine: Dietary Reference Intakes for Vitamin C, Vitamin E, Selenium and Carotenoids: a Report of the Panel on Dietary Antioxidants and Related Compounds, Subcommittes on Upper Reference Levels of Nutrients, and the Standing Committee on the Scientific Evaluation of Dietary Reference Intakes, Food and Nutrition Board, Institute of Medicine. Washington, National Academy Press, 2000, pp 186-283.

IUPAC-IUB Commission on Biochemical Nomenclature: The nomenclature of lipids (recommendations, 1976). Biochem J 1978;171: 21-35.

Jacob RA, Kutnink MA, Csallany AS, Daroszewska M, Burton GW: Vitamin C nutritive has little short-term effect on vitamin E concentrations in healthy women. J Nutr 1996; 126:2268-2277.

Jensen RG, Dejong FA, Clark RM: Determination of lipase specificity. Lipids 1995;18:239252.

Jones PJH: Dietary linoleic, $\alpha$-linolenic and oleic acids are oxidized at similar rates in rats fed a diet containing these acids in equal proportion. Lipids 1994;29:491-495.

Jones PJH, Pencharz PB, Clandinin MT: Whole body oxidation of dietary fatty acids: implication for energy utilization. Am J Clin Nutr 1985;42:769-777.

Johnston JM: Intestinal absorption of fats; in Florkin M, Stotz EH (eds): Comprehensive Biochemistry. Amsterdam, Elsevier, 1970, vol $18, \mathrm{p} 1$.

-Jump DB: Dietary polyunsaturated fatty acids and regulation of gene transcription. Curr Opin Lipidol 2002;13:155-164.

Jump DB: n-3 Polyunsaturated fatty acid regulation of hepatic gene transcription. Curr Opin Lipidol 2008;19:242-247.

Kamal-Eldin A, Appelqvist L: The chemistry and antioxidant properties of tocopherols and tocotrienols. Lipids 1996;31:671-701.

-Kelley DS, Nelson GJ, Hunt JE: Effect of prior nutritional status on the activity of lipogenic enzymes in primary monolayer cultures of rat hepatocytes. Biochem J 1986;235:87-90.

Kepler CR, Hirons KP, McNeil JJ, Tove SB: Intermediates and products of the biohydrogenation of linoleic acid by Butyrivibrio fibrisolvens. J Biol Chem 1966;241:1350-1354.

King IB, Lemaitre R, Kestin M: Effect of a low-fat diet on fatty acid composition in red cells, plasma phospholipids, and cholesterol esters: investigation of a biomarker of total fat intake. Am J Clin Nutr 2006;83:227-236.

King JW: Supercritical fluid extraction: present status and prospects. Grasas Aceites 2002;53: $8-21$.
Kolbe K, Akahoshi A, Yamasaki M, Tanaka K, Yamada K, Iwata T, Kamegai T, Tsutmi K, Sugano K: Dietary conjugated linolenic acid in relation to CLA differently modified body fat mass and serum liver lipids in rats. Lipids 2002;37:343-350.

Kramer JKG, Fellner V, Dugan MER, Sauer FD, Mossoba MM, Yurawecz MP: Evaluating acid and base catalysts in the methylation of milk and rumen fatty acids with special emphasis on conjugated dienes and total trans fatty acids. Lipids 1997;32:1219-1228.

Kramer JKG, Cruz-Hernandez C, Deng Z, Zhou J, Jahreis G, Dugan MER: Analysis of conjugated linoleic acid and trans 18:1 isomers in synthetic and animal products. Am J Clin Nutr 2004;79:1137S-1145S.

Krimbou L, Marcil M, Genest J: New insights into the biogenesis of human high-density lipoproteins. Curr Opin Lipidol 2006;17:258267.

-Lagarde M, Géloën A, Record M, Vance D, Spener F: Lipidomics is emerging. Biochim Biophy Acta 2003; 1634:61.

Lands B: A critique of paradoxes in current advice on dietary lipids. Progress in Lipid Res 2008;47:77-106.

Lee J, Hwang DH: Dietary fatty acids and eicosanoids; in Chow CK (ed): Fatty Acids in Foods and Their Health Implications. London, CRC Press, 2008, pp 713-739.

Lehner R, Kuksis A: Biosynthesis of triacylglycerols. Prog Lipid Res 1996;35:169-201.

Leng GC, Smith FB, Fowkes FG, et al: Relationship between plasma essential fatty acids and smoking, serum lipids, blood pressure and haemostatic and rhelogical factors. Prostaglandins Leukot Essent Fatty Acids 1994;51: 101-108.

Lewis GF, Rader DJ: New insights into the regulation of HDL metabolism and reverse cholesterol transport. Circ Res 2005;96:12211232.

Leyton J, Drury PJ, Crawford MA: Differential oxidation of saturated and unsaturated fatty acids in vivo in the rat. Br J Nutr 1987;57: 383-393.

Li D, Sinclair A, Wilson A, Nakkote S, Kelly F, Abedin L, Watson A: Effect of dietary alphalinolenic acid on thrombotic risk factors in vegetarian men. Am J Clin Nutr 1999;69: 872-882.

Li D, Bode O, Drummond H, Sinclair AJ: Omega-3 (n-3) fatty acids; in Gunstone FD (ed): Lipids for Functional Foods and Nutraceuticals. The Oily Press, UK, 2002a, pp $225-$ 262.

Li D, Turner A, Sinclair A: Relationship between platelet phospholipid FA and mean platelet volume in healthy men. Lipids 2002b;37: 901-906.

Lin YH, Salem N Jr: Whole body distribution of deuterated linoleic and alpha-linolenic acids and their metabolism in the rat. J Lipid Res 2007;48:2709-2724. 
Lopez C, Briard-Bion V, Menard O, Rousseau F, Pradel P, Besle JM: Phospholipid, sphingolipid, and fatty acid composition of the milk fat globule membrane are modified by diet. J Agric Food Chem 2008;56:5226-5236.

-Marangoni F, Mosconi C, Galella G, Galli C: Increments of dietary linoleate raise liver arachidonate, but markedly reduced heart n-6 and n-3 fatty acids. Lipids 1992;27:624628.

Marangoni F, Colombo C, Galli C: A method for the direct evaluation of the fatty acid status in a drop of blood from a fingertip in humans: applicability to nutritional and epidemiological studies. Anal Biochem 2004a;326: 267-272.

Marangoni F, Colombo C, De Angelis L, Gambaro V, Agostoni C, Giovannini M, Galli C: Cigarette smoke negatively and dose-dependently affects the biosynthetic pathway of the $n-3$ polyunsaturated fatty acid series in human mammary epithelial cells. Lipids 2004b;39:633-637.

-Marangoni F, Colombo C, Martiello A, Negri E, Galli C: The fatty acid profiles in a drop of blood from a fingertip correlate with physiological, dietary and lifestyle parameters in volunteers. Prostaglandins, Leukot Essent Fatty Acids 2007;76:87-92.

-Mantzioris E, James MJ, Gibson RA, Cleland LG: Dietary substitution with an $\alpha$-linolenic acid-rich vegetable oil increases eicosapentaenoic acid concentrations in tissues. Am J Clin Nutr 1994;59:1304-1309.

- McCloy U, Ryan MA, Pencharz PB, Ross RJ, Cunnane SC: A comparison of the metabolism of eighteen-carbon ${ }^{13} \mathrm{C}$-unsaturated fatty acids in healthy women. J Lipid Res 2004; 45:474-485.

-Mendis S, Cruz-Hernandez C, Ratnayake WMN: Fatty acid profile of Canadian dairy products with special attention to the transocatadecenoic acid and conjugated linoleic acid isomers. J AOAC Int 2008;91:811-819.

Mest HJ, Beitz I, Block HU, Forster W: The influence of linseed oil diet on fatty acid pattern in phospholipids and thromboxanes formation in platelets in man. Klin Wochenschr 1983;61:187-191.

- Moore SA, Hurt E, Yoder E, Sprecher H, Spector AA: Docosahexaenoic acid synthesis in human skin fibroblasts involves peroxisomal retroconversion of tetracosahexaenoic acid. J Lipid Res 1995;36:2433-2443.

Mori TA, Burke V, Puddey GF, Watts DN, O’Neal JD, Best JD, Beilin LJ: Purified eicosapentaenoic and docosahexaenoic acids have different effects on serum lipids and lipoproteins, LDL particle size, glucose, and insulin in mildly hyperlipidemic men. Am J Clin Nutr 2000;71:941-946.

-Mossoba MM, Yurawecz MP, Delmonte P, Kramer KG: Overview of infrared methodologies for trans fat determination. J AOAC Int 2004;87:540-544.
Mozaffarian D, Ascherio A, Hu F, Stampfer MJ, Willett WC, Siscovick DS, Rimm EB: Interplay between different polyunsaturated fatty acids and risk of coronary heart disease in men. Circulation 2005;111:157-164.

Mu H, Porsgaard T: The metabolism of structured triacylglycerols. Prog Lipid Res 2005; 44:430-448.

Mukherjee S, Lekli I, Das M, Azzi A, Das DK: Cardioprotection with $\alpha$-tocopheryl phosphate: amelioration of myocardial ischemia reperfusion injury is linked with its ability to generate a survival signal through Akt activation. Biochim Biophys Acta 2008;1782: 498-503.

Mustacich DJ, Bruno RS, Traber MG: Vitamin E; in: Litwack G (ed): Vitamin E: Vitamins and Hormones. San Diego, Academic Press, 2006, vol 76, pp 1-21.

Nestel PJ, Chronopulos A, Cehun M: Dairy fat in cheese raises LDL cholesterol less than that in butter in mildly hypercholesterolaemic subjects. Eur J Clin Nutr 2005;59:1059-1063.

Nettleton JA: Omega-3 fatty acids: comparison of plant and seafood sources in human nutrition. J Am Diet Assoc 1991;91:331-337.

Nichols BW: Separation of the lipids of photosynthetic tissues: improvements in analysis by thin-layer chromatography. Biochim Biophys Acta 1963;70:417-422.

Niki E, Saito T, Kawakami A, Kamiya Y: Inhibition of oxidation of methyl linoleate in solution by vitamin $\mathrm{E}$ and vitamin C. J Biolog Chem 1984;259:4177-4182.

Nilsson A: Metabolism of cerebroside in the intestinal tract of the rat. Biochim Biophys Acta 1969;187:113-121.

-Okada Y, Okajima H, Konishi H, Terauchi M, Ishii K, Liu IM, Watanabe H: Antioxidant effect of naturally occurring furan fatty acids on oxidation of linoleic acid in aqueous dispersion. J Am Oil Chem Soc 1990;67:858862.

Okada Y, Kaneko M, Okajima H: Hydroxyl scavenging activity of naturally occurring furan fatty acids. Biol Pharm Bull 1996;19:16071610.

Park Y, Harris W: EPA, but not DHA decreases mean platelet volume in normal subjects. Lipids 2002;37:941-946.

- Parodi PW: Distribution of isomeric octadecenoic fatty acids in milk fats. J Dairy Sci 1976; 59:1870-1873.

Parodi PW: Conjugated linoleic acid in food; in Sebedio JL, Christie WW, Adlof R (eds): Advances in Conjugated Linoleic Acid Research. Urbana, AOCS Press, 2003, vol 2, pp 101-122.

Pawlosky RJ, Salem N Jr: Ethanol exposure causes a decrease in docosahexaenoic acid and an increase in docosapentaenoic acid in feline brains and retina. Am J Clin Nutr 1995;61:1284-1289.

- Pawlosky RJ, Salem N Jr: Perspectives on alcohol consumption: liver polyunsaturated fatty acids and essential fatty acid metabolism. Alcohol 2004;34:27-33.
Pawlosky RJ, Hibbeln JR, Novotny JA, Salem N Jr: Physiological compartmental analysis of $\alpha$-linolenic acid metabolism in adult humans. J Lipid Res 2001;42:1257-1265.

- Pawlosky RJ, Hibbeln JR, Salem N Jr: Compartmental analyses of plasma n-3 essential fatty acids among male and female smokers and nonsmokers. J Lipid Res 2007;48:935-943.

Piironen V, Lampi AM: Occurrence and levels of phytosterols in foods; in Dutta PC (ed): Phytosterols as Functional Food Components and Nutraceuticals. New York, Marcel Dekker, 2004, pp 1-32.

- Plourde M, Cunnane SC: Extremely limited synthesis of long chain polyunsaturates in adults: implications for their dietary essentiality and use as supplements. Appl Physiol Nutr Metab 2007;32:619-634.

Polonovski J, Beucler I: Structure et métabolisme des lipoproteines plasmatiques. Pathol Biol 1983;31:225.

Portolesi R, Powell BC, Gibson RA: Competition between 24:5n-3 and ALA for $\Delta 6$ desaturase may limit the accumulation of DHA in HepG2 cell membranes. J Lipid Res 2007;48: 1592-1598.

Qureshi AA, Qureshi N, Wright JJK, Shen Z, Kramer G, Gapor A, Chong YH, DeWitt G, Ong ASH, Peterson DM, Bradlow BA: Lowering of serum cholesterol in hypercholesterolemic humans by tocotrienols (palmvitee). Am J Clin Nutr 1991;53(suppl):1021S1026S.

Ratnayake WMN: Overview of methods for the determination of trans fatty acids by gas chromatography, silver-ion thin-layer chromatography, silver-ion liquid chromatography, and gas chromatography/mass spectrometry. J AOAC Int 2004;87:523-529.

Ratnayake WMN, Zehaluk C: Trans fatty acids in foods and their labelling regulations; in Akoh CC, Lai OM (eds): Healthful Lipids. Urbana, AOCS Press, 2005, pp 1-32.

- Ratnayake WMN, Hansen SL, Kennedy MP: Evaluation of the CP-Sil 88 and SP-2560 GC columns used in the recently approved AOCS Official Method Ce 1h-05: Determination of cis-, trans-, saturated, monounsaturated and polyunsaturated fatty acids in vegetable or non-ruminant animal oils and fats by capillary GLC method. J Am Oil Chem Soc 2006; 83:475-488.

Redgrave TG: Chylomicron metabolism. Biochem Soc Trans 2004;32:79-82.

- Reseland JE, Anderssen SA, Solvoll K, Hjerman J, Urdal P, Holme I, Drevon CA: Effect of long term changes in diet and exercise on plasma leptin concentrations. Am J Clin Nutr 2001;73:240-245.

Risé P, Colombo C, Galli C: Effects of simvastatin on the metabolism of polyunsaturated fatty acids and on glycerolipids: cholesterol and de novo lipid synthesis in THP-1 cells. J Lipid Res 1997;38:1299-1307. 
-Risé P, Pazzucconi F, Sirtori CR, Galli C: Statins enhance arachidonic acid synthesis in hypercholesterolemic patients. Nutr Metab Cardiovasc Dis 2001;11:88-94.

-Risé P, Eligini S, Ghezzi S, Colli S, Galli C: Fatty acid composition of plasma, blood cells and whole blood: relevance for the assessment of the fatty acid status in humans. Prostaglandins, Leukot Essent Fatty Acids 2007;76: 363-369.

- Rogers EJ, Rice SM, Nicolosi RJ, Carpender DR, McClelland CA, Romanczyk LR Jr: Identification and quantification of $\gamma$-oryzanol components and simultaneous assessments of tocols in rice bran oil. J Am Oil Chem Soc 1993;70:301-307.

-Salem N Jr, Reyer M, Karanian J: Losses of arachidonic acid in rat liver after alcohol inhalation. Lipids 1996;31(suppl):S153-S156.

-Santos MT, Valles J, Aznar J, Beltrán M, Herraiz M: Effect of smoking on plasma fatty acid composition in middle-aged men. Atherosclerosis 1984;50:53-62.

-Sampath H, Ntambi JM: Polyunsaturated fatty acid regulation of genes of lipid metabolism. Annu Rev Nutr 2005;25:317-340.

-Sastry PS: Lipids of nervous tissue: composition and metabolism. Prog Lipid Res 1985;24: 169-176.

- Schoene NW: Design criteria: tests used to assess platelet function. Am J Clin Nutr 1997;65: 1665S-1668S.

Sebedio JL, Ratnayake WMN: Analysis of trans mono- and polyunsaturated fatty acids; in Dijkstra AJ, Hamilton RJ, Hamm W (eds): Trans Fats. New York, Blackwell, 2008, pp 102-131.

-Serhan CN, Savill J: Resolution of inflammation: the beginning programs the end. Nat Immunol 2005;6:1191-1197.

-Serhan CN, Clish CB, Brannon J, Colgan SP, Chiang N, Kronert K: Novel functional sets of lipid-derived mediators with antiinflammatory actions generated from omega-3 fatty acids via cyclooxygenase 2-nonsteroidal antiinflammatory drugs and transcellular processing. J Exp Med 2000;192:1197-1204.

-Serhan CN, Hong S, Gronert K, Colgan SP, Devchand PR, Mirick G, Moussignac RL: Resolvins: a family of bioactive products of omega-3 fatty acid transformation circuits initiated by aspirin treatment that counter proinflammation signals. J Exp Med 2002; 196:1025-1037.

Simmonds WJ: Fat absorption and chylomicron formation; in Nelson GJ (ed): Blood Lipids and Lipoproteins: Quantitation, Composition, and Metabolism. New York, Wiley Interscience, 1972, pp 705-743.

- Simon JA, Fong J, Bernert JT, Browner WS: Relation of smoking and alcohol consumption to serum fatty acids. Am J Epidemiol 1996;144: 325-334.

-Sinclair AJ, Attar-Bashi NM, Li D: What is the role of alpha-linolenic acid for mammals? Lipids 2002;37:1113-1123.
Skeaff CM, Hodson L, McKenzie JE: Dietary-induced changes in fatty acid composition of human plasma, platelet, and erythrocyte lipids follow a similar time course. J Nutr 2006; 136:565-569.

Smith LC, Pownall HJ, Goto AM: The plasma lipoproteins: structure and metabolism. Ann Rev Biochem 1978;47:751.

Sodhi HS, Kudchodkar J, Mason DT: Cholesterol metabolism in clinical hyperlipidimias; in Paoletti R, Kritchevsky D (eds): Advances in Lipid Research. New York, Academic Press, 1978, vol 17, pp 107-153.

- Solakivi T, Jaakkola O, Kalela A, Pispa M, Salomaki A, Lehtimaki T, Hoyhtya M, Jokela H, Nikkari ST: Lipoprotein docosapentaenoic acid is associated with serum matrix metalloproteinase- 9 concentration. Lipds Health Dis Apr 2005;4:8.

Spener F, Lagarde M, Géloën A: What is lipidomics? Eur J Lipid Sci Technol 2003;105:481482.

Spiteller G: Furan fatty acids: occurrence, synthesis, and reactions. Are furan fatty acids responsible for the cardiopotective effects of a fish diet? Lipids 2005;40:753-771.

Sprecher H: The roles of anabolic and catabolic reactions in the synthesis and recycling of polyunsaturated fatty acids. Prostaglandins Leukot Essent Fatty Acids 2002;67:79-81.

Strawford A, Antelo F, Christiansen M, Hellerstein MK: Adipose tissue triglyceride turn over, de novo lipogenesis, and cell proliferation in humans measured with ${ }^{2} \mathrm{H}_{2} \mathrm{O}$. Am J Physiol Endocrinol Metab 2004;286:E577E588.

-Suzuki R, Noguchi R, Ota T, Abe M, Miyashita K, Kawada T: Cytotoxic effect of conjugated trienoic fatty acids on mouse tumor and human monocystic leukaemia cells. Lipids 2001;36:477-482.

Takagi T, Itabashi Y: Occurrence of mixtures of geometric isomers of conjugated octadecatrienoic acids in some seed oils: analysis by open tubular gas liquid chromatography and high performance liquid chromatography. Lipids 1981;16:546-551.

Tidwell HC, Pope JL, Askins RE, MacPherson JC: Specificity of a lipase of the intestinal mucosa. Biochem Probl Lipids 1963;1:219223.

Tran K, Chan AC: R,R,R-alpha-tocopherol potentiates prostacyclin release in human endothelial cells: evidence for structural specificity of the tocopherol molecule. Biochim Biophys Acta 1990;1043:189-197.

- Tricon S, Burge GC, Williams CM, Calder PC: The effects of conjugated linoleic acid on human health-related outcomes. Proc Nutr Soc 2005;64:171-182. Tso P: Gastrointestinal digestion and absorption
of lipid. Adv Lipid Res 1985;21:143-186.

- Tsuzuki T, Tokuyama Y, Igarashi M, Miyazawa $\mathrm{T}$ : Tumor growth suppression by $\alpha$-eleostearic acid, a linolenic acid isomer with a conjugated triene system, via lipid peroxidation. Carcinogenesis 2004;25:1417-1425.
Tsuzuki T, Kawakami Y, Abe R, Nakagawa K, Koba K, Imamura J, Iwata T, Ikeda I, Miyazawa $\mathrm{T}$ : Conjugated linolenic acid is slowly absorbed in rat intestine, but quickly converted to conjugated linoleic acid. J Nutr 2006;136: 2153-2159.

Ursin VM: Modifications of plant lipids for human health: development of functional landbased omega-3 fatty acids. J Nutr 2003;133: 4271-4274.

US Public Health Service. Office of smoking and health, Centre for Chronic Disease Prevention and Health Promotion, Centres for Disease Control: The health benefits of smoking cessation: a report of the Surgeon General, Rockville, DDS publication no. (CDC) 908416, 1990.

Vemuri M, Kelley DS: The effects of dietary fatty acids on lipid metabolism; in Chow CK (ed): Fatty Acids in Foods and Their Health Implications. London, CRC Press, 2007, pp 591-630.

-Visioli F, Risé P, Barassi MC, Marangoni F, Galli C: Dietary intake of fish vs. formulations leads to higher plasma concentrations of $n-3$ fatty acids. Lipids 2003;38:415-418.

Watts GF, Hugh P, Barrett HR, Chan DC: HDL metabolism in context: looking on the bright side. Curr Opin Lipidol 2008;19:395-404.

Wood JD, Enser M, Richardson RI, Whittington FM: Fatty acids in meat and meat products; in Chow CK (ed): Fatty Acids in Foods and Their Health Implications. London, CRC Press, 2008, pp 87-107.

-Woodman RJ, Mori TA, Burke V, Puddey GF, Watts GF, Beilin IJ: Effects of purified eicosapentaenoic and docosahexaenoic acids on glycemic control, blood pressure, and serum lipids in type 2 diabetic patients with treated hypertension. Am J Clin Nutr 2002;76:10071015.

Woods J, Ward G, Salem N Jr: Is docosahexaenoic acid necessary in infant formula? Evaluation of high linolenate diets in the neonatal rat. Pediatr Res 1996;40:687-694.

Wolf C, Quinn PJ: Lipidomics: practical aspects and applications. Prog Lipid Res 2008;47:1536.

Wolff RL: Control and distribution of trans-18:1 acids in ruminant milk and meat fats: their importance in European diets and their effects on human milk. J Am Oil Chem Soc 1995;72:259-272.

Yang LY, Kuksis A, Myher JJ: Lipolysis of menhaden oil triacylglycerols and the corresponding fatty acid alkyl esters by pancreatic lipase in vitro: a reexamination. J Lipid Res 1990;31:137-148.

Zidar N, Odar K, Glavac D, Jerse M, Zupanc T, Stajer D: Cyclooxygenase in normal human tissues: is COX-1 really a constitute isoform, and COX-2 an inducible isoform? J Cell Mol Med 2008; Epub ahead of print. DOI: 10.1111/ j.1582-4934.2008.00430.x 